\title{
Carotenoids of Microalgae Used in Food Industry and Medicine
}

\author{
Hélène Gateau ${ }^{1}$, Katalin Solymosi $^{2}$, Justine Marchand ${ }^{1, *}$, Benoît Schoefs ${ }^{1}$ \\ ${ }^{1}$ MicroMar, Mer Molécules Santé, University of Le Mans, IUML - FR 3473 CNRS, Le Mans, France; \\ ${ }^{2}$ Department of Plant Anatomy, Institute of Biology, Eötvös Loránd University, Budapest, Hungary
}

\begin{abstract}
Since the industrial revolution, the consumption of processed food increased dramatically. During processing, food material loses many of its natural properties. The simple restoration of the original properties of the processed food as well as fortification require food supplementation with compounds prepared chemically or of natural origin. The observations that natural food additives are safer and better accepted by consumers than synthetic ones has strongly increased the demand for natural compounds. Because some of them have only a low abundance or are even rare, their market price can be very high. This is the case for most carotenoids of natural origin to which this review is dedicated. The increasing demand for food additives of natural origin contributes to an accelerated depletion of traditional natural resources already threatened by intensive agriculture and pollution. To overcome these difficulties and satisfy the demand, alternative sources for natural carotenoids have to be found. In this context, photosynthetic microalgae present a very high potential because they contain carotenoids and are able to produce particular carotenoids under stress. Their potential also resides in the fact that only ten thousands of microalgal strains have been described while hundred thousands of species are predicted to exist. Carotenoids have been known for ages for their antioxidant and coloring properties, and a large body of evidence has been accumulated about their health potential. This review summarizes both the medicinal and food industry applications of microalgae with emphasis on the former. In addition, traditional and alternative, microalgal sources for industrial carotenoid extraction, the chemical and physical properties, the biosynthesis and the localization of carotenoids in algae are also briefly discussed.
\end{abstract}

Keywords: Astaxanthin, $\beta$-carotene, cancer, diatom, food colorant, fucoxanthin, Haematococcus, health.

\section{INTRODUCTION}

Since the industrial revolution, in the middle of the 19th century, the rise of human populations and the growth of cities accelerated. This process was accompanied, especially after World War II, by an increase in the consumption of processed food. During processing, food material loses many of its natural properties [1,2]. Concomitantly, the proportion of global population suffering of malnutrition has increased, more because of failures in food access than to production difficulties [3]. The fortification or simply restoration of the original properties of the processed food requires the supplementation with one or several compounds $[4,5]$. The use of artificial additives is at odd with the opinion polls that militate for the application of the concept according to which an adequate food supply in terms of nutrition and calories favors a good health and well-being [6]. Indeed, the observations that natural molecules are safer and better accepted by consumers than those synthesized chemically has strongly increased the demand for natural compounds on the global market. Because some of them have only a low

*Address correspondence to this author at MicroMar, Mer Molécules Santé, University of Le Mans, IUML - FR 3473 CNRS, Le Mans, France; Tel: +33-243-832-3250; E-mail: justine.marchand@univ-lemans.fr abundance and/or are rare, their market price can be very high. For instance, the price of the natural astaxanthin is expected to reach $14,000 \mathrm{USD} \mathrm{kg}^{-1}$ in 2018 [7]. The, global (both natural and synthetic, i.e., nature-identical) carotenoid market value was 1.5 billion USD in 2014 and is expected to reach nearly 1.8 billion USD in 2019 with lutein (a), astaxanthin (Fig. 1) and $\beta$-carotene (Fig. 2), accounting to appr. 230, 220 and 261 million USD in 2010, and estimated to reach a commercial value of around 310,250 and 334 million USD in 2018, respectively (http://www.bccresearch.com).

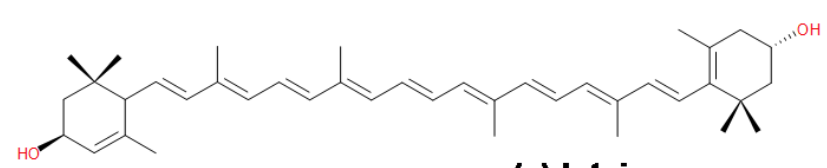

(a) lutein

The total production of natural carotenoids (with major carotenoids including fucoxanthin in marine algae, lutein, violaxanthin and neoxanthin in green leaves) has been estimated as 100 million tons/year [8]. However, the increasing demand for food additives of natural origin (especially for those which are not abundant) also contributes to an accelerated depletion of traditional natural 
resources [9], that in turn, further increases the market prices of these resources. To overcome these difficulties, the search for alternative sources for carotenoids has started [10] and microalgae emerged as organisms with a very high potential in this respect because in addition to the primary carotenoids they ordinarily synthesize for photosynthesis, they are also able to produce particular, so-called secondary carotenoids under stress [11-13] (Table 1). This potential also resides in the fact that only ten thousands of microalgal strains out of the 700,000 expected species have been described [14]. Consequently, the newly described taxa [e.g., 15-18] are of interest, even if many of them have not yet been characterized from the biochemical and/or biotechnological point of view.
Table 1. Traditional and alternative sources for the production of carotenoids for the food and health care industries. Gray shade indicates carotenoids the synthesis of which can be enhanced in algae under stress conditions.

\begin{tabular}{|c|c|c|}
\hline Carotenoids & Traditional sources & $\begin{array}{l}\text { Microalgal alternative } \\
\text { source }\end{array}$ \\
\hline \multirow[t]{2}{*}{$\alpha$-carotene } & & Red alga [19] \\
\hline & & $\begin{array}{l}\text { Dunaliella salina } \\
{[20]}\end{array}$ \\
\hline$\beta$-carotene & 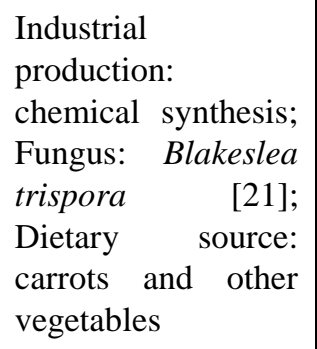 & 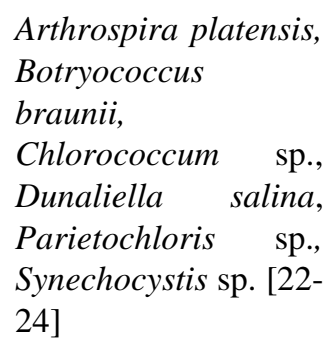 \\
\hline Astaxanthin & $\begin{array}{l}\text { Fungus: } \\
\text { Xanthophyllomyces } \\
\text { dendrorhous yeast } \\
\text { (earlier: Phaffia } \\
\text { rhodozyma) }[25,26]\end{array}$ & $\begin{array}{l}\text { Botryococcus } \\
\text { braunii, Chlorella } \\
\text { zofingiensis, } \\
\text { Diacronema } \\
\text { vlkianum, Euglena } \\
\text { rubida, } \\
\text { Haematococcus } \\
\text { pluvialis, Neochloris } \\
\text { wimmeri, } \\
\text { Scotiellopsis } \\
\text { oocystiformis } \\
{[11,20,27-32]}\end{array}$ \\
\hline $\begin{array}{l}\text { Canthaxanth } \\
\text { in }\end{array}$ & $\begin{array}{l}\text { Bacterium: } \\
\text { Gordonia jacobaea } \\
{[33]}\end{array}$ & Anabaena sp. [34] \\
\hline Fucoxanthin & - & $\begin{array}{l}\text { Cylindrotheca } \\
\text { closterium, } \\
\text { Eustigmatos magnus, } \\
\text { Eustigmatos } \\
\text { polyphem, } \\
\text { Eustigmatos vischeri, } \\
\text { Phaeodactylum } \\
\text { tricornutum, } \\
\text { Vischeria helvetica, } \\
\text { Vischeria punctata, } \\
\text { Vischeria stellata } \\
\text { [35-37] }\end{array}$ \\
\hline Lutein & $\begin{array}{l}\text { Plant: marigold } \\
\text { petals }[10,38]\end{array}$ & $\begin{array}{l}\text { Botryococcus } \\
\text { braunii, Chlorella } \\
\text { minutissima, } \\
\text { Chlorella } \\
\text { protothecoides, }\end{array}$ \\
\hline
\end{tabular}




\begin{tabular}{|c|c|c|}
\hline & & $\begin{array}{l}\text { Chlorella } \\
\text { zofingiensis, } \\
\text { Chlorococcum sp., } \\
\text { Muriellopsis sp., } \\
\text { Neospongiococcus } \\
\text { gelatinosum, } \\
\text { Scenedesmus } \\
\text { almeriensis } \\
{[10,28,29,32,39]}\end{array}$ \\
\hline $\begin{array}{l}\text { Siphonaxant } \\
\text { hin }\end{array}$ & - & Nephroselmis [40] \\
\hline Zeaxanthin & $\begin{array}{l}\text { Chemical synthesis; } \\
\text { Bacterium: } \\
\text { Flavobacterium } \\
\text { sp. }[41,42]\end{array}$ & $\begin{array}{l}\text { Arthrospira sp., } \\
\text { Botryococcus } \\
\text { braunii, } \\
\text { Chlamydomonas } \\
\text { acidophila, } \\
\text { Dunaliella salina, } \\
\text { Microcystis } \\
\text { aeruginosa, } \\
\text { Neospongiococcum } \\
\text { excentricum } \\
{[20,28,41,42,43]}\end{array}$ \\
\hline
\end{tabular}

Carotenoids have been known for ages for their antioxidant and coloring properties $[44,45]$ and a large body of evidences has been accumulated about their 'health' potential and crucial roles in the human body [12,46-50]. Because animals - except aphids [51] and spotted spider mites [52] - and humans are not able to produce carotenoids, they must be obtained from food. Once assimilated, carotenoids enter the biochemical pathways along which they may be eventually modified and have several health benefits [53], may improve sexual behavior and may be essential for reproduction in several species [54].

The main Sections of this review paper are dedicated to the potential of carotenoids from microalgae used in the food industry and medicine. The Sections are preceded by short descriptions of the physico-chemical properties of carotenoids, their biosynthetic pathways, cellular localization and functions. The contribution ends with a discussion on the interest of using microalgae for production of customized carotenoids. In this manuscript, algae should be taken sensu lato (in the broadest sense), i.e., as unicellular organisms performing oxygenic photosynthesis regardless of their prokaryotic or eukaryotic organization/origin.

\section{CHEMICAL AND PHYSICAL PROPERTIES OF CAROTENOIDS}

Carotenoids constitute a family of more than 750 pigments belonging to the large family of terpenoid compounds $[13,55,56]$. Carotenoids can be divided into xanthophyll or carotene subfamilies. The members of the former subfamily contain at least one oxygen atom whereas the members of the latter subfamily are devoid of oxygen. Carotenoids owe their name to carrots (Daucus carota), while the term xanthophyll derives from the Greek words

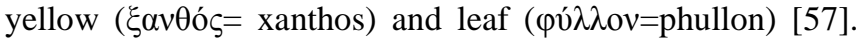
Violaxanthin and $\beta$-carotene are representative examples of each sub-family, respectively.

Carotenoids are C30-C50 molecules characterized by an extended network of conjugated double bonds allowing carotenoids to absorb visible light in the violet-green region. The range of the absorbed wavelengths can be in first approximation determined by the amount of conjugated double bonds along the carbon backbone. The higher the number of conjugated double bonds the longer the wavelengths the pigments absorb [58]. A consequence of the presence of double bonds is the abundant number of carotenoid isomers $[1,44,58]$. Thus, in vivo, but also in vitro, carotenoids may adopt several 3D-configurations that are important for their biological properties. For instance, cisisomers of fucoxanthin have been reported to be more valuable than all-trans-isomers in human cancer lines [59] (see Section 5.2.2). Another consequence of the extended network of conjugated double bonds of carotenoids resides in their capacity to act as antioxidant and reactive oxygen species (ROS) quenchers $[1,44,55,58]$.

Although the carotenoid composition of higher plant leaves is rather similar, the carotenoid diversity in microalgae is very large and in many cases specific of taxa. For instance, lutein, a typical xanthophyll of higher plants [55,60] is only found in Chrysophyta, Euglenophyta, Chlorarachniophyta, Chlorophyta and some Rhodophyta [19,61]. Table 2 summarizes the carotenoid distribution among the different major algal taxa.

Table 2. Occurrence of the main carotenoid types in various algal taxa (modified after [61]).

\begin{tabular}{|c|c|c|c|c|c|c|}
\hline $\begin{array}{c}\text { Pigment } \\
\text { type }\end{array}$ & $\begin{array}{c}\text { Cyanoba } \\
\text { cteria }\end{array}$ & $\begin{array}{c}\text { Glauco } \\
\text { phytes }\end{array}$ & $\begin{array}{c}\text { Red } \\
\text { algae }\end{array}$ & $\begin{array}{c}\text { Din } \\
\text { ofla } \\
\text { gell } \\
\text { ates }\end{array}$ & Diatoms & $\begin{array}{c}\text { Green } \\
\text { algae }\end{array}$ \\
\hline $\begin{array}{c}\beta- \\
\text { carotene }\end{array}$ & + & + & $\begin{array}{c}\text { Unice } \\
\text { llular }\end{array}$ & + & + & + \\
\hline $\begin{array}{c}\text { Canthax } \\
\text { anthin }\end{array}$ & $\begin{array}{c}\text { Anabaen } \\
\text { a }\end{array}$ & - & - & - & - & $\begin{array}{c}\text { + in } \\
\text { taxa } \\
\text { accumu } \\
\text { lating } \\
\text { ketocar } \\
\text { otenoid } \\
\text { s }\end{array}$ \\
\hline $\begin{array}{c}\text { Diadinox } \\
\text { anthin }\end{array}$ & - & - & - & + & + & + \\
\hline $\begin{array}{c}\text { Diatoxan } \\
\text { thin }\end{array}$ & - & - & - & - & + & + \\
\hline $\begin{array}{c}\text { Fucoxant } \\
\text { hin }\end{array}$ & - & - & - & - & + & + \\
\hline \begin{tabular}{c} 
Lutein \\
\hline
\end{tabular} & - & - & - & - & - & \\
\hline
\end{tabular}




\begin{tabular}{|c|c|c|c|c|c|c|}
\hline Peridinin & - & - & - & + & - & - \\
\hline $\begin{array}{c}\text { Violaxan } \\
\text { thin }\end{array}$ & - & - & + & - & $\begin{array}{c}\text { only } \\
\text { under } \\
\text { high light }\end{array}$ & + \\
\hline $\begin{array}{c}\text { Zeaxanth } \\
\text { in }\end{array}$ & $\begin{array}{c}\text { Depends } \\
\text { on } \\
\text { species }\end{array}$ & + & + & - & $\begin{array}{c}\text { only } \\
\text { under } \\
\text { high light }\end{array}$ & + \\
\hline
\end{tabular}

Some microalgal groups contain carotenoids with one or several unique chemical structures. A good example is the family of ketocarotenoids such as astaxanthin, canthaxanthin, fucoxanthin, peridinin and siphonaxanthin (Fig. 1). In the case of fucoxanthin, the keto group is accompanied by a 5,6-epoxy group and an allelic bond (Fig. 1), the latter constituting a key feature for the bioactivity of this compounds [62] (see Section 5). It is out of the scope of this review to describe the different types of carotenoids present in microalgae in details, therefore, interested readers are directed towards excellent reviews and monographies on that topic (e.g., [55].)

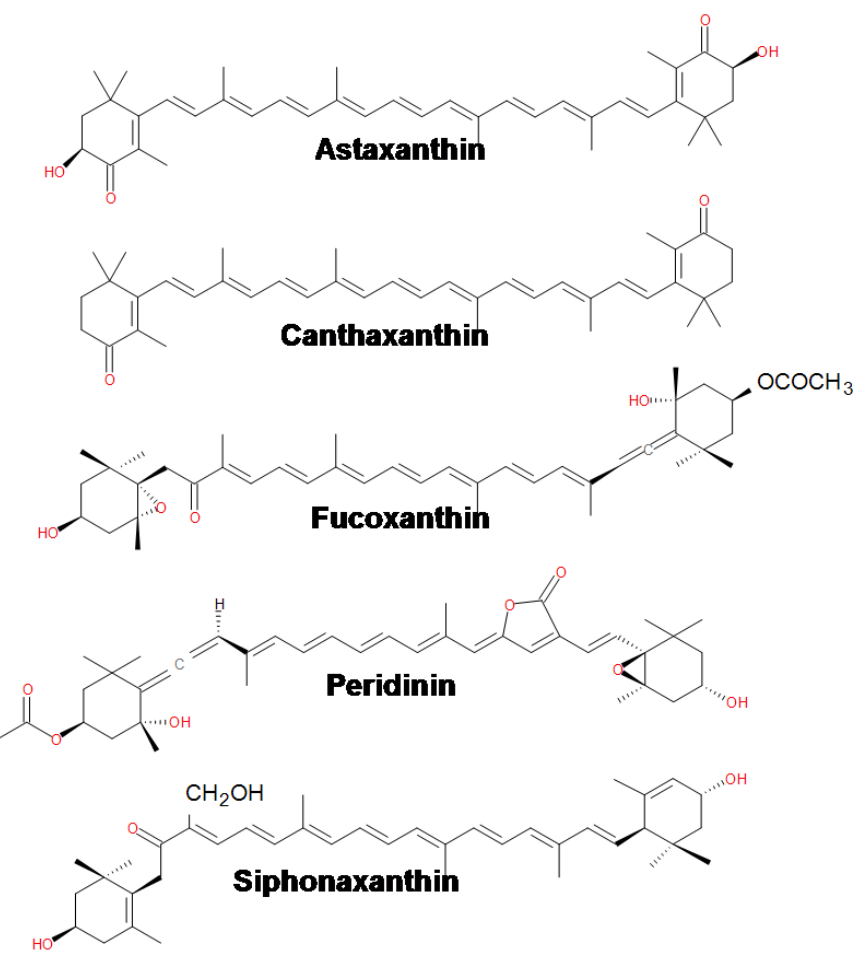

Fig. (1). Structures of typical keto-carotenoids from + mic oalgae.

3. BIOSYNTHETIC PATHWAY

C5 sopentenyl diphosphate units are the building blocks of

+ cardtenoids (Fig. 2) [63]. Since this pioneering publication, much progress has been achieved in the elucidation and understanding of the biochemical pathways leading to the formation of xanthophyll molecules. Briefly, isopentenyl diphosphate (IPP) can be synthesized by two different routes. Beside the classical mevalonic acid (MVA) pathway, a methylerythritol phosphate (MEP or mevalonateindependent route) was described ([64]; for reviews, see $[11,13,65,66])$. The numerous studies devoted to MVA and MEP routes in living organisms have enabled the development of a global view of the distribution of these pathways in the living kingdom (e.g., [64,67-70]). Archaea, certain bacteria, yeasts, fungi, some protozoa and animals use only the MVA pathway [71-73]. Many bacteria, green algae, some protists and some diatoms (Table 3 ) rely only on the MEP pathway [71]. Some streptomyces, apicomplexa (a clade of parasitic protists derived from a photosynthetic ancestor, for a review see [74]), mosses, liverworts, land plants and some algae, including diatoms (Table 3) appear to use both routes $[13,68,70]$. All these eukaryotic groups carry plastids (either photosynthetic or, in the case of apicomplexa highly reduced ones; for reviews, see [74-76]), suggesting that they obtained the MEP pathway through the transfer of genes from the original cyanobacterial endosymbionts which became plastids during endosymbiogenesis [77]. When this occurs, cytosolic sterols are synthesized through the cytosolic MVA pathway in the cytosol while chloroplastic isoprenoids such as phytol and carotenoids are synthesized along the chloroplastic MEP pathway in the chloroplast $[13,68,78,79]$. One interesting question, however, remains to be answered: does a cross-talk between the two routes exist?

Table 3. Occurrence of the different isopentenyl diphosphate (IPP) biosynthetic pathways in different microalgal taxa. 


\begin{tabular}{|l|l|l|l|l|}
\hline \multirow{2}{*}{$\begin{array}{l}\text { Superphy } \\
\text { lum/Phyl } \\
\text { um }\end{array}$} & Genus & Species & MVA & MEP \\
synthesize IPP to \\
\hline $\begin{array}{l}\text { Chloroph } \\
\text { yta }\end{array}$ & $\begin{array}{l}\text { Scenedesm } \\
\text { us }\end{array}$ & obliquus & $(-)[80]$ & $+[80]$ \\
\cline { 2 - 5 } & $\begin{array}{l}\text { Chlamydo } \\
\text { monas }\end{array}$ & $\begin{array}{l}\text { reinhard } \\
\text { tii }\end{array}$ & $-[81]$ & $+[81]$ \\
\cline { 2 - 5 } & Chlorella & fusca & $-[81]$ & $+[81]$ \\
\hline $\begin{array}{l}\text { Chrysoph } \\
\text { yta }\end{array}$ & $\begin{array}{l}\text { Ochromona } \\
\text { s }\end{array}$ & $\begin{array}{l}\text { malhame } \\
\text { nsis }\end{array}$ & $+[82]$ & $+[82]$ \\
\hline \multirow{2}{*}{$\begin{array}{l}\text { Euglenoz } \\
\text { oa }\end{array}$} & $\begin{array}{l}\text { Euglena } \\
\text { Heteroko } \\
\text { nta }\end{array}$ & $\begin{array}{l}\text { vulgaris } \\
\text { a }\end{array}$ & $+[81]$ & $-[81]$ \\
\cline { 2 - 5 } & Haslea & ostrearia & $(-)[69]$ & $+[69]$ \\
\cline { 2 - 5 } & $\begin{array}{l}\text { Phaeodacty } \\
\text { lum }\end{array}$ & $\begin{array}{l}\text { tricornut } \\
\text { um }\end{array}$ & $+[78]$ & $+[78]$ \\
\cline { 2 - 5 } & Nitzschia & ovalis & $+[78]$ & $+[78]$ \\
\hline $\begin{array}{l}\text { Rhodoph } \\
\text { yta }\end{array}$ & $\begin{array}{l}\text { Cyanidium } \\
\text { caldariu } \\
\text { m }\end{array}$ & $-[81]$ & $+[81]$ \\
\hline
\end{tabular}

(-) very weak if any contribution. The MVA pathway is localized in the cytoplasm, while the methylerythritol phosphate (MEP) pathway is plastid located.

A comprehensive description of the biosynthetic pathway leading to the formation of carotenoids and xanthophylls can be found in $[11,13,65,66]$. Therefore, only a brief outline is presented here.

\subsection{Common/Universal Steps}

The carotenoid backbone is formed by the condensation of two geranylgeranyl diphosphate molecules producing phytoene (Fig. 2). The reaction is catalyzed by phytoene synthase (CRTB). The next steps of the pathway consist of the extension of the size of the conjugated double bond system through the sequential addition of double bonds by phytoene desaturase (CRTQ). The large chemical variety of carotenoids is reached thanks to the presence of various carotenoid-modifying enzymes, including lycopene cyclase (CRTY), carotene ketolase (CRTW), carotene hydroxylase (CRTZ). Both CRTY- $\varepsilon$ epsilon (LCYE) and CRTY- $\beta$ (LCYB) are cycling the end of lycopene differently (see Fig. 2), resulting in the division of the carotenoid pathway in two branches, starting with $\alpha$-carotene and $\beta$-carotene, respectively $[65,83]$.

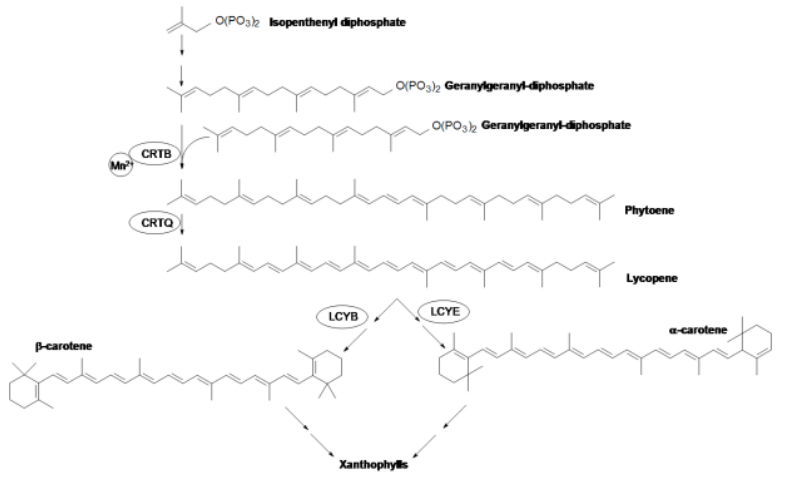

Fig. (2). The carotenoid biosynthetic pathway.

\subsection{Regulation}

Carotenoids participating in the photosynthetic process are synthesized according to the actual demand of the cell. For instance, when cells are exposed to shade, they increase their content in pigments, including carotenoids. It has been established that the carotenoid amount can be modified and/or enhanced by stress conditions (such as heavy metals: [84]; nutrient deficiency: [39]; light intensity: [85]; for reviews, see $[11,86])$. To illustrate this point, the regulation by nitrogen or light availability are described in the two next subsections.

\subsubsection{Influence of Nitrogen Availability}

In an elegant study combining advanced mathematical modeling and optimization techniques, Dineshkumar et al. [39] evaluated the impact of changes in macro- and micronutrients on lutein production by the green microalga Chlorella minutissima. For instance, limitation in ions serving as cofactor for the carotenoid biosynthetic pathway reduces the carotenoid production (Mn: phytoene synthase, CRTB; Fe: $\beta$-carotene hydroxylase, CRTZ) [83] (Fig. 2). However, these ions should not be present in excess because then they generate ROS and thus cause oxidative stress (Fe: [87], $\mathrm{Cu}$ : [88]).

Nitrogen is essential for growth and for the synthesis of fundamental building blocks of cells such as proteins and enzymes, including those needed for carotenoid accumulation as stress-induced carotenoid accumulation may require de novo enzyme biosynthesis (e.g., Haematococcus pluvialis-astaxanthin: [85]. Thus, the nitrogen level in the growth medium seems to be of primary importance for carotenoid production. However, nitrogen deficiency generally induces carotenogenesis. For instance, Dineshkumar et al. [39] and others found that high nitrogen content of the growth medium promotes lutein (a) production. To illustrate this point, we have replotted the data from Dineshkumar et al. [39] in order to show how the lutein amount is affected by the initial nitrogen content in the growth medium (Fig. 3). Under low initial nitrogen content, the amount of lutein increased until about $48 \mathrm{~h}$ and then decreased. However, high initial nitrogen content allowed the accumulation of lutein over the entire growth period (Fig. 3, [39]). It is not completely clear why the presence of high nitrogen concentration in the growth medium allowed higher 
lutein accumulation. It can be, however, hypothesized that in the presence of a high amount of nitrogen, cells were growing for a longer time and used the energy produced by photosynthesis to accumulate lutein whereas in the presence of low amounts of nitrogen, cell growth was arrested earlier - the nitrogen content declined after $48 \mathrm{~h}$ of growth - and the accumulated lutein molecules were metabolized for instance to provide energy to cells.

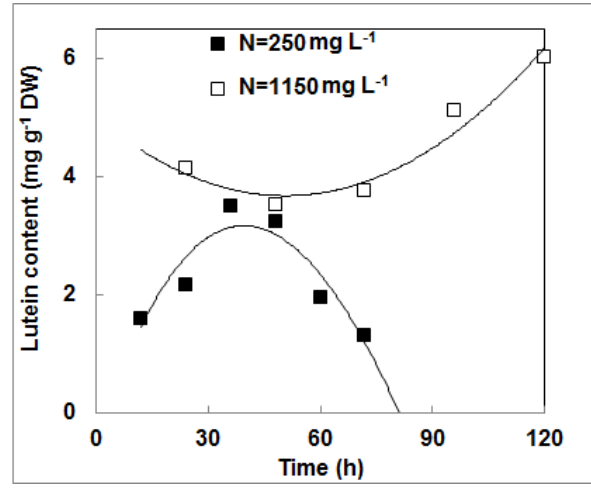

Fig. (3). Effect of the initial nitrogen content on the accumulation of lutein in the green alga Chlorella minutissima (Figure constructed on the basis of raw data from [39]). The data have been calculated from the timecourse profiles of biomass and lutein concentration of Chlorella minutissima grown in a 2-L airlift photobioreactor published in [39]. The operating conditions were $150 \mu \mathrm{mol}$ photons $\mathrm{m}^{-2} \mathrm{~s}^{-1}$ light intensity; $2.5 \% \mathrm{CO}_{2}$ and $0.45 \mathrm{vvm}$ flow rate.

\subsubsection{Influence of the Light Intensity}

It is well established that the amount of carotenoids in microalgae is regulated by light intensity. The lower the light intensity the higher the carotenoid content (under a certain limit, however). Many green algae acclimate to high light (HL) conditions through the accumulation of carotenoids [27]. Transcriptional, post-transcriptional and biochemical factors are all involved in the regulatory network (for a review, see [11]). For instance, high levels of white light $\left(1000 \mu \mathrm{mol} \mathrm{m} \mathrm{m}^{-2} \mathrm{~s}^{-1}\right)$ induced a significant decrease of the mRNA level of carotenoid hydroxylase Cyp97a1, at the early stage of the treatment of Chlorella kessleri and Haematococcus pluvialis before a strong increase when the treatment was continued after $10 \mathrm{~h}$. The amount of carotenoids varied concomitantly with the mRNA level [89].

Altogether, stress conditions enhance carotenoid production in many microalgae. Understanding the regulation of the stress effect could be important to enhance the production of selected carotenoids in biotechnological applications.

\section{OCCURRENCE, LOCALIZATION AND ROLES IN MICROALGAE}

\subsection{Occurrence and Cellular Localization}

Carotenoids are ubiquitous molecules. In microalgae, they are mostly found inside the photosynthetic membranes where they are involved in light harvesting, in the protection against photodamage and oxidative stress. There, carotenoids are bound to dedicated proteins through weak hydrophobic interactions. This does not exclude the presence of unbound pools of carotenoid molecules (for a review, see [86]). In situ, carotenoids are often esterified and bound to fatty acids, with more hydrophobic carotenes being thought to be immersed in the lipid bilayer, while more polar and hydrophilic xanthophylls being thought to bind to the lipid surface or to proteins.

Carotenoid biosynthesis is believed to occur entirely in chloroplasts. However, final steps of the branching can be localized in another compartment. This is the case for the enzymes transforming $\beta$-carotene (Fig. 2) into astaxanthin (Fig. 1) in Haematococcus pluvialis that are active in the cytoplasm [85]. In some microalgae such as the chrysophyte Ochromonas malhamensis, the mevalonate pathway is also present (Table 3). In this alga, the 3hydroxy-3-methylglutaryl-CoA reductase activity, a key enzyme of the mevalonate pathway, has been demonstrated to be associated with microsomes [82]. It is not clear whether this pathway participates to the formation of carotenoids through the delivery of IPP to the chloroplast or not.

\subsection{Roles}

Light is essential for photosynthesis. In the photosynthetic apparatus, photons are harvested by pigments, including carotenoids, located in the light-harvesting antennas that are associated to the reaction centers. The energy associated to the absorbed photons is usually transferred to chlorophyll molecules. However, when the energy is arriving at the reaction center, the carotenoids of the light-harvesting antenna switch from the light-harvesting mode to the energyquenching mode, i.e., dissipating the excess of energy as heat [90]. The molecular mechanism involved in the process is not yet completely understood and several possibilities have been proposed: (1) excitonic interactions between carotenoids and chlorophyll molecules [91], (2) electron transfer [92] and (3) energy transfer from the excited chlorophyll molecules to the carotenoid $[93,94]$. Carotenoids involved in photosynthesis are often referred to as primary carotenoids. At the same time, carotenoids not directly involved in primary metabolism, but occurring and accumulating in chromoplasts of reproductive organs (flowers, seeds and fruit parts of plants or in the shield cells of the antheridium of the green alga Chara corallina [95]) or only under certain conditions in the cytoplasm (e.g., in Haematococcus pluvialis (reviewed in [11]) are termed secondary carotenoids, These may have roles in reproduction (especially in plants) or in stress defense (in algae).

\section{CAROTENOIDS AS HEALTH PROMOTING COMPOUNDS}

In recent decades, a convincing body of evidence has been accumulated to support the association between higher carotenoid intakes and reduced chronic disease risks [6]. Because vertebrate cells are unable to synthesize these compounds, they should be acquired through diet [6].

Some in vitro data indicate that $20-40 \%$ of dietary carotenoids may be absorbed/accumulated by Caco- 2 human cells [96]. In vivo absorption of carotenoids like $\beta$-carotene is in general estimated as $5-22 \%$. The protein-mediated uptake of $\beta$-carotene is restricted to the duodenum of the small intestine, and occurs on the same receptor (SR-B1) as that of 
vitamin E ( $\alpha$-tocopherol) [97]. After absorption, carotenoids may be mobilized and stored in the liver and body fat.

Carotenoids have biological actions such as antioxidant and anti-inflammatory effects that may help to maintain health and prevent the appearance of diseases. Studies focused first on the provitamin A activity of carotenoids and especially $\beta$-carotene. More recent studies showed that several carotenoids without provitamin A activity can be even more efficient in the prevention of many serious diseases such as cardiovascular and neurodegenerative disease, diabetes, obesity, etc. Moreover, due to safety concerns, people tend to give preference to carotenoids obtained from natural sources (see Section 1). In this context, microalgae and their carotenoids, show promising benefits for the health prevention field $[12,40,98]$.

Humans and some omnivorous animals are poor converters of carotenoids to colorless retinoids, and thus may accumulate ingested carotenoids to relatively large extent, with best-known examples including (1) astaxanthin in marine animals such as salmon, shrimps, lobsters and their eggs [99], (2) canthaxanthin accumulating in bird plumage in flamingo or red ibis [54], and (3) intact absorbed $\beta$-carotene accumulating in humans (plus other mammals including horse and ferret, and birds like chicken) in the blood and tissues (especially in adipose tissue which owes its yellow coloration to carotenes in humans and chicken for example) after increased carotenoid intake [53]. This latter phenomenon is also known as carotenodermia (or carotenosis), i.e., orange skin tint due to the accumulation and deposition of carotenoids in the stratum corneum of the skin at distinct places (palms, soles, knees) [100].

\subsection{Provitamin A Activity}

Vitamin A (b) is essential for the promotion of growth, embryonal development, proper function of the immune system and vision [101]. Because human cells are unable to synthesize both provitamin A and vitamin A, they should be acquired through the diet. Consequently, a deficiency in the intake of these compounds can have dramatic consequences for health.
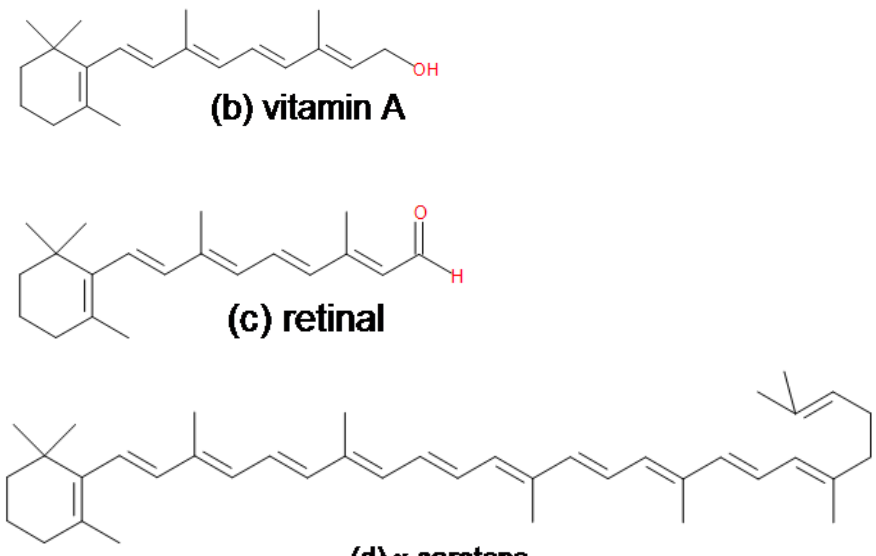

(d) $\gamma$-carotene

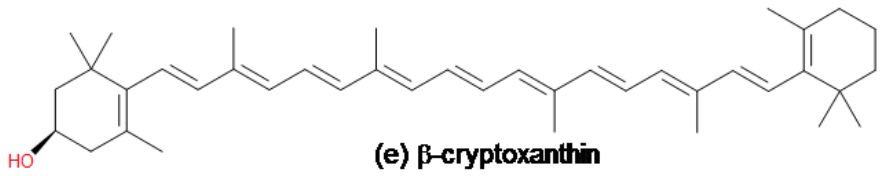

Steenbock [102] suggested on the basis of indirect evidence that there could be a relationship between $\beta$ carotene (Fig. 2) and vitamin A (b). The scientifically and commercially important concept of provitamins (precursor molecules which are converted into vitamins by the body) was entirely new, and became generally accepted only after 1965 based on evidence of the formation of retinal (a derivative of vitamin A) (c) from this pigment in cell free extracts [103]. Actually, around 50 carotenoids have been shown to have provitamin-A activity, because they contain one ( $\alpha$-carotene) (Fig. 2), $\gamma$-carotene (d), $\beta$-cryptoxanthin (e) or two ( $\beta$-carotene) (Fig. 2) retinyl groups and can be therefore easily transformed into this vital pigment for vision, skin protection and cell growth, if necessary $[104,105]$. In this respect, $\beta$-carotene is the most important pigment, which can be cleaved into two retinal molecules by $\beta$-carotene-15,15'-monooxygenase of the cells (localized primarily in the duodenal mucosa cells, but also present in the liver) [103]. Based on these evidences it is clear that dietary carotenoids can prevent vitamin A deficiency in humans [106].

However, the pro-vitamin A activity (bioavailability, bioconversion and bioefficacy) of the dietary pigments depends and varies a lot on different factors related to the pigment itself (i.e., chemical structure of the given carotenoid, its molecular linkage, its matrix properties, etc.), to ingestion (the way the food and the pigment has been previously processed, i.e., as raw or cooked vegetable, as dietary supplement, etc., the amount in the meal, the presence of fats that may facilitate carotenoid uptake), and other factors such as nutrient status, present stores of vitamin A and the given carotenoid, effectors, genetics, host specifity and interactions between factors [107]. For instance, in the absence of vitamin $E$ ( $\alpha$-tocopherol) the normal cleavage of $\beta$-carotenes is inhibited and apocarotenoids are formed instead of vitamin A [103].

Both all-trans and 9-cis isomers of for example $\beta$ carotene (Fig. 4) can be metabolized to their respective retinoic acid isomers [108], which are both active in gene regulation [109]. This clearly shows that consumption of cisisomers from food may be important, although the mechanisms behind the observed differences between the uptake, transport and tissue accumulation of the different isomers is still not fully understood [110]. Due to the variable absorption and conversion of the different carotenoids to vitamin A (b) by humans, Dietary Reference Intakes are defined in the USA as retinol activity equivalents (RAE) since 2001 [111].

Although carotenoids from fruits and vegetables provide up to $70 \%$ of the vitamin A (b) intake in some countries, carotenoids from microalgae represent a good alternative. In the last decades, the commercial production of microalgae enriched in provitamin A carotenoids has been mainly focused on Spirulina, Chlorella, and Dunaliella $[112,113]$. Due to their simple unicellular organization these algae are thought to be more digestible. Digestible means that more carotenoids would be released from the food matrix than from leafy green vegetables such as spinach, a traditional source of provitamin A carotenoids [114]. A study carried out in India on humans showed significant improvements in hemoglobin, serum protein, and serum retinol levels when $1 \mathrm{~g}$ per day of Spirulina was given for 6 
weeks [115]. Although the world production of these microalgae is quite high (for Spirulina it reached 3,000 metric tons in 2012 [116]), their utilization as vitamin A source in humans is still limited.

\subsection{Antioxidant Effects}

Many diseases such as cancer, diabetes, neurodegenerative and cardiovascular diseases all have oxidative stress as a major cause of inflammatory events. Molecules such as ROS (e.g., superoxide anion $\mathrm{O}_{2}^{-0}$, singlet oxygen ${ }^{1} \mathrm{O}_{2}$, hydroxy radical $\mathrm{OH}^{*}$, or peroxyl radicals $\mathrm{OO}^{*}$ ) and reactive nitrogen species (RNS) (e.g., nitric oxide $\mathrm{NO}^{\circ}$, peroxynitrite $\mathrm{ONOO}^{-}$) are produced in the body during normal metabolic reactions and are well recognized as essential to maintain homeostasis and to regulate several metabolic processes. For example, the formation of ROS by phagocytic cells constitutes an essential host defense mechanism necessary to combat infection. Likewise, ROS produced in response to stimulation by growth factors are involved in regulating the proliferative response $[117,118]$. Under certain situations of metabolic stress, oxidative molecules seem to modulate cellular signaling pathways $[119,120]$. However, ROS and RNS can also be potentially harmful when the imbalance between oxidants and antioxidants is in favor of the oxidants ('oxidative stress'). Physiological stress, air pollution, tobacco smoke, exposure to chemicals or exposure to ultraviolet light can enhance the production of such molecules. Regardless how or where they are generated, a rise in intracellular oxidant levels has two potentially important effects: damages to various cell components (DNA, proteins, lipid membranes) and activation of specific signalling pathways. Both of these effects can cause aberrant cell division, which sequentially contributes to aging and to the development of a number of diseases such as atherogenesis, ischemia-reperfusion injury, infant retinopathy, age-related macular degeneration and carcinogenesis [121].

Carotenoids attracted attention because a number of epidemiological studies have revealed a positive link between higher dietary intake and tissue concentrations of carotenoids and lower risk for several degenerative disorders, including various types of cancer, cardiovascular or ophthalmological diseases [122-125]. The preventive effects of carotenoids have been associated with their antioxidant activity, protecting cells and tissues from oxidative damages [126]. However, still limited information is available on the antioxidant activity of microalgae. Murthy et al. [127] highlighted the ability of Dunaliella salina powder extract to protect against oxidative stress in vivo using animal models and demonstrated the beneficial effect of algal $\beta$-carotene compared to synthetic carotene as antioxidant. Actually, Levin and Mokady [128] showed that 9-cis- $\beta$-carotene has a higher antioxidant potency than the all-trans isomer and therefore protects not only the fatty acids but also the all-trans isomer. This difference might be explained by the higher reactivity of cis, compared to trans, bonds (Fig. 4). Li et al. [129] investigated the antioxidant capacity of 23 different microalgae. They found Synechococcus sp., Chlamydomonas nivalis and Nostoc ellipsosporum to possess the highest antioxidant capacities and thus be potential rich sources of natural antioxidants. More recently, Dambeck and Sandmann [130] showed that fucoxanthin and astaxanthin (see Fig. 1 for the structures) isolated from the two microalgae Phaeodactylum tricornutum and Haematococcus pluvialis, had the potential to protect against lipid peroxidations caused by singlet oxygen or oxy radicals.

Carotenoids scavenge harmful radicals through (1) electron transfer, (2) radical adduct formation or (3) hydrogen atom transfer [131,132]. They are most likely involved in the scavenging of two ROS, singlet oxygen and peroxyl radicals $[133,134]$. The electron-rich conjugated system of the polyene and cyclic end groups of the carotenoid molecule determine the power of its antioxidant activity [135]. Based on in vitro tests, astaxanthin exhibited the most powerful scavenging capacity among all marine carotenoids [136]. The polyene chain in astaxanthin (Fig. 1) traps radicals in the cell membrane, while the terminal ring of astaxanthin could scavenge radicals at the outer and inner parts of the cell membrane. The antioxidant activity of astaxanthin was shown to be stronger than that of quercetin (a well-known bioactive flavone), lutein, canthaxanthin, $\beta$ carotene, zeaxanthin as well as more than 100 times stronger than $\alpha$-tocopherol ([136]; for more details see [137]). Due to the presence of an oxo-carbonyl and hydroxyl group on each ionone ring of its molecule, astaxanthin (Fig. 1) may also convert free radicals into stable products, thus preventing from peroxidations $[28,135,138,139]$. Astaxanthin has been shown to reduce lipid peroxidation by up to $40 \%$ while other carotenoids such as lutein, lycopene, $\beta$-carotene and zeaxanthin have been found to act as pro-oxidant molecules and disturb the lipid membrane bilayer [140].

Reports support the assumption that daily ingestion of astaxanthin may protect body tissues from oxidative damage and this might be a practical and beneficial strategy in health management [141]. In rabbits fed with astaxanthin supplemented diet, superoxide dismutase and thioredoxin reductase activities were enhanced in the serum [142]. The level of antioxidant enzymes were increased in astaxanthin fed rats with ethanol-induced gastric ulcer [143]. Indeed, astaxanthin effects were observed with rats fed with astaxanthin-enriched Haematococcus pluvialis [28]. Actually, catalase, superoxide dismutase, peroxidase and thiobarbituric acid reactive substances were significantly high in plasma and liver in the hours following administration, offering thus a long-term protection against free radicals.

The presence of an allenic bond and six oxygen atoms in the fucoxanthin molecule (Fig. 1) was found to be responsible for the higher antioxidant activity of fucoxanthin compared to $\beta$-carotene (Fig. 2) ([144,145], see [146] for more details). Interestingly, fucoxanthin acts as an antioxidant under anoxic conditions, whereas other carotenoids (like $\beta$-carotene and lutein) show little or no quenching activities in such environment [144].

It has also been suggested that interactions between structurally different compounds with antioxidant activity provides additional protection against increased oxidative stress. For example, synergic interactions between $\beta$ carotene and other antioxidants such as $\alpha$-tocopherol and ascorbic acid have been described against UVA stress in cultured human fibroblasts [147] while the combination of vitamin $\mathrm{E}$, vitamin $\mathrm{C}$ and $\beta$-carotene exhibited synergic effects against RNS [148]. Stahl et al. [100] showed that mixtures of carotenoids were more effective than either single compounds, and that synergic effects were more pronounced when lutein or lycopene (f) was present. 


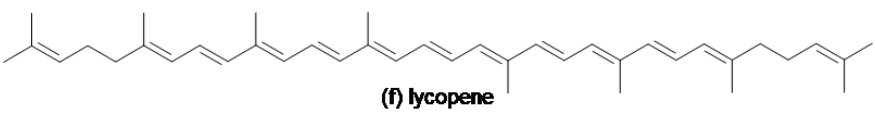

\subsection{Anti-inflammatory Effects}

Inflammation is reported to be associated with a wide range of diseases, including cancer, cardiovascular diseases, neurodegeneration and metabolic disorders [149,150]. Inflammation involves the production of various inflammatory chemicals, such as interleukin (IL) family cytokines, ROS and RNS, and prostaglandin $\mathrm{E}_{2}\left(\mathrm{PGE}_{2}\right)$ synthesized by inducible nitric oxide synthase (iNOS) and cyclooxygenase-2 (COX-2). These inflammatory chemicals are produced to eliminate pathogens and repair injured tissues. The nuclear factor- $\mathrm{\kappa B}(\mathrm{NF}-\mathrm{\kappa B})$ is a key transcription factor involved in the regulation of inflammation, and an abnormal and constitutive activation of this factor has been linked to a number of chronic inflammatory diseases [151]. Inhibiting NF- $\mathrm{kB}$ is a major way to suppress the expression of inflammation-associated genes. Some carotenoids are natural inhibitors of NF- $\mathrm{KB}$, suggesting their great potential for the treatment of inflammatory diseases. For example, in LPS-stimulated macrophages, astaxanthin has been shown to

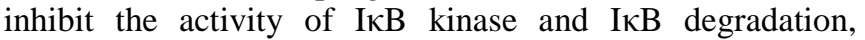
leading the NF- $\kappa \mathrm{B}$ p65 subunit to be blocked and unable to be translocated to the nucleus for the activation of inflammation-related genes [152]. Through this mechanism, astaxanthin and lutein treatments have been shown to inhibit the expression of several inflammatory chemicals and led to a significant inhibition of macrophage infiltration into choroidal neovascularization associated with macular degeneration [153]. With the same mechanism, carotenoid extracts of Dunaliella salina, and especially all-trans- $\beta$ carotene and, 9- or 9'-cis- $\beta$-carotene, were found to modulate inflammatory processes [154] (Fig. 4).

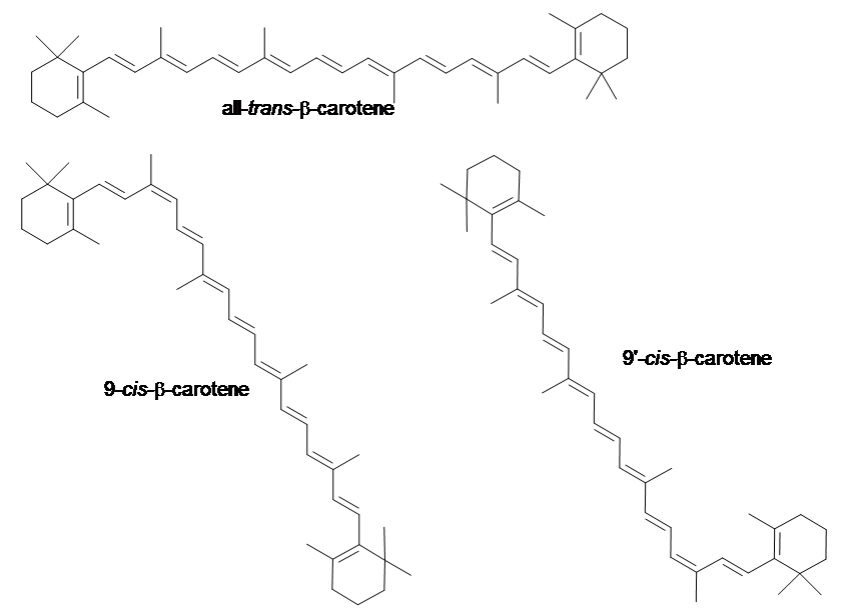

Fig. (4). Structures of all-trans- $\beta$-carotene and its 9-cisisomers. $\beta$-carotene being a symmetric molecule, the structures of 9- and 9'-cis- $\beta$-carotene are identical. They are displayed here in order to illustrate this point.

Several studies also reported the role of lutein and other carotenoids in the inhibition of NF- $\kappa$ B. For example, lutein and $\beta$-carotene were found to inhibit IкB- $\alpha$ degradation and $\mathrm{NF}-\mathrm{\kappa B}$ p65 nuclear translocation as well as the production of proinflammatory mediators (such as NO, TNF- $\alpha$, IL-6,
$\mathrm{PGE}_{2}, \mathrm{MCP}-1$ and MIP-2) both in vivo and in vitro [155157].

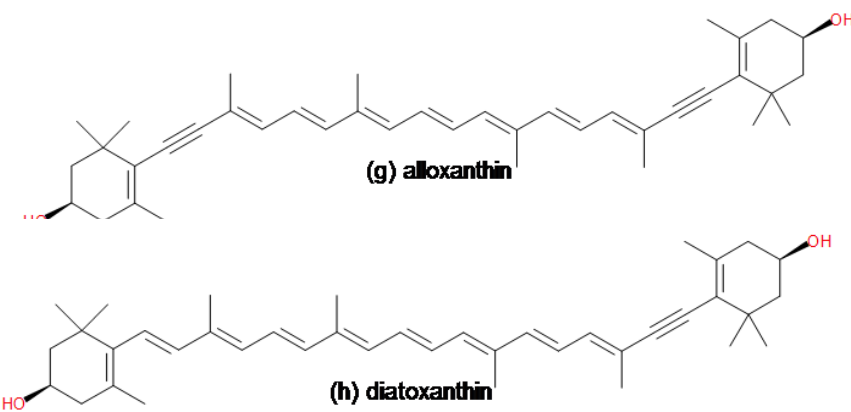

Fucoxanthin [158] and violaxanthin [151] showed anti-inflammatory effects based on the inhibition of the NF$\kappa \mathrm{B}$ and mitogen-activated protein kinase pathways. Astaxanthin, fucoxanthin, alloxanthin (g) and diatoxanthin (h) were also found to suppress the overexpression of COX2 and iNOS mRNA in lipopolysaccharide stimulated different cell lines [158-162]. Moreover, Sakai et al. $[163,164]$ showed that astaxanthin, fucoxanthin, $\beta$-carotene and zeaxanthin significantly suppressed degranulation of mast cells in vitro and in vivo (only fucoxanthin) by inhibiting antigen-induced aggregation of high affinity $\operatorname{IgE}$ receptor followed by activation of the degranulation signals of mast cells, which play important roles in inflammation and immediate-type allergic reaction. In addition, González et al. [165] demonstrated that oral supplementation of lutein and zeaxanthin diminishes the effects of UV-B irradiation by reducing acute inflammatory responses and epidermal hyperproliferation, which may thus be used in the prevention of carcinogenesis in chronically UV-exposed skin.

\subsection{Cardiovascular Effects}

\subsubsection{Hypolipidemic Properties}

It is recognized that high levels of low-density lipoprotein cholesterol (LDL-C), and low levels of high-density lipoprotein cholesterol (HDL-C), low-density lipoprotein (LDL) oxidation and, globally, hyperlipidemia are key risk factors to develop cardiovascular disease (CVD) such as atherosclerotic lesions, thrombotic and coronary heart diseases [166,167]. In this context, hypolipidemic, hypoglycemic and anti-hypertensive properties of carotenoids make them potential protective and even therapeutic agents against CVD [168].

Carotenoids have several hypolipidemic effects. For example, astaxanthin decreased triacylglycerol (TAG) as well as LDL-C levels, and inhibited lipid peroxidation in addition to LDL oxidation in a dose-dependent manner $[115,169]$. In rats fed with $1 \%$ astaxanthin supplemented diet, the LDL-C level decreased while that of HDL-C increased [170]. Astaxanthin had also a potentially beneficial role in the prevention of lipid peroxidation in rabbits fed with an atherogenic diet [171]. In addition, in human patients with mild hyperlipidemia, this carotenoid also decreased TAG levels and enhanced HDL-C and adiponectin levels [172].

$\beta$-carotene (Fig. 2) could also be useful against hyperlipidemia. Besides reducing LDL oxidation risks, it improves lymphocyte proliferation, and thus immunological 
functions [173]. Furthermore, a mixture of bezafibrate and 9cis- $\beta$-carotene-rich Dunaliella bardawil powder improved bezafibrate impact on the increase of HDL-C in human apolipoproteins [174]. Harari et al. [175] found similar results in a mouse model of atherosclerosis with an inhibition of the disease following a diet enriched in 9-cis- $\beta$ carotene (Fig. 4). According to the authors, this effect was due to (1) the concentration decrease of plasmatic non-HDL$\mathrm{C}$ and (2) the inhibition of fatty liver development and inflammation. Interestingly, this diet was shown to reduce the expression of proinflammatory genes and genes coding for enzymes involved in cholesterol metabolism as well [167]. A diet supplemented with total carotenoids extracted from Dunaliella, including $\beta$-carotene, is also beneficial in rats: conversely to a complement containing synthetic alltrans- $\beta$-carotene, the total carotenoid extract reduces total plasmatic and hepatic cholesterol, plasmatic as well as hepatic total lipids, TAG and phospholipids [176]. A mix of natural carotenoids with trans- and cis-isomers presents the same kind of effects, in a dose-dependent manner [176,177]. El-Baky et al. [176] also showed that $\beta$-carotene supplement can increase the activity of TAG- and phospholipases. Moreover, specific genera of microalgae or cyanobacteria (Chlorella and Arthrospira) have proven to be effective in reducing serum cholesterol and raising HDL-C and HDL/LDL ratio in rats, mice and humans [178-180]. Lycopene, similarly to astaxanthin and fucoxanthin, also positively impacts lipid homeostasis [181]. Indeed, in vitro studies have shown that lycopene leads to a stop of cholesterol synthesis [182,183]. It also inhibits LDL peroxidation and can protect the vascular endothelium from oxidative lesions [184]. As for fucoxanthin, it is described as a strong inhibitor of plasma and liver TAG and cholesterol accumulation, as well as that of high blood pressure and chronic inflammations [185-188]. Lutein is another carotenoid involved in the prevention of lipid peroxidation [189]. An inverse relationship was also found between plasma lutein levels and LDL oxidation in guinea pigs [190]. A study performed with humans showed that the serum levels of circulating antioxidants, including $\beta$-cryptoxanthin, are inversely related to the concentration of oxidized LDL-C and C-reactive protein, a CVD risk factor implicated in inflammatory reactions [191].

\subsubsection{Anti-hypertensive Properties}

Maintaining endothelium-generated NO levels and bioavailability has a positive impact on vasodilatation, which is in turn beneficial for endothelial functions. Molecules with antihypertensive properties, like carotenoids, can regulate blood pressure and thus are antiatherogenic agents, which would improve cardiovascular health [167,192].

Astaxanthin regulates NO level and decreases blood pressure, which is linked to the enhanced endotheliumdependent vasodilatation in resistance vessels [193,194]. A study conducted for 5 weeks in spontaneously hypertensive rats demonstrated that besides lowering blood pressure, the astaxanthin administration increased blood flow, reduced the number of aortic elastin bands, the wall-to-lumen ratio in the coronary arteries and arterioles as well as plasma levels of nitrite and nitrate $\left(\mathrm{NO}_{2}^{-}\right.$and $\left.\mathrm{NO}_{3}^{-}\right)$[138,195]. Simultaneously, astaxanthin induced vascular relaxation due to an increase in NO level. Another study conducted in the same model has confirmed these analyses highlighting that astaxanthin increases NO bioavailability in brain blood vessels [196]. It can, therefore, be concluded that astaxanthin has antithrombotic effects and can delay the impact of a stroke.

$\beta$-carotene and lycopene also enhance NO levels and bioavailability [192,197]. In addition, lycopene reduces the expression of adhesion molecules and, thus, the adhesion of endothelial cells to monocytes [198], which are potentially atherogenic processes associated with the vascular endothelium, through the inhibition of IL-1 secretion. Furthermore, stronger levels of lutein, as well as $\beta$ cryptoxanthin and, $\alpha$-carotene and $\beta$-carotene are linked to lower blood pressure in human subjects [199].

\subsubsection{Anti-atherosclerotic Properties}

The level of serum adiponectin is positively correlated with HDL-C [172] and this adipocytokine inhibits the formation of atherosclerotic plaques [200], making it an antiatherosclerotic factor [201]. Carotenoids can improve adiponectin levels, being therefore beneficial against atherosclerosis. Indeed, this has been shown for astaxanthin [202]. This pigment could increase the adiponectin level and stability of atherosclerotic plaques via macrophage infiltration, apoptosis and atheroma vulnerability reduction in hyperlipidemic rabbits with atherosclerosis [202]. Positive impact of astaxanthin on adiponectins was also found in people with a risk to develop metabolic syndrome [203]. Moreover, Kishimoto et al. [204] have shown that astaxanthin inhibited macrophage activation in a human monocyte cell line.

Several studies have highlighted that low tissue and blood levels of $\alpha$-carotene, $\beta$-carotene and lycopene are related to signs of carotid atherosclerosis, increase of calcified plaques of the abdominal aorta in humans as well as to the frequency of coronary heart disease and arterial plaque formation [205-207].

The efficacy of lycopene to prevent atherogenesis has been elucidated thanks to three studies that showed that the pigment protects biomolecules such as lipids, lipoproteins, proteins and DNA [208-210]. In addition, lycopene is associated with a reduction in carotid intimamedia thickness [211]. Lutein, zeaxanthin and the microalgae Dunaliella salina are also potentially protective against (early) atherosclerosis [176,177,190,212,213].

\subsubsection{Protective Effects Against Stroke, Myocardial Infarction and Other Cardiovascular Diseases (CVD)}

Dietary intake of Dunaliella salina and lutein can prevent or reduce the risk of stroke, just as lycopene and astaxanthin $[176,177,214,215]$. Moreover, in stroke-prone spontaneously hypertensive rats fed with fucoxanthin or astaxanthin, the impact of stroke was delayed [195,216].

Three studies have demonstrated the link between carotenoid level and the risk of subsequent myocardial infarction (MI) in people with a first MI: in the first two studies, low carotenoid levels were linked to an increased risk of MI and myocardial injury among smokers [217,218]. In the third study, lycopene but not $\beta$-carotene presented protective effect against MI risk because of its antioxidant power [219]. Moreover, Koh et al. [220] have highlighted the fact that high plasma levels of $\beta$-cryptoxanthin, as well as lutein, also reduced the risk of MI. Furthermore astaxanthin, fucoxanthin, lutein, lycopene and/or other oxygenated carotenoids have been found to be preventive, protective or 
therapeutic agents or at least negatively linked to CVD like myocardial damage and re-thrombosis, ischemia and reperfusion injury as well as to acute coronary syndromes, coronary artery diseases (CAD), and mortality risk associated with CVD [118,184,205,210,211,214,221-228]. Astaxanthin, administered at a concentration of $0.08 \%$ of the diet, also improves myocardial mitochondrial membrane potential and contractility index in mice, and thus confers cardiac protection [229].

Kritchevsky [230] and Ford and Giles [231] have found that, through their strong provitamin A activity, $\beta$ carotene, $\alpha$-carotene and $\beta$-cryptoxanthin are associated with the decreased risk of angina pectoris disease. In addition, administration of natural $\beta$-carotene from Dunaliella would protect against the development of cardiovascular diseases in humans with a history of angina or revascularization [232].

\subsection{Anticancer Effects}

One-third of the risk factors of cancer are linked to the diet [233]. In this context, carotenoid uptake could present a real interest because carotenoids exhibit a direct antiproliferative effect on the in vitro growth of cancer cells and induce their apoptosis [59,234-241]. Actually, carotenoids can have a direct action on DNA and consequently on the regulation of RNA production. Thus they can induce the overexpression of genes implied in the regulation of cell communication processes and so activate gap junction communications [242,243]. Thereby, carotenoids improve the intercellular communication and inhibit cell growth modification due to carcinogens [139,244,245] because carcinogenesis is characterized, among others, by the misplacing of gap junctional communication [137]. The improvement of the communication between cells can also favor the activity of the immune system cells [20]. So carotenoids have a dual impact on cancer. However, although this may apply to a large number of carotenoids, there is one exception namely natural astaxanthin. In fact, a study has showed that in primary human skin fibroblasts, astaxanthin decreases the communication between cells and alters channel function [246], conversely to disodium disuccinate astaxanthin, a synthetic derivative of the pigment [247], canthaxanthin or other carotenoids [246], that increase intercellular communication. Below we review data about the direct anticancer activity of carotenoids.

\subsubsection{Fibrosarcoma and Neuroblastoma}

According to Jyonouchi et al. [248], astaxanthin stops tumor cell growth in mice with transplantable methylcholanthreneinduced fibrosarcoma. Actually, if the astaxanthin supplementation starts before inoculation, the pigment induces a reduction of tumor size and weight. It also stimulates the immunity against tumor antigen through the improvement of the cytotoxic $\mathrm{T}$ lymphocyte activity and interferon-gamma production. Otherwise, Okuzumi et al. [249] have found that fucoxanthin is efficient against neuroblastoma cells, mainly because of its antiproliferative activity inducing cell cycle arrest and apoptosis.

\subsubsection{Breast Cancer}

During the last twenty years, several carotenoids such as lutein, astaxanthin, violaxanthin, fucoxanthin and fucoxanthinol have been reported for their antitumor activity against mammary tumors. Cerveny et al. [250] were among the first to discover that dietary lutein reduced mammary tumor growth, suggesting apoptosis induction by lutein. Besides confirming this result, Chew et al. [251] have also elucidated the action mechanisms of lutein against mammary tumor cells in mice fed with this carotenoid. Actually, lutein regulates the expression of specific genes, decreasing the expression of the anti-apoptotic $\mathrm{Bcl}-2$ gene, increasing mRNA expression of the proapoptotic $p 53$ and $B A X$ genes, thus changing the $\mathrm{BAX} / \mathrm{Bcl}-2$ ratio in tumor cells. In parallel, lutein reduces apoptosis in blood leukocytes suggesting an intensified immune status. This study has therefore highlighted the selective action of lutein showing that it reduced apoptosis in immune cells while enhancing apoptosis in tumor cells. The same kind of effect has also been found in vitro in human mammary cells [252]. In summary, lutein presents antiproliferative activity and regulates tumor immunity via apoptosis and gene regulation [253]. Astaxanthin is another powerful breast antitumor agent. Several studies have shown that a supplementation of astaxanthin in the diet can reduce breast tumor cell proliferation. Its in vivo antitumor activity against mammary tumor growth is higher than that of canthaxanthin and $\beta$ carotene in mice [254]. Moreover, Nakao et al. [229] have discovered that the astaxanthin impact in mice injected with a mammary tumor cell line depends on the time of administration with the pigment. When astaxanthin was given before the tumor inoculation, the tumor growth was stopped while the natural killer cell subpopulation and the plasma interferon- $\gamma$ concentration were augmented. In contrast, when mice were fed with astaxanthin after tumor initiation, the pigment had adverse effects, i.e., it induced a quicker tumor growth and an increase in plasma inflammatory cytokines IL- 6 and tumor necrosis factor- $\alpha$. Thus a good antioxidant status before tumor initiation, through a regular and continuous intake of common quantities of astaxanthin and/or others carotenoids, is necessary because it provides good conditions for cancer prevention and protection [207,229].

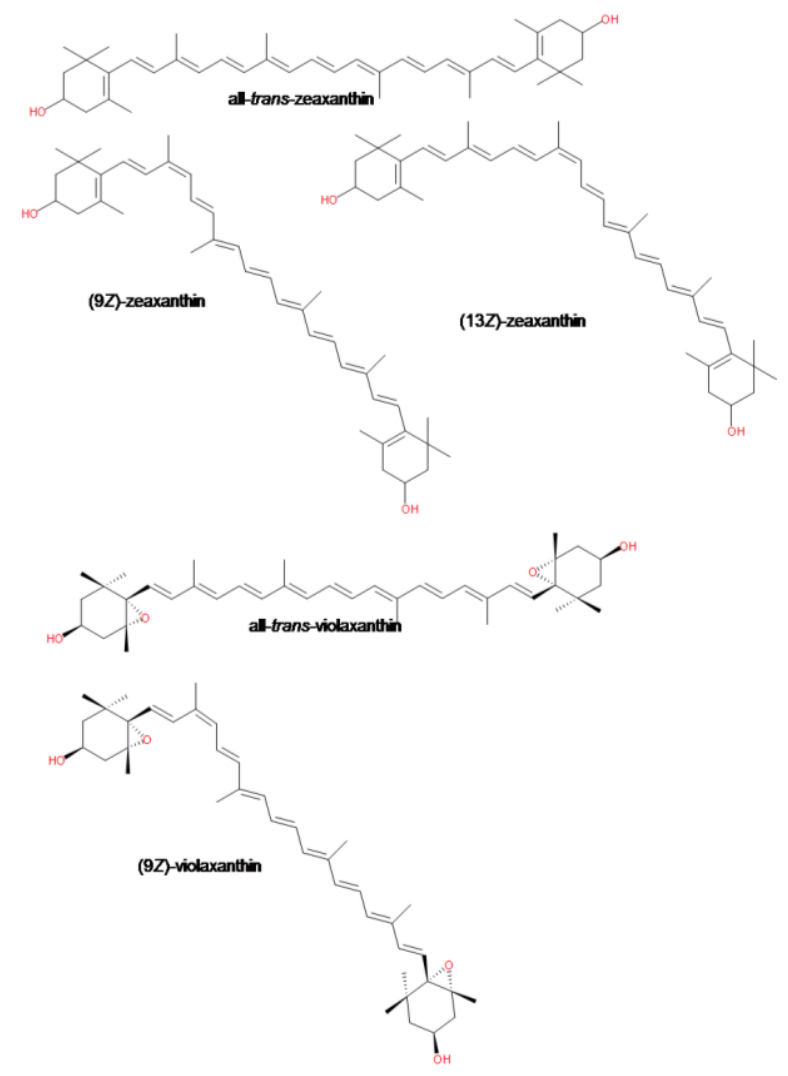


Fig. (5). Structures of some zeaxanthin and violaxanthin isomers.

Besides their direct antiproliferative action, carotenoids are able to enhance the activity of different anticancer drugs. This is especially the case of (9Z)zeaxanthin, (13Z)-zeaxanthin and (9Z)-violaxanthin (Fig. 5), which have been reported as carotenoids improving the antiproliferative activity of epirubicin on mouse lymphoma and/or human breast cancer cell line resistant to anticancer agents [255]. These authors have concluded that depending on the kind of cancer, the two pigments could be synergistic with epirubicin and therefore useful in the case of multidrug resistant (MDR) cancer cells. Moreover, an in vitro study conducted by Pasquet et al. [256] has showed that violaxanthin, which is the major carotenoid with antiproliferative action extracted from the microalga Dunaliella tertiolecta, impacted MCF-7 breast cancer cells and led to biochemical changes characteristic of early apoptosis. Interestingly, violaxanthin was the only molecule extracted from Dunaliella, which had an antiproliferative activity. No synergy between this pigment and other molecules extracted from the microalga was reported. By contrast, dietary intake of microalgae as a source of violaxanthin to prevent or treat cancer could be less beneficial than expected. In fact, Hashimoto et al. [257] showed that in mice, dietary epoxy carotenoids (such as fucoxanthin) were metabolized before accumulating in the body. Therefore, further studies must be conducted to determine whether pigments such as violaxanthin can be used in vivo to inhibit cancer cell growth. Otherwise, fucoxanthin and fucoxanthinol both enhance apoptosis in breast cancer cells leading to decreased viability in a timedependent manner [258]. However, fucoxanthinol is more efficient to modulate nuclear levels of NF- $\mathrm{B}$ members in these cells, and thus to induce apoptosis.

\subsubsection{Bronchopulmonary and Lung Cancers}

A study conducted by Jewell and O'Brien [259] has shown that canthaxanthin and astaxanthin induced xenobiotic metabolizing enzymes in lung, liver and kidney, explaining how carotenoids are protective against these cancers. Moreau et al. [240] have found that extracts from two diatoms (Odontella aurita, Chaetoceros sp.) and one haptophyte (Isochrysis galbana) are effective to inhibit cell growth of bronchopulmonary (NSCLC-N6) as well as lung (A549) and lens (SRA 01/04) epithelial cancer cell lines. The major or even the only bioactive component of the extracts proved to be fucoxanthin. Tests with pure fucoxanthin allowed the discovery of its dose-dependent cytostatic activity. The mode of action of fucoxanthin involves irreversible inhibitory effects, as well as DNA fragmentation and morphological changes typical of apoptotic cells in NSCLC-N6 and A549 cell lines. Fucoxanthin could, therefore, have antiproliferative activity through triggering terminal differentiation of well-differentiated cancer cells in vitro.

Several epidemiological studies have shown that dietary $\beta$-cryptoxanthin is linked to lower rates of lung cancers [167,260]. Moreover, Baudelet et al. [261] have discovered that zeaxanthin and $\beta$-cryptoxanthin, both extracted from the microalga Cyanophora paradoxa, strongly inhibited the growth of melanoma, breast and lung cancer cells. $\beta$-cryptoxanthin is also cytotoxic and presented a pro-apoptotic activity in the three cell lines, which confirms its potential role as antiproliferative agent.

In a recent study, Liu et al. [262] have compared the action of $\alpha$-carotene alone or combined with taxol, an anticancer drug, in tumor xenografted mice. They have found that $\alpha$-carotene alone inhibited Lewis lung carcinoma metastasis in vitro, without decreasing primary tumor growth, whereas the combination of $\alpha$-carotene and taxol suppressed lung metastasis and tumor growth demonstrating the synergistic effects of these two compounds. Furthermore, a comparison between $\alpha$-carotene and $\beta$-carotene effects against two-stage mouse lung carcinogenesis has been conducted in mice: only $\alpha$-carotene decreased the number of lung tumors per mouse [263]. $\alpha$-carotene had also a stronger antitumor-promoting activity than $\beta$-carotene in the case of skin carcinogenesis [263]. Similarly, $\beta$-carotene was inefficient to protect humans with a high risk of lung cancer [264]. Furthermore, the pigment induced lung pathology, maybe because of its provitamin A activity [265]. This observation was supported by Mayne et al. [266] who revealed that $\beta$-carotene increased lung cancer incidence in smokers, instead of reducing it. Actually there is a link between the effects of $\beta$-carotene and the smoking status of the patients: Senesse et al. [267] found that $\beta$-carotene was correlated with a non-significant rise in the risk of colon adenomas in former or current smokers whereas, in nonsmoker patients, it was inversely linked to colon adenomas. $\beta$-carotene could therefore be protective in non-smoker patients only. The antitumor activity of $\beta$-carotene could also be related to the nutritional status (e.g., dietary deficiency) of the studied population (for more details, see [207]).

\subsubsection{Leukemia}

Because of its antioxidant properties and its impact on molecules related to apoptosis, fucoxanthin shows a great anticancer potential [62,268].

Several studies have been conducted to determine the effects of fucoxanthin on HL-60 human leukemia cells. According to Hosokawa et al. [234], fucoxanthin extracted from Undaria pinnatifida exhibited antiproliferative effects and was responsible for apoptosis in HL-60 cells, unlike $\beta$ carotene. Authors have therefore suggested that the carotenoid structure could be a determining factor in the ability to induce apoptosis [234]. Kotake-Nara et al. [236] suggested that the pro-apoptotic properties of fucoxanthin in HL-60 cells could actually be the result of mitochondrial membrane permeabilization and caspase-3 activation. Fucoxanthin also induced cleavage of poly-ADP-ribose polymerase (PARP). This last point was confirmed by Kim et al. [268], who also discovered in HL-60 cells that fucoxanthin induced ROS accumulation and reduced levels of Bcl-xL (B-cell lymphoma-extra large), a transmembrane protein, which is an anti-apoptotic member of the Bcl-2 family. Using a ROS scavenger, they succeeded in cancelling apoptosis and inhibiting fucoxanthin effect on Bcl-xL. That's how they concluded that ROS can play a preponderant role both in fucoxanthin-mediated Bcl-xL signaling pathway and apoptosis in HL-60 cells. Furthermore, Nakazawa et al. [59] have found that 13'-cisfucoxanthin was more efficient than 13-cis- and all-transisomers to inhibit HL-60 cell growth (Fig. 6). Likewise, a treatment with a mixture of cis isomers significantly reduced the number of viable cells compared to a treatment with alltrans-fucoxanthin. Actually, these higher inhibitory and 
antiproliferative effects may be due to (1) the steric hindrances given by the structure of cis-fucoxanthin or to (2) the suppression of proteins that reduce apoptosis [59].

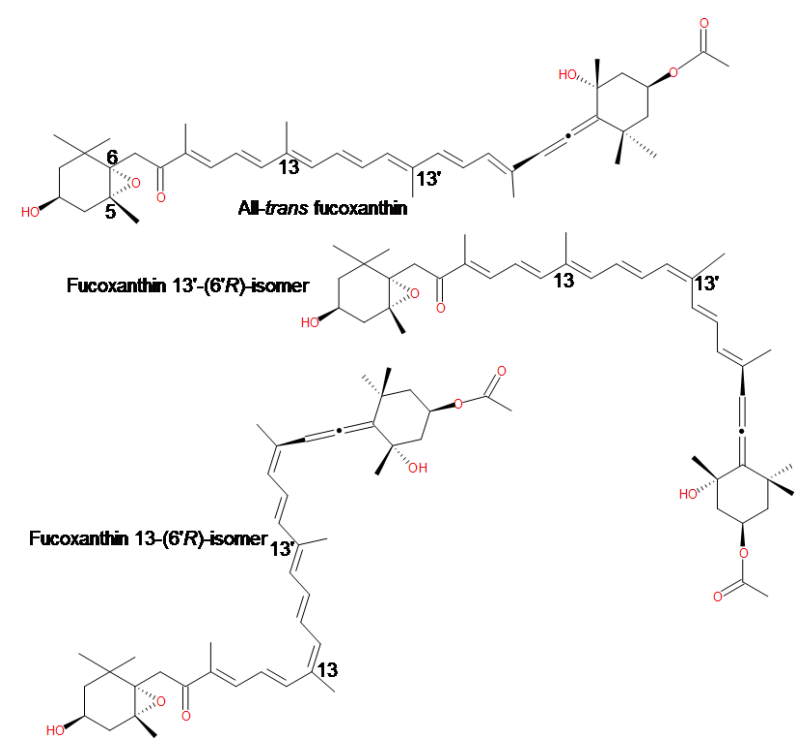

Fig. (6). Structures of fucoxanthin isomers.

Studies have also been conducted on HL-60 cells treated with fucoxanthinol. According to Konishi et al. [269], this pigment showed antiproliferative effects via apoptosis induction (e.g., reduction of $\mathrm{Bcl}-2$ expression level) like fucoxanthin on HL-60 cells as well as on breast and colon cancer cells. Interestingly, in the three cases, fucoxanthinolinduced apoptosis was greater than that caused by fucoxanthin. The replacement of the acetyl group of fucoxanthin by the alcohol group in fucoxanthinol could explain this difference (compare Figs. 6 and 7). Actually, this hydrolysis occurs during fucoxanthin absorption by intestinal cells, which makes fucoxanthinol more bioavailable for the organism [270].

Furthermore, Ishikawa et al. [271] discovered that fucoxanthin (Fig. 1) and fucoxanthinol (Fig. 7) were more effective than astaxanthin and $\beta$-carotene (Fig. 2) to inhibit specifically cell viability of human $\mathrm{T}$-cell leukemia virus type 1 (HTLV-1)-infected T-cell lines, and adult T-cell leukemia cells. Besides, the growth of tumors induced by HTLV-1-infected T cell inoculation in mice was stopped by fucoxanthinol (Fig. 7). In addition, mice showed a vast tissue distribution of fucoxanthinol. Similarly, Ganesan et al. [272] have found that fucoxanthin was more effective than several carotenoids to inhibit HL-60 cell viability. However, according to their study, the most efficient carotenoid to induce apoptosis was siphonaxanthin [272].

Thanks to their antiproliferative activity, fucoxanthin and fucoxanthinol (Fig. 7) were also effective against lymphoma [273].

\subsubsection{Cancers of the Urinary System}

Several studies have highlighted the fact that a diet supplemented with astaxanthin (Fig. 1) can reduce the cell proliferation of urinary bladder [274] and prostate tumors [275]. Actually, Anderson [275] discovered that astaxanthin inhibits the 5 - $\alpha$-reductase enzyme that is involved in

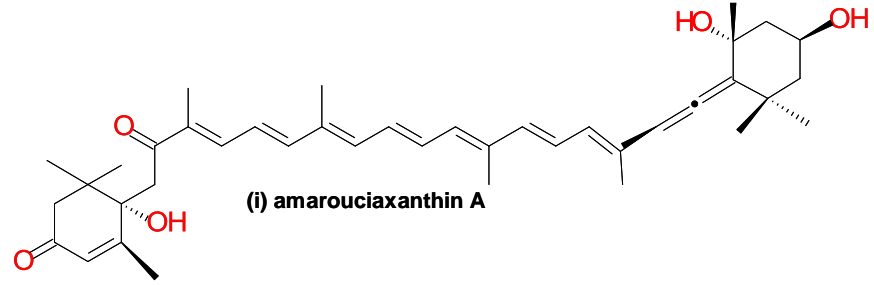

Fucoxanthin (Fig. 1) and its metabolites [amarouciaxanthin A (i), and fucoxanthinol - Fig. 7] were also effective against PC-3 human prostate cancer cells, as shown by Asai et al. [276]. Indeed, the three carotenoids induced a decrease of cancer cell viability. However, fucoxanthin and fucoxanthinol had a lower $\mathrm{IC}_{50}$ than amarouciaxanthin $\mathrm{A}$ reflecting their stronger cytotoxic effect. The origin of this difference could be the absence of the 5,6-epoxide group in amarouciaxanthin A. Because amarouciaxanthin A decreased PC-3 cell viability like the two other pigments, the presence of a 5,6-epoxide group does not seem to be essential for the cytotoxicity of epoxy-xanthophylls (Fig. 7) and mechanisms other than epoxide cytotoxicity should be involved in the antiproliferative activity of epoxy-xanthophylls on PC-3 cells. This conclusion is strengthened by the recent finding of Rafi et al. [277]. These authors have shown that PC-3 cell proliferation tended to decrease when they were cultured in vitro in the presence of lutein, a xanthophyll deprived of the epoxy-group, all the more so when lutein was combined with a chemotherapeutic agent. Actually, lutein modulated the expression of growth and survival-associated genes leading to an enhancement of cell cycle arrest and apoptosis induced by drugs in PC-3 cells. Unfortunately the epoxy-derivative of lutein, namely lutein-5,6-epoxide (Fig. 7), was not tested for comparison. In addition, Kotake-Nara et al. [237] have found that both fucoxanthin and neoxanthin induced apoptosis in PC-3 cells via caspase-3 activation. Fucoxanthin also inhibited the viability of two other human prostate cancer cell lines (DU145 and LNCaP) through apoptosis induction [278]. Moreover, fucoxanthin was efficient against urinary bladder cancer because of its antiproliferative activity linked to the induction of cell cycle arrest and apoptosis [279].
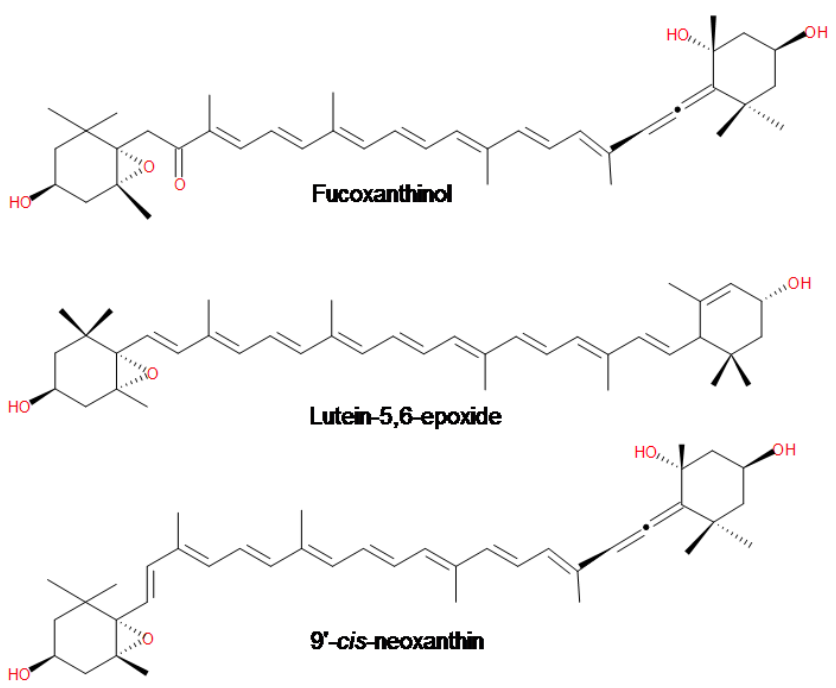
Fig. (7). Structure of some carotenoid-5,6-epoxides.

Unlike Kotake-Nara et al. [278], Yoshiko and Hoyoku [280] have discovered that fucoxanthin did not cause apoptosis in DU145 prostatic cancer cell line and HepG2 cells. However, it induced cell cycle arrest at G1 phase, induced growth arrest and DNA damage-inducible gene (gadd45a) expression in a dose- and time-dependent manner [280]. According to Satomi and Nishino [281], MAPK pathways were implicated in the aforementioned effects of fucoxanthin. Indeed, inhibition of p38 MAPK or SAPK/JNK, respectively, increased or stopped the induction of gadd45a expression and G1 arrest in HepG2 or DU145 cells. It therefore seems that the pattern of MAPK involvement in the induction of gadd45a expression and G1 arrest by fucoxanthin depends on the cell type [281]. Furthermore, several studies have highlighted that lycopene could be efficient against prostatic hyperplasia and prostate cancer [282,283] and lycopene intake was linked to lower risk of prostate cancer [284,285].

\subsubsection{Cancers of the Digestive Tract}

As with other kinds of cancer, carotenoids are particularly efficient against cancers of the digestive tract thanks to their ability to inhibit cell proliferation and even to induce apoptosis of cancer cells.

One of the cancers of the digestive tract most studied is colon cancer. $\beta$-carotene was one the first carotenoids whose positive effects against this cancer have been demonstrated. In fact, Enger et al. [286] have discovered that dietary intake level of $\beta$-carotene was inversely linked to risks of colorectal adenomas. Similarly, astaxanthin and canthaxanthin have been found to be considerable preventive agents against large bowel and tongue carcinogenesis because they control carcinogeninduced cell hyperproliferation in the two organs [287]. Similarly, inhibition of cell proliferation activity could be one of the mechanisms explaining that astaxanthin and canthaxanthin administration during the post-initiation phase of colon carcinogenesis suppressed the azoxymethaneinduced carcinogenesis of the colon [288]. Interestingly, astaxanthin and the microalga Haematococcus pluvialis have similar effects on cancer. Indeed, in HCT-116 human colon cancer cells, the microalga stimulated apoptosis and cell cycle arrest in a dose- and time-dependent manner. At the same concentration of astaxanthin, Haematococcus pluvialis extract was even more powerful to inhibit cell growth than purified astaxanthin [289], suggesting a synergic effect with other molecules contained in the microalga. According to Cha et al. [290], Chlorella ellipsoidea extract containing mainly violaxanthin has similar effects as Haematococcus pluvialis extract in HCT-116 cells: it inhibits cell growth in a dose-dependent manner and induces apoptosis. Microalgal extracts could, therefore, be interesting colon cancer protective and preventive agents as well. This idea was supported by Kawee-Ai and Kim [291] who found that fucoxanthin extracted from Phaeodactylum tricornutum impacted DLD-1 colon cancer cells through its strong $\beta$ glucuronidase inhibitory activity. Several other studies have also shown that fucoxanthin would be a good chemopreventive and/or chemotherapeutic carotenoid in other colon cancer cell lines or in mouse colon carcinogenesis [235,292].
Similarly, lutein and lycopene, as well as $\alpha$-carotene and red palm carotenes have been found to reduce the growth of colonic aberrant crypt foci, which are preneoplastic markers of colon cancer, in rats [293]. So lycopene and lutein could be, in small doses, used as preventive agents against colon carcinogenesis, at least in this experimental model [293,294]. Moreover, Erhardt et al. [295] have discovered that plasma lycopene level was lower in patients with colorectal adenoma and a concentration lower than $70 \mathrm{mg} \mathrm{L}^{-1}$ represents a risk factor for adenomatous polyps.

According to Huang et al. [296], nanoemulsion containing both lycopene and gold nanoparticles $(0.4 \mu \mathrm{M}$ and $0.16 \mathrm{ppm}$, respectively) was more efficient to enhance the number of early apoptotic cells and inhibit cell growth of colon cancer cells than the conventional combined administration of both molecules $(10 \mathrm{ppm}$ of gold nanoparticles and $12 \mu \mathrm{M}$ of lycopene). Lycopene and gold nanoparticles have therefore presented synergistic effects in the nanoemulsion at lower doses than in the conventional combined treatment, making nanoemulsion potentially applicable in colon cancer therapy. $\beta$-cryptoxanthin and oxaliplatin have also synergistic effects in colon cancer cells [297]: to achieve the same percentage of cell growth inhibition, the amount of oxaliplatin in a combined treatment with $\beta$-cryptoxanthin is lower than the amount of oxaliplatin when it is dispensed alone. Both molecules also cooperated to induce apoptosis.

For their part, Ugocsai et al. [298] have shown that lutein, $\beta$-cryptoxanthin, violaxanthin and neoxanthin induced drug (rhodamine 123) accumulation and early apoptosis in MDR1/LRP-expressing human colon cancer cells.

Carotenoids have also been found to be efficient against liver cancer. According to Murakoshi et al. [263], $\alpha$ carotene supplementation reduced the number of hepatomas in mice developing spontaneous liver cancer. Simultaneous tests have also been made with $\beta$-carotene but it was ineffective against hepatomas. In rats treated with aflatoxin B1, canthaxanthin and astaxanthin decreased effectively the number and size of liver preneoplastic foci [299]. Astaxanthin and canthaxanthin also reduced in vivo DNA single-breaks induced by the toxin as well as its binding to liver DNA and plasma albumin. Both pigments enhanced in vitro aflatoxin B1 metabolism to less genotoxic aflatoxin M1. Through the induction of detoxification pathways, these carotenoids would thus have protective effects against the initiation of liver carcinogenesis [299]. In rats injected with diethylnitrosamine, lycopene also reduced the initiation of liver preneoplastic foci by decreasing the size of the foci and the fraction of liver volume that they occupied [300]. Actually, these results may be explained through the modulating effect of lycopene on the liver enzyme activating diethylnitrosamine, i.e., cytochrome P-450 2E1 [300]. Moreover, Yang et al. [301] have discovered that the chemopreventive effects of lycopene against human HepG2 cells, via induction of phase II detoxifying/antioxidant enzymes, may be partially ascribed to its metabolite apo-8'lycopenal (j), which is one of the main metabolites found in human plasma.

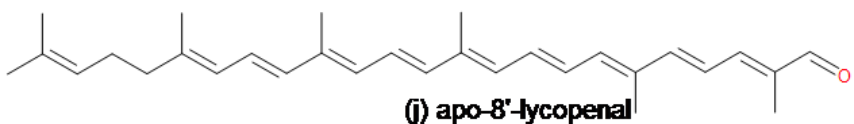


On the other hand, Song et al. [302] have found that astaxanthin induced apoptosis of hepatocellular carcinoma CBRH-7919 cells through the inhibition of JAK1/STAT3 signaling pathway and induction of changes in cell ultrastructure. Furthermore, Das et al. [239] have proved that fucoxanthin had cytostatic activity in HepG2 cells: it induced cell cycle arrest in the G0/G1 phase in relation to downregulation of cyclin D but interestingly, in HepG2 cells fucoxanthin did nott show apoptosis-inducing effect. Inversely, in SK-Hep-1 cells fucoxanthin induced apoptosis, in addition to cell cycle arrest in G0/G1 phase [303]. Actually, it up-regulated connexin 43 and connexin 32 enhancing gap junctional intercellular communication and thus intracellular calcium levels, thereby causing cell cycle arrest and apoptosis [303]. Moreover, in HepG2 cells fucoxanthin enhanced cisplatin-induced cytoxicity and down-regulated DNA repair gene expression, which led to a decrease of cell proliferation [304].

The third kind of gastrointestinal cancers on which the action of carotenoids has been particularly studied is gastric cancer. According to Lee et al. [305], astaxanthin dose-dependently reduced cell proliferation in two human gastric cancer cell lines by increasing the expression of the p27 protein, an inhibitor of the cyclin-dependent kinases, which was responsible for cell cycle arrest, therefore, explaining the antiproliferative effect of astaxanthin. For its part, fucoxanthin decreased cyclin B1 and survivin expression leading also to cell cycle arrest as well as apoptosis in human gastric adenocarcinoma cells [306]. $\beta$ carotene has also been found to be efficient against gastric cancer cells. Actually, it had an action in two stages: it activated caspase-3, increased ROS level and then it reduced the level of DNA repair protein Ku70/80 thereby inducing apoptosis [307]. According to Kim and Kim [308], lycopene is also protective against gastric carcinogenesis. Thanks to its antioxidant properties, lycopene scavenges ROS and enhances the activities of antioxidant enzymes leading to the increase of cell cycle arrest in G0/G1 phase, the prevention of the overexpression of $\mathrm{p} 53$, the suppression of extracellular signal-regulated kinases (ERK) signaling pathway as well as the reduction of oxidative damages and the protection of immune function. Through these different actions, lycopene induces apoptosis, inhibits hyperproliferation and, therefore, may prevent oxidative stress-mediated gastric carcinogenesis [308].

Helicobacter pylori is identified as the first cause of gastric cancer development [309]. Kamath et al. [143] have assessed the effects of astaxanthin fractions (such as astaxanthin esters) extracted from $H$. pluvialis on rats with gastric ulcers. Astaxanthin esters allowed the regulation of gastric mucosal injury and gastric acid secretion which provides astaxanthin in vivo preventive and antioxidative properties against gastric ulcers. Amaro et al. [310] have summarized concrete action of astaxanthin, extracted from microalgae, against gastric cancer. The pigment has three kinds of effects: (1) it is competitive with bacteria for binding on gastric mucosa, (2) it inactivates ROS and (3) induces a shift from Th1 (T helper type 1) response to a mixed Th1/Th2 response being less aggressive. Actually, according to Bennedsen et al. [311], Th1 response is exhibited by infected mice and participates in mucosal damage. This kind of immune response would thus be linked to the progression of gastric pathogenesis. Inversely, a Th2 response would be associated with control of the infection [311]. Therefore, a shift from Th1 response to a mixed Th1/Th2 response expresses a modulation of the immune response to better fight gastric disease [310].

As regards oral cavity cancer, Garewal and Schantz [312] and Garewal [313] have discovered that $\beta$-carotene could be used to inhibit carcinogenesis and induce regression of oral leukoplakia. It could potentially prevent the development of second malignancies in patients healed of a primary oral cancer as well. However, $\beta$-carotene was inefficient in the chemoprevention of oral leukoplakia, which was confirmed by Nagao et al. [314].

As explained earlier, the antioxidant properties of carotenoids can be an important factor in the fight against cancer. This is particularly the case for astaxanthin. This idea is supported by several studies. According to Kurihara et al. [315], astaxanthin improved the antitumor effector activity of natural killer cells suppressed by stress and reduced the promotion of metastasis in mice treated with restraint stress, therefore, improving antitumor immune responses, probably through the inhibition of lipid peroxidation provoked by stress. Moreover, Kozuki et al. [316] have showed a dosedependent effect of carotenoids, including astaxanthin, on the invasion of rat ascites hepatoma AH109A cells cultured with rat mesentery-derived mesothelial cells. Besides, astaxanthin and $\beta$-carotene suppressed the heightened invasive capacity of AH109A cells treated with two enzymes generating ROS [316]. The anti-invasive activity of these two pigments could therefore be related to their antioxidant action. For their part, Tripathi and Jena [317] have found that astaxanthin reduced oxidative stress, DNA damage, cell death and early hepatocarcinogenesis in liver of rats treated with cyclophosphamide, demonstrating again its strong antioxidant properties. In $\mathrm{CCl}_{4}$-treated rat liver, astaxanthin stimulated the cell antioxidant system and inhibited lipid peroxidation, therefore, protecting the liver from damages induced by $\mathrm{CCl}_{4}$ [318]. According to Ohno et al. [319], astaxanthin can prevent the development of liver tumorigenesis in obese mice by improving oxidative stress and serum adiponectin level. Prabhu et al. [320] have found another target of astaxanthin through its antioxidant properties: the colonic pre-neoplastic progression. Indeed, in rats with chemically induced colon carcinogenesis, the pigment enhanced the level of colonic enzymic and nonenzymic antioxidants and reduced the lipid peroxidation marker levels [320]. In parallel it decreased the development of aberrant crypt foci. So astaxanthin could also be beneficial against colonic pre-neoplastic progression. Furthermore, astaxanthin combined with retinoids up-regulated connexin 43 gene expression [321], leading to decreasing indices and proliferation of neoplasia [138].

\subsection{Neuropreventive Effects}

Alzheimer's disease (AD) is the most frequent progressive neurodegenerative disease. Like amyotrophic lateral sclerosis (ALS), it impacts the brain and spinal cord neurons. Neuro-inflammation as well as apoptosis are key factors in the progressive damages of the neurons in AD and ALS [322]. As for Parkinson's disease (PD), it is the second most common neurodegenerative disease affecting mainly movements of aged people [323]. The main common trait and mediator of pathogenesis between all neurodegenerative diseases is oxidative stress [324]. To illustrate this fact, 
ischemia is known to generate free radicals inducing pathological cerebral and neural impacts, leading to vascular dementia with memory deficit [195].

Through their antioxidant, anti-inflammatory and anti-apoptotic properties, carotenoids may be beneficial as neuroprotectants or adjuvants in the prevention or the treatment of neurodegenerative diseases, like $\mathrm{AD}$ and $\mathrm{PD}$, or ischemic events and the damages they induce [137,325]. Besides, carotenoids are also known to prevent LDL oxidation, which is also useful against neuron diseases or to improve cognitive functions [228,326,327]. The protective effects of astaxanthin against apoptosis were analyzed in dopaminergic SH-SY5Y cell line treated with 6hydroxydopamine (6-OHDA) and/or docosahexaenoic acid hydroperoxide [324,328]. In both cases, the neurotoxic molecules induced neuronal apoptosis, mitochondrial abnormalities and ROS generation. Thanks to its strong antioxidant properties (see Section 5.2), astaxanthin blocked the 6-OHDA-induced p38 MAPK activation and apoptosis in a dose-dependent manner. Besides, in both studies, astaxanthin pre-treatment inhibited mitochondrial dysfunctions due to ROS accumulation, which may also explain its neuroprotective effect against apoptosis in SHSY5Y cells.

In SH-SY5Y cells, astaxanthin also increased heme oxygenase-1 (HO-1) in vitro, naturally induced by prooxidative agents [329], and Hsp70 protein levels while it suppressed iNOS induction in the case of oxygen-glucose deprivation-induced oxidative stress [330]. The study also showed that astaxanthin protects rats from global cerebral ischemia [330].

Wang et al. [331] proved how astaxanthin upregulates $\mathrm{HO}-1$ in $\beta$-amyloid 25-35-treated SH-SY5Y cells: the pigment activated ERK 1-2 pathways. It also prevented the activation of the p38 MAPK kinase pathway. Therefore, it may be concluded that astaxanthin is able to protect cells from $\beta$-amyloid 25-35-induced oxidative cell death [331]. Chang et al. [332] have made a similar conclusion but this time regarding $\beta$-amyloid peptide 25-35induced apoptosis in PC-12 cells. In this case, astaxanthin exerted its protective effect via several ways including inhibition of Bax expression and suppression of p38 MAPK phosphorylation. Besides, in PC-12 cells, astaxanthin was also protective against MPP(+)-induced oxidative stress via the HO-1/NOX2 (a cytochrome subunit of NADPH oxidase) axis that is to say it increased the expression of HO-1 and reduced NOX2 expression [333]. Otherwise, Chan et al. [334] discovered that astaxanthin and canthaxanthin improved cell viability and cellular as well as mitochondrial membrane stability in nerve growth factor differentiated PC12 cells. Authors concluded that both pigments are neuroprotectants through their antioxidant and antiinflammatory properties.

Recently, Wen et al. [335] have highlighted a new feature of astaxanthin. The pigment protects HT22 cells from glutamate-induced cytotoxicity by decreasing caspase activation as well as mitochondrial dysfunction and modulating the Akt/GSK-3 $\beta$ signaling. Actually, the characteristic feature of astaxanthin treatment is that it restores p-Akt and p-GSK-3 $\beta$ (Ser9) expression, decreased by glutamate.

Furthermore, in mouse neural progenitor cells astaxanthin pre-treatment induced cell growth and inhibited $\mathrm{H}_{2} \mathrm{O}_{2}$-mediated apoptotic death in a dose-dependent manner
[336]. Actually this is possible because astaxanthin can modulate p38 and MEK signaling pathways and then inhibit caspase activation. Astaxanthin pre-treatment also helps treated cells to recover their ATP production ability [336].

Shen et al. [325] have found that, thanks to its antioxidant properties, its ability to decrease glutamate release and its anti-apoptotic capacity, astaxanthin is not only able to decrease apoptosis but also ischemic brain damage as well as neurodegeneration and cerebral infarction in rats pre-treated before a middle cerebral artery occlusion. Similar results concerning the potential neuroprotective effects of astaxanthin have been further highlighted by Lu et al. [337] with in vitro and in vivo tests. In primary culture of cortical neurons, astaxanthin pre-treatment inhibited $\mathrm{H}_{2} \mathrm{O}_{2}$ induced apoptosis and restored mitochondrial membrane potential. In parallel, in the case of focal cerebral ischemiareperfusion inducing brain damage in rats, astaxanthin was also protective because it prevented cerebral ischemic injury and thus reduced brain damage [337]. The negative impact of astaxanthin on glutamate release was also found by Lin $e t$ al. [338] in rat cerebral cortex nerve terminals where astaxanthin decreased this release in a dose-dependent manner. In fact this is explained by the suppression of presynaptic voltage-dependent $\mathrm{Ca}^{2+}$ entry and MAPK signaling cascade.

Otherwise, astaxanthin enhances the cellular proliferation capacity of neural stem cells in a dose- and time-dependent manner leading to an over-expression of several proliferation-related proteins and then to an induction of proliferation-related transcription factors as well as stemness genes expression. In parallel, astaxanthin also improves osteogenic and adipogenic differentiation potential, which is in agreement with the over-expression of osteogenesis- and adipogenesis-related genes. So in this case, astaxanthin acts on the regulatory circuitry which controls both neural stem cell proliferation and differentiation [339].

Furthermore, after compressive spinal cord injury, astaxanthin could increase neurotrophin-3 expression in rats [340] thus highlighting its role in the differentiation and regeneration of spinal cord neurons and axons. Moreover, Abadie-Guedes et al. [341] have found that astaxanthin has a dose-dependent antagonist effect on the facilitation of cortical spreading depression (CSD) propagation in chronically ethanol-treated adult rats, probably because of its antioxidant properties. Actually, CSD is an excitabilityrelated brain electrophysiological phenomenon present in several animal species. Few years later the same authors have discovered that astaxanthin pre-treatment antagonizes the impairing and acute effect of a single dose of ethanol in young and adult rats, by enhancing CSD propagation because this time ethanol treatment negatively impacts CSD [342]. Furthermore, Hussein et al. [195] have highlighted that dietary natural astaxanthin has an impact on the transient ischemia-induced impairment of Morris water maze learning performance in ICR mice because it reduces the latency of escaping onto the pool platform.

Nakashima et al. [343] found that diet supplemented with Chlorella sp., containing principally $\beta$ carotene and lutein, decreased oxidative stress and the number of activated astrocytes in mice. It also prevented cognitive ability decline. They therefore concluded that prolonged consumption of Chlorella can prevent the 
progression of cognitive impairment in age-dependent dementia model mice.

According to Krishnaraj et al. [322], P53 kinase receptor, EphA4 and histone deacetylase are promising disease targets of Alzheimer's disease (AD) and amyotrophic lateral sclerosis (ALS). Authors tried to predict $\beta$-carotene binding on these targets and found that this pigment has high binding energies indicating its antagonistic activity against the disease targets. Authors concluded that $\beta$-carotene could be a therapeutic molecule to treat both neuroinflammation and apoptosis in AD and ALS patients.

Otherwise, Min and Min [344] found an inverse relation between serum levels of lycopene as well as lutein plus zeaxanthin and the risk of AD mortality in older adults, suggesting that a high dietary intake of these carotenoids could be helpful to decrease the mortality risk of $\mathrm{AD}$. Moreover, according to Prema et al. [323], lycopene was already found to be an effective neuroprotective agent against experimental Huntington's disease and brain ischemia. They recently showed that lycopene may also constitute an interesting strategy to treat Parkinson's disease (PD) [323]. Actually, in the case of 1-methyl-4-phenyl1,2,3,6-tetrahydropyridine (MPTP)-induced experimental PD in mice, lycopene reversed neurochemical deficits, i.e., it reduced striatal dopamine and its metabolites as well as apoptosis induced by MPTP [323]. Besides, lycopene reduced oxidative stress and motor abnormalities. However, although these results are promising, Takeda et al. [345] did not find a link based on epidemiological studies between blood levels or dietary intakes of carotenoids, including lycopene, and risk of PD.

\subsection{Antidiabetic Effects}

Diabetes mellitus is a significant public health threat with multiple complications. Generally, oxidative stress levels are very high and induced by hyperglycemia due to the dysfunction of pancreatic $\beta$-cells and tissue damage in patients. $\beta$-carotene supplements were reported to be associated with lower risk of diabetes by reducing the level of free radicals impairing glucose transport and improving the baseline insulin-sensitivity [346]. Moreover, natural $\beta$ carotene has been shown to be more easily absorbed by the body than the synthetic $\beta$-carotene, because it is more soluble in bile and able to mix with chylomicrons [347]. Ma et al. [348] demonstrated that $\beta$-carotene extracts had antidiabetic effects in diabetic mice by reducing blood glucose level. In the same manner, Harari et al. [349] highlighted that $\beta$-carotene containing Dunaliella supplementation, significantly inhibited the elevation of plasma glucose, TAG and the mRNAs of several pro-inflammatory genes in adipose tissue. A diet supplemented with fucoxanthin was shown to regulate adipocytokine secretion, thus preventing hyperglycemia in type 2 diabetic mice [350,351].

Astaxanthin was shown to reduce the oxidative stress caused by hyperglycemia in pancreatic $\beta$-cells and also improve glucose and serum insulin levels [352]. It was also shown to be a good immunological agent in the recovery of lymphocyte dysfunctions associated with diabetic rats [353]. Improved insulin sensitivity and restricted weight gain was observed in spontaneously hypertensive corpulent rats and mice after feeding with astaxanthin [354-356].

Advanced glycation end-products (AGE) designate a complex and heterogeneous group of compounds resulting from glycation reaction, i.e., the nonenzymatic addition of a carbohydrate on a protein. AGE compounds are believed to act as major pathogenic process in diabetic complications such as retinopathy, cataract, neuropathy and nephropathy [357-362]. The toxic effects of AGE result from the formation of cross-links between key molecules such as DNA and proteins and interactions of AGE with their receptors and/or binding proteins, causing structural and functional alterations in plasma and extracellular matrix proteins. Many synthetic inhibitors of AGE formation were withdrawn from clinical trials due to their low efficacy, poor pharmacokinetics, and unsatisfactory safety [363,364]. Finding AGE inhibitors from natural sources is therefore a promising strategy for the prevention or treatment of diabetes. Several extracts from microalgae were shown to be potential AGE inhibitors. An ethyl acetate extract of the green alga Chlorella zofingiensis significantly suppressed the glycation cascade in vitro [365]. Sun et al. [366] identified astaxanthin, especially the diester form, as the major component responsible for the antiglycoxidative properties of Chlorella zofingiensis (for a comprehensive review on astaxanthin biosynthesis in microalgae, including Chlorella zofingiensis, see [11]). Among 20 microalgal species, a few other strains, such as the green alga Chlorella protothecoides and the diatom Nitzschia laevis exhibited similar effects with inhibition rates higher than with aminoguanidine, a commonly used glycation inhibitor. The major effective compounds of the extract were identified as lutein for Chlorella protothecoides and eicosapentaenoic acid (EPA) for Nitzschia laevis [365] (for a comprehensive review on EPA effects on health, see [367] in this Special Issue).

Several studies strongly suggest that zeaxanthin and astaxanthin have the potential to inhibit the development of diabetic retinopathy and nephropathy by reduction of the oxidative stress, growth factor expression and inflammation [366,368-372]. Additionally, astaxanthin supplementation was shown to act on antithrombin-III and protein $\mathrm{C}$ activities, potentially reducing atherogenesis and thrombosis often associated to diabetes ([373], see [137] for more details).

\subsection{Anti-obesity Effects}

Obesity is caused by an excessive accumulation of lipids in adipose tissues, generating a disturbance of cytokine secretion and an increased risk of many serious diseases such as type II diabetes, hyperlipidemia, hypertension, and cardiovascular disease [374,375]. Astaxanthin is one of the most promising natural anti-obesity agents and has been proved to be effective and safe for body weight management [376].

Ikeuchi et al. [377] found that a supplementation with astaxanthin significantly reduced the body weight and adipose tissues weight gain in mice with a high fat diet and also reduced the liver weight, liver and plasma TAG and total cholesterol. They also showed an increase in fatty acid utilization [378]. Astaxanthin has been reported in mice to ameliorate insulin resistance and insulin signaling often associated with obesity $[354,356,379]$.

Fucoxanthin has been reported to suppress the development of white adipose tissue in obese/diabetic mice (reviewed in [380]). The expression of the uncoupling protein 1 (UCP1), involved in energy expenditure, was found to be induced in white adipose tissue and suggested to be responsible for the 
anti-obesity effect of fucoxanthin [375,381,382]. These researchers also demonstrated that dietary fucoxanthin-rich lipids reduced body fat accumulation in a mouse model with diet-induced obesity conditions. Fucoxanthin-rich lipids were additionally shown to modulate blood glucose and insulin levels, possibly by suppressing MCP-1 (involved in the inflammatory response) and promoting Adrb3 (involved in lypolysis and thermogenesis) and GLUT4 (glucose transporter) expression in mice [350].

\subsection{Ocular Protective Effect}

Lutein and zeaxanthin are the most abundant carotenoids that accumulate in the lens of the eye, where they are supposed to filter the phototoxic blue light, and neutralise ROS [383]. A high dietary intake of carotenoids, specifically lutein and zeaxanthin, was shown to be associated with a reduced risk for nuclear cataracts and age-dependent macular degeneration (AMD) [384-386]. AMD is a major cause for irreversible blindness and it may affect $20 \%$ of the population above the age of 65 [383]. More recently, Karppi et al. [387] suggested that high plasma concentrations in lutein and zeaxanthin were associated with a decreased risk of age-related nuclear cataract in humans. The filtering effects of lutein and zeaxanthin were superior to those provided by lycopene and $\beta$-carotene when investigated in a membrane model using liposomes [388]. Zhao and Sweet [389] used Chlorella extracts (containing 2-4 $\mathrm{mg} \mathrm{g}^{-1}$ dry weight of lutein) and reported prevention of AMD. In comparison to controls unaffected by AMD, lower levels of lutein and zeaxanthin were found in the retina from donors suffering from AMD [390].

Visual function was also shown to be improved in patients suffering from atrophic AMD when lutein alone or lutein together with other nutrients was supplemented [391]. Astaxanthin has not been isolated from the human eye but it has a stronger antioxidant activity and UV-light protection effect than lutein and $\beta$-carotene [392]. Tso and Lam [393] demonstrated that astaxanthin is able to cross the blood-brain barrier and can be deposited in the retina of mammals. The retinal photoreceptors of rats fed with astaxanthin were less damaged by a UV-light injury and recovered faster than animals not fed with astaxanthin. After ingestion of astaxanthin (4 or $12 \mathrm{mg}$ per day) for 28 days, the uncorrected far visual acuity of humans was significantly improved and the accommodation time was significantly shortened. It was also found that astaxanthin extracted from the microalga Haematococcus pluvialis significantly improved deep vision, critical flicker fusion, eye fatigue, retinal capillary blood flow [394,395]. In addition, Izumi-Nagai et al. [396] concluded that astaxanthin treatment, together with inflammatory processes such as those described in Section 5.3., significantly suppressed the development of choroidal neovascularization capable of leading to severe vision loss and blindness. Several studies also showed the ocular antiinflammatory effect of astaxanthin and fucoxanthin through the downregulation of proinflammatory factors and inhibition of the NF- $\kappa \mathrm{B}$ pathway and nitric oxide synthase [397-399]. Cort et al. [400] highlighted the protective effect of astaxanthin in ocular hypertension by decreasing the percent of apoptotic cells on the retina in rats.

Fucoxanthin extracted from Odontella aurita has been shown to be an efficient and safe antiproliferative agent for human lens epithelial cell line since it inhibits their growth and might thus be used efficiently in cataract treatment [240].

The study of Tsai et al. [401] demonstrated that the microalga Dunaliella salina exhibited potent protective effects on UVB radiation-induced corneal oxidative damage in mice, likely due to both the increase of antioxidant enzyme activity and the inhibition of lipid peroxidation.

\subsection{Skin Protective Effect}

Several studies suggested that carotenoid uptake and in particular astaxanthin, might prevent or minimize the effects of UVA radiation such as skin sagging or wrinkling. For example, Lyons and O'Brien [402] highlighted the potential of an algal extract containing astaxanthin to prevent from UVA alterations in irradiated cells. Camera et al. [403] found in human dermal fibroblasts that astaxanthin exhibited the highest photoprotective effect compared to canthaxanthin and $\beta$-carotene. Suganuma et al. [404] showed that astaxanthin could interfere with UVA-induced matrixmetalloproteinase-1 and skin fibroblast elastase/neutral endopeptidase expression.

$\beta$-carotene was also shown to prevent photooxidative damage and protect against sunburn (erythema solare). Erythema formation induced with a solar light simulator was significantly diminished when $\beta$-carotene was applied for 12 weeks either alone or in combination with $\alpha$-tocopherol [405] and the same effects were found with a dietary intake of tomato paste particularly rich in lycopene [406].

\section{CAROTENOIDS FROM MICROALGAE AS FOOD COLORANTS}

Carotene was the first carotenoid isolated and described in 1831 by Heinrich Wilhelm Ferdinand Wackenroder during his research related to the development of an anthelminthic for use in ridding the body of parasitic worms (for review, see [407]). The first total synthesis of $\beta$-carotene was achieved in $1950[408,409]$ and synthetic $\beta$-carotene started to be commercialized by Roche in 1954 . Since then, $\beta$-apo8'-carotenal (E160e) (k), canthaxanthin (E161g), and astaxanthin (E161j) have been also chemically synthesized and are classified as colorants [410]. It has to be noted, however, that carotenoids of plant, algal, fungal and synthetic (nature-identical) origin (Table 1) can be used as colorants, but not animal carotenoids [57].

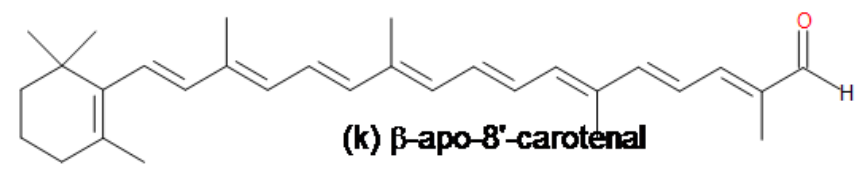

Due to their color and beneficial health effects (see Section 5) carotenoids are nowadays widely applied in oily or aqueous media as food colorants and additives (e.g., emulsions, colloidal suspensions and complexes with proteins) [8]. Most important applications include pigmenting margarine, butter, bakery products, sugar confectionery, meat, pasta and egg products, deserts and mixes, dairy and related products, fruit juices and beverages, canned soups, preserves and syrups [8]. For lipid systems (margarines and oils) powdered and oil-based carotenoid preparations are commercially available, but water- 
dispersible formulations are also present on the market [411].

Depending on the wavelength range they absorb, carotenoids in solution exhibit a range of colors between pale yellow ( $\zeta$-carotene), yellow (xanthophylls), orange $(\beta$ carotene), or red (lycopene). In addition, the observed color depends on pigment concentration. For instance, the yellow $\beta$-carotene turns orange and then red when its concentration increases [411].

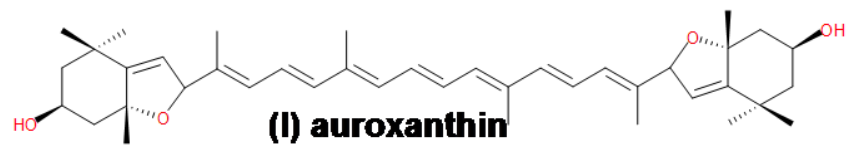

Carotenoids can be destroyed during food processing steps such as freezing (mild impact), canning and/or boiling (strong impact) $[1,8,44,58]$, which trigger color modifications. Physical and/or chemical changes may influence the composition and concentration of the carotenoids in the products. For example, yellow violaxanthin is easily transformed during processing to the faint-yellow auroxanthin (1) [412] giving a grey tint to the processed products $[1,44,413]$. $\beta$-carotene undergoes oxidation, isomerization and degradation under certain conditions including high temperature and strong light [8]. Acidification necessary for example during juice preparation also induces chemical modifications of carotenoids [413]. Carotenoid degradation can even impart the odor of food products, for instance it is important to prevent the degradation of $\beta$-carotene into the violet-smelling $\beta$-ionone in such products [413]. However, carotenoids are in general more stable than chlorophylls (with carotenes being more stable than xanthophylls).
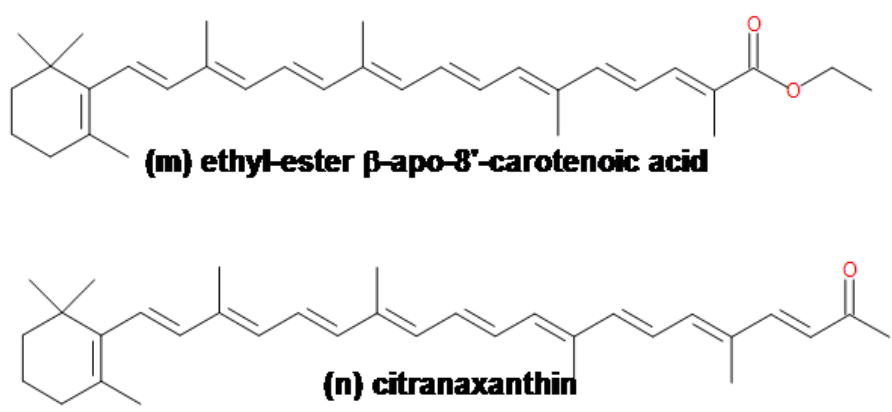

The most important carotenoids from microalgae used as food colorants are discussed below. Due to their lower importance and not general acceptance as food colorants [e.g., $\beta$-apo-8'-carotenal - E160e (k), ethyl ester of $\beta$-apo-8'carotenoic acid - E160f (m)], and in some cases their predominantly synthetic origin [e.g., canthaxanthin - E161g (Fig. 1), citranaxanthin - E161i (n)], some carotenoids are not discussed in detail below. Other pigments are only allowed as food colorants in a few countries like France (orange yellow to red colored zeaxanthin - E161h) or in Australia and New Zealand [yellow flavoxanthin - E161a (o); orange cryptoxanthin - E161c (e); red-orange rubixanthin (p) also termed natural yellow 27 - E161d; orange violaxanthin - E 161e (Fig. 5); purple rhodoxanthin E161f (q)] and are thus also not discussed in detail below.

It may be noteworthy to mention that apocarotenal (trans- $\beta$-apo-8'-carotenal) (k) used as E160e is in fact also present in the body as a $\beta$-carotene breakdown product suspected of causing cancer at high dose, and demonstrated in one study as cytotoxic, genotoxic and mutagenic agent in cell cultures [414]. Therefore, its quantity and use in some food products are limited for example in the USA.
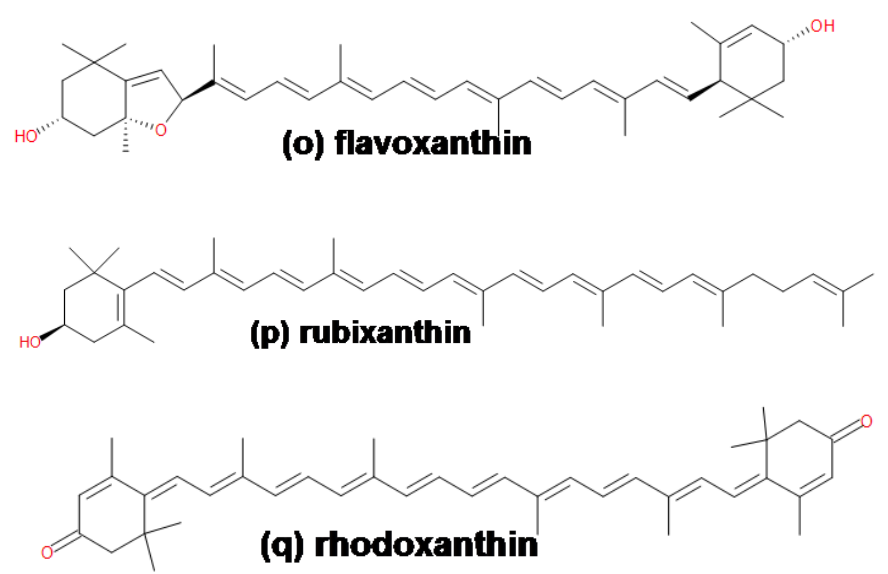

6.1. $\alpha$-, $\beta$-, and $\gamma$-Carotene (E160a, CI Food Orange 5)

Aside from their synthetic nature-identical analogues, E160a usually refers to a complex mixture of $\alpha-, \beta-$, and $\gamma$-carotenes and their isomers, containing predominantly $\beta$-carotene. Naturally, most carotenoids occur as all-trans- or different cis-isomers (9-cis, 13-cis, 15-cis isomers) (Figs. 4-5). As detailed earlier, the configuration can be important for the activity of the carotenoid. However, the type of processing, heat, and light all influence the isomerization of carotenoids in food products [415]. $\beta$-carotene accumulates to significant levels in microalgae (e.g., Dunaliella salina [22]). Therefore, the industrial production of natural carotenoid food color additives from microalgae involves mostly Dunaliella [22] available for fermentation technology and approved in the United States and by the EU legislation [416]. Under certain stress conditions Dunaliella cells may accumulate $\beta$-carotene up to $12 \%$ algal dry weight [22]. However, natural E160a can be also obtained from Blakeslea trispora (fungus) or plants (e.g., carrot in the USA, alfalfa, nettle and vegetable oil in the EU) [57]. The agent used for extraction also varies from different organic solvents (like hexane in the USA) to essential oils (Dunaliella carotenes in EU). After the removal of the organic solvents, the remaining oleoresin contains - in addition to pigments - vaxes and other lipophilic molecules present in the cells.

Unless synthetic all-trans-carotene, E160a refers to complex mixtures of $\alpha$-, $\beta$ - and $\gamma$-carotene and other carotenoids, and its pigment composition may vary depending on the source used for extraction. For example, Dunaliella carotenes consist of 94-95\% $\beta$-carotene, with other carotenes ( $\alpha$-carotene, lutein, zeaxanthin, $\beta$ cryptoxanthin) being present in minor amounts [57]. The carotene from Blakeslea trispora contains $97 \%$ of trans- $\beta$ carotenes and appr. 3\% other carotenoids. Carrot and plant species also contain a species-specific composition of the different isomers. One major advantage of the natural algal carotene is that in contrast to cheaper synthetic $\beta$-carotene produced in all-trans configuration, and carotene of Blakeslea trispora composed mostly of trans- $\beta$-carotene, algal cells produce an almost $50-50 \%$ mixture of all-trans 
and 9-cis stereoisomers (trans-isomers have to be in the range $50-71 \%$ according to legislation), which has thus probably increased biological and health effects [417].

The different stereoisomers also have slightly different spectral properties and, thus, color. Therefore, at the same total carotenoid concentration, the color of red palm oil carotene mixture is more yellowish than that of synthetic all-trans- $\beta$-carotene, which has orange color, and the carotenes of Dunaliella have in general similar color to red palm oil or a color in-between those of the two other pigment mixtures [57].

E160 is very widely used by the food industry to obtain yellowish-orange hues, with the best-known example probably representing margarine and butter.

\subsection{Astaxanthin (E161j)}

Astaxanthin (3,3-dihydroxy- $\beta, \beta$-carotene-4,4-dione) is an orange-red colored ketocarotenoid derived from canthaxanthin [85] containing both hydroxyl and ketone functional groups (Fig. 8). Its structure was first proved by chemical synthesis in 1975 [418]. In nature, astaxanthin is synthesized and accumulated to relatively large extent in some green algae (Haematococcus pluvialis, Chlorella zofingiensis and Chlorococcum sp.), some fungi (most importantly in the red yeast Xanthophyllomyces dendrorhous earlier termed Phaffia rhodozyma), and bacteria (like the marine bacterium Agrobacterium aurantiacum), but it also occurs in some red algae [11,20,25-32,99,419] (Table 1). Dietary astaxanthin is absorbed and deposited in animals such as krill, shrimp, and fish. The most striking natural examples of astaxanthin accumulation in animals (and food products) are flamingo feathers, salmon and trout flesh, and crustacean shells (e.g., lobsters in which astaxanthin is bound to proteins [420]). Astaxanthin is used mostly as a pigmentation source in animal feed in marine aquaculture, including primarily salmonids (where it is responsible for the flesh coloration of salmon and trout), red sea bream and ornamental fish (where it provides skin pigmentation), shrimps (the hypodermal chromophores and the pigmented layer of the epidermal exoskeleton of several cultured species contain astaxanthin), and to a lesser extent in poultry (for coloration of egg yolk) [421]. It also has applications in nutraceuticals (human dietary supplements) and the cosmetic industry [421]. The EU considers astaxanthin as a food dye (E161j). In the United States, the FDA has approved astaxanthin and astaxanthin dimethyldisuccinate (Fig. 8), Haematococcus algae meal, and Xanthophyllomyces dendrorhous as food colorings and additives for specific uses in animal and fish feed and recognizes natural astaxanthin as safe (GRAS - generally recognized as safe). However, as food coloring astaxanthin is restricted to use in animal food and astaxanthin shall not exceed $80 \mathrm{mg} \mathrm{kg}^{-1}$ of finished feed [410]. This pigment is quite expensive (approx. 5000-6000 USD per $\mathrm{kg}$, with natural astaxanthin estimated to reach 14000 USD per kg in 2018 [7]), and although its circa 220 million USD global market is dominated by the synthetic pigment (more than 95\%), consumer demand for natural products has raised interest in natural astaxanthin. The natural pigment is primarily extracted from Haematococcus pluvialis $[11,22]$. Under certain conditions, astaxanthin accumulates up to $4-5 \%$ cell dry weight in the green alga Haematococcus pluvialis, which is now cultivated on a large scale by several companies using different approaches $[22,99,419]$.

Alternatively, shrimp (Pandalus borealis) or krill species (Euphausia sp.) [11,22] can be used for astaxanthin extraction, however, krill fishing under extreme weather conditions in Antarctic waters is expensive, and only slowly developing, therefore, gaining astaxanthin from shrimp processing waste is more current, and microalgae clearly represent the most sustainable and environment-friendly production platform.

Natural astaxanthin is preferred in dietary supplements in different forms (e.g., soft gels, tablets, capsules, syrups, oils and creams), which are getting more and more popular due to its potent antioxidant healthpromoting effects (see Section 5). However, it has to be noted that there are only few studies available about its stability, biochemistry, bioavailability, pharmacokinetics and toxicology (safety) [99].

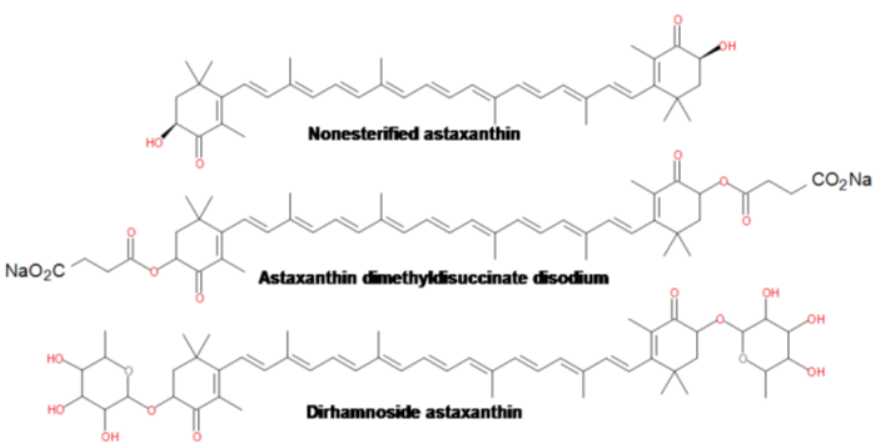

Fig. (8). New forms of astaxanthin esters obtained through genetic engineering.

\section{CONCLUSIONS AND PERSPECTIVES}

Natural colorants are two to ten times more expensive than synthetic ones and are often not very convenient or easy-tohandle stock commodities [57,422]. Microalgae constitute a very promising platform for the production of high value molecules, including natural carotenoids $[7,12,17]$. Even if suitable microalgal strains are used to produce only one type of carotenoid in economically viable concentrations e.g., astaxanthin in Haematococcus pluvialis or $\beta$-carotene in Dunaliella sp., the chemical properties of the accumulated carotenoid can be heterogenous making utilization more complicated. A good example is astaxanthin that accumulates under three different forms, i.e., as nonesterified, monoesterified and diesterified astaxanthin [85] and in different proportions according to the taxon and culture conditions [27]. In addition, the fatty acid composition is not homogeneous [423]. The changes of the polarity linked to different proportions of esterified astaxanthin lowers the use of astaxanthin esters as a coloring agent for hydrophilic media or as a drug. This represents an important limitation because astaxanthin is a molecule exhibiting a very high antioxidant activity. To circumvent these difficulties carotenoid polarity can be modified either through hemi-synthesis or through molecular engineering. For instance, disodium disuccinate astaxanthin (Cardax $\left.{ }^{\mathrm{TM}}\right)$ (Fig. 8), has been chemically prepared at multi-gram scale [424]. The new molecule, that presents a water dispersibility of $8.64 \mathrm{mg} \mathrm{mL}^{-1}$, is an effective superoxide anion scavenger in the aqueous phase [425] and efficient in plasma protein binding [426]. Administration of Cardax provided 
cardioprotection in dog hearts [427]. Alternatively, the cloning of heterologous gene(s) coding for carotenoid modifying enzymes into the genome of a microalga could be also envisioned. For instance, the bacterium Sphingomonas astaxanthinifaciens TDMA $-17^{\mathrm{T}}$ (Fig. 8) uses the glucosyltransferase CRTX [428] to add glucoside residues on the astaxanthin backbone [429]. The resulting polar astaxanthin dirhamnoside presents a very high antioxidant activity [429].

Another possibility to extend and diversify the production of carotenoids consists in the exploitation of biodiversity. Indeed, it is usually admitted that biodiversity constitutes the richest source of bioactive molecules [430]. Unfortunately, since World War II, the search for such compounds from natural sources has been gradually replaced by synthetic and combinatorial chemistry (for a review, see [431]. In the recent past, many different scale bioprospecting programs such as Tara Cruise (http://oceans.taraexpeditions.org/en/m/science/news/theoceanomics-project/)) have aimed to find new sources and/or high value molecules from nature. This shift back to bioprospecting programmes partly relies on the assumption that living organisms are a storehouse for carotenoids that are just waiting to be discovered. For instance, Deli et al. [432] have characterized the carotenoid composition of three non-toxic algal isolates namely Dunaliella salina, Euglena sanguinea and a Nostoc strain. All three species contained high amounts of carotenoids. Biotechnological interest in carotenoids has focused on their antioxidant, anticancer and anti-inflammatory activities both for human health application as well as for food/feed [433] that has strongly increased the demand for these compounds. To speed up and reduce the costs of carotenoid production, other organisms than microalgae but modified genetically with algal genes have been proposed. For instance, Chang et al. [434] have used yeast as an astaxanthin production platform. To reach this goal, they cloned $\beta$-carotenoid hydroxylases from different algae. Transformation with the genes from Haematococcus pluvialis provided the highest yield of $\beta$ carotene $\left(224 \mu \mathrm{g} \mathrm{g}^{-1}\right.$ dry weight) and canthaxanthin $(39.8 \mu \mathrm{g}$ $\mathrm{g}^{-1}$ dry weight) [434]. Recently, overexpression of cyanobacterial genes involved in carotenoid biosynthesis within a $\beta$-carotene accumulating Escherichia coli host enabled a 23.5-fold improvement in total carotenoid yield (1.99 $\mathrm{mg} \mathrm{g}^{-1}$ ), over the parental strain, with $>90 \%$ astaxanthin [435]. This opens up new possibilities for increased yields of natural astaxanthin synthesis in genetically modified organisms. The combination of carotenoid biosynthetic genes from different organisms can be also used to produce rare and/or novel carotenoids the properties of which should be tested.

Additionally, the sustainability and ecomic viability of industrial production could be improved by using the same strains to obtain different high value added products, pigments and/or molecules. This way, for instance Arthrospira sp. (commonly termed spirulina) could not be only used for the production of the dietary supplement 'spirulina' containing dried algal biomass, but the so-called inferior quality spirulina obtained during large-scale production due to different stressors may be used to prepare food coloring 'spirulina extract' containing mostly phycobiliproteins, or phycocyanin, chlorophylls and/or distinct carotenoids ( $\beta$-carotene, zeaxanthin) ([436], for reviews see $[437,438])$. All these examples and recent findings demonstrate that carotenoids from microalgae represent a rapidly expanding and developing field of high value added natural products. Important and interesting basic and applied (food and health industrial) developments are expected in this field in the near future.

\section{CONFLICT OF INTEREST}

The authors confirm that this article content has no conflict of interest.

\section{ACKNOWLEDGEMENTS}

The authors thank the University of Le Mans for financial support. HG is grateful to the Collectivité Locale 72 for her PhD fellowship. KS would like to thank the Région 'Pays de la Loire' and the University of Le Mans for a 'High Level Researcher' grant and the János Bolyai Research Scholarship of the Hungarian Academy of Sciences.

\section{ABBREVIATIONS}

6-OHDA = 6-hydroxydopamine

$\mathrm{AD}=$ Alzheimer's disease

$\mathrm{AGE}=$ advanced glycation end-produits

ALS = amyotrophic lateral sclerosis

AMD = age-macular degeneration

Bcl-xL = B-cell lymphoma-extra large

COX-2 = cyclooxygenase -2

CVD = cardiovascular diseases

HDL-C = high-density lipoprotein cholesterol

IC50 $=$ half maximal inhibitory concentration

$\operatorname{IgE}=$ immunoglobulin $\mathrm{E}$

$\mathrm{IL}=$ interleukin

INOS $=$ inducible nitric oxide

IPP = isopentenyl diphosphate

$\mathrm{LDL}=$ low-density lipoprotein

LDL-C = low-density lipoprotein cholesterol

LPS = lipopolysaccharides

MAPK = mitogen-activated protein kinases

$\mathrm{MDR}=$ multidrug resistant

$\mathrm{MI}=$ myocardial infarction

MIP-2 = macrophage inflammatory protein 2

$\mathrm{NF}-\kappa \mathrm{B}=\mathrm{NF}-$ kappa-B

NF- $\mathrm{B}$ p65 $=$ NF-kappa-B with a MM of $65 \mathrm{kD}$

$\mathrm{NO}=$ nitric oxide

NOX2 = NADPH oxidase 2

$\mathrm{PD}=$ Parkinson disease 
$\mathrm{PGE}_{2}=$ prostaglandin $\mathrm{E}_{2}$

ROS $=$ reactive oxygen species

RNS $=$ reactive nitrogen species

TNF-a = tumor necrosis factor alpha

$\mathrm{TAG}=$ triglyceride

\section{REFERENCES}

|1] Schoefs, B. Chlorophyll and carotenoid analysis in food products. Part II. A case by case. Trends Anal. Chem., 2003, 22, 335-339.

2] Schoefs, B. Determination of pigments in vegetables. J. Chromatogr. A, 2004, 1054, 217-226.

[3] Long, S.P.; Marshall-Lolon, A.; Zhu, X.-G. Meeting the global food demand of the future by engineering crop photosynthesis and field potential. Cell, 2015, 161, 56-66.

[4] Miyawaki, H.; Takahashi, J.; Tsukahara, H.; Takehara, I. Effects of astaxanthin in human blood rheology. J. Chim. Biochem. Nutr., 2008, 43, 69-74.

[5] Aoi, W.; Naito, Y.; Sakuma, K.; Kuchide, M.; Tokuda, H.; Maoka, T.; Toyokumi, S.; Oka, S.; Yasuhara, M.; Yoshikawa, T. Astaxanthin limits exercise-induced skeletal and cardiac muscle damage in mice. Antioxid. Redox Signal., 2003, 5(1), 139-144.

[6] Martin, C.; Zhang, Y.; Tonelli, C.; Petroni, K. Plants, diet, and health. Annu. Rev. Plant Biol., 2013, 64, 19-46.

[7] Leu, S.; Boussiba, S. Advances in the production of high-value products by microalgae. Ind. Biotech., 2014, 10, 169-183.

[8] Delgado-Vargas, F.; Jiménez, A.R.; Paredes-Lopez, O. Natural pigments: carotenoids, anthocyanins, and betalains - characteristics, biosynthesis, processing, and stability. Crit. Rev. Food Sci. Nutr., 2000, 40, 173-289.

[9] Alexandratos, N.; Bruinsma, J. World Agriculture Towards 2030/2050: the 2012 revision; ESA Working paper, FAO: Rome, 2012.

[10] Fernandez-Sevilla, J.M.; Acien Fernandez, F.G.; Molina Grima, E. Biotechnological production of lutein and its applications. Appl. Microbiol. Biotechnol., 2010, 86, 27-40.

[11] Lemoine, Y.; Schoefs, B. Secondary ketocarotenoid astaxanthin biosynthesis in algae: a multifunctional response to stress. Photosynth. Res., 2010, 106, 155-177.

[12] Mimouni, V.; Ulmann, L.; Pasquet, V.; Mathieu, M.; Picot, L.; Bougaran, G.; Cadoret, J.-P.; Morant-Manceau, A.; Schoefs, B. The potential of microalgae for the production of bioactive molecules of pharmaceutical interest. Curr. Pharm. Biotechnol., 2012, 13(15), 2733-2750.

[13] Heydarizadeh, P.; Poirier, I.; Loizeau, D.; Ulmann, L.; Mimouni, V.; Schoefs, B.; Bertrand, M. Plastids of marine phytoplankton produce bioactive pigments and lipids. Mar. Drugs, 2013, 11, 3425-3471.

[14] Guiry, M. How many species of algae are there? J. Phycol., 2012, 48, 1057-1063.

[15] Schoefs, B. Progress in diatom research: from taxonomy to physiology. Diatom Res., 2014, 29, 3-4.

[16] Vinayak, V.; Gordon, R.; Gautam, S.; Rai, A. Discovery of a diatom that oozes oil. Adv. Sci. Lett., 2014, 20, 1256-1267.

[17] Vinayak, V.; Manoylov, K.M.; Gateau, H.; Blanckaert, V.; Penchreac'h, G.; Hérault, J.; Marchand, J.; Gordon, R.; Schoefs, B. Diatom milking: a review and new approaches. Mar. Drugs, 2015, 13, 2629-2665.

[18] Beauger, A.; Serieyssol, K.; Schoefs, B. Recent progress in diatom's taxonomy and freshwater ecology. Cryptogamie Algol., 2015, 36, 241244.

[19] Takaichi, S. Carotenoids in algae: distributions, biosyntheses and functions. Mar. Drugs, 2011, 9(6), 1101-1118.

[20] Christaki, E.; Bonos, E.; Giannenas, I.; Florou-Paneri, P. Functional properties of carotenoids originating from algae. J. Sci. Food Agric., 2013, 93(1), 5-11.

[21] Britton, G.; Liaanen-Jensen, S.; Pfander, H. Carotenoids. Vol 5: Nutrition and Health, Birkhäuser: Basel, 2009.

[22] Del Campo, J.A.; Garcia Gonzalez, M.; Guerrero, M.G. Outdoor cultivation of microalgae for carotenoid production: current state and perspectives. Appl. Microbiol. Biotechnol., 2007, 74, 1163-1174.

[23] Ghosh, T.; Paliwal, C.; Maurya, R.; Mishra, S. In: Plant Biology and Biotechnology: Volume I: Plant Diversity, 777 Organization, Function and Improvement; Bahadur, B., Rajam, M.V., Sahijram, L., Krishnamurthy, K.V., Eds.; Springer: New Delhi, 2015; Vol. I, pp. 777-791.
[24] Solovchenko, A.E.; Khozin-Goldberg, I.; Didi-Cohen, S.; Cohen, Z; Merzlyak, M.N. Effects of light and nitrogen starvation on the content and composition of carotenoids of the green microalga Parietochloris incisa. Russ. J. Plant Physiol., 2008, 55(4), 455-462.

[25] Rodriguez-Saiz, M.; de la Fuente, J.L.; Barredo, J.L. Xanthophyllomyces dendrorhous for the industrial production of astaxanthin. Appl. Microbiol. Biotechnol., 2010, 88, 645-658.

[26] Schmidt, I.; Schewe, H.; Gassel, S.; Jin, C.; Buckingham, J.; Hümbelin, M.; Sandmann, G.; Schraber, J. Biotechnological production of astaxanthin with Phaffia rhodozyma/Xanthophyllomyces dendrorhous. Appl. Microbiol. Biotechnol., 2011, 89, 555-571.

[27] Kopecky, J.; Stys, D.; Loetz, K.; Poulz, O.; Schoefs, B. Microalgae as a source for secondary carotenoid production. A screening study. Arch. Hydrobiol. - Algol. Stud., 2000, 98, 153-167.

[28] Ranga Rao, A.; Raghunath Reddy, R.L.; Baskaran, V.; Sarada, R.; Ravishankar, G.A. Characterization of microalgal carotenoids by mass spectrometry and their bioavailability and antioxidant properties elucidated in rat model. J. Agric. Food Chem., 2010, 58(15), 85538559.

[29] Del Campo, J.A.; Rodriguez, H.; Moreno, J.; Vargas, M.A.; Rivas, J.; Guerrerro, M.G. Accumulation of astaxanthin and lutein in Chlorella zofingiensis (Chlorophyta). Appl. Microbiol. Biotechnol., 2004, 64, 848-854.

[30] Orosa, M.; Torres, E.; Fidalgo, P.; Abalde, J. Production and analysis of secondary carotenoids in green algae. J. Appl. Phycol., 2000, 12, 553-556.

[31] Zhang, D.H.; Lee, Y.K. Enhanced accumulation of secondary carotenoids in a mutant of the green alga, Chlorococcum sp. J. Appl. Phycol., 1997, 9, 459-463.

[32] Durmaz, Y.; Donato, M.; Monteiro, M.; Gouveia, L.; Nunes, M.L.; Pereira, T.G.; Gökpinar, S.; Bandarra, N.M. Effect of temperature on $\alpha$-tocopherol, fatty acid profile, and pigments of Diacronema vlkianum (Haptophyceae). Aquaculture Int., 2009, 17(4), 391-399.

[33] Veiga-Crespo, P.; Blasco, L.; dos Santos, F.R.; Poza, M.; Villa, T.G. Influence of culture conditions of Gordonia jacobaea MV-26 on canthaxanthin production. Int. Microbiol., 2005, 8, 55-58.

[34] Shahidi, F.; Brown, J.A. Carotenoid pigments in seafoods and aquaculture. Crit. Rev. Food Sci., 1998, 38, 1-67.

[35] Kim, S.; Jung, Y.-J.; Kwon, O.-N.; Cha, K.; Um, B.-H.; Chung, D.; Pan, C.-H. Potential commercial source of fucoxanthin extracted from the microalga Phaeodactylum tricornutum. Appl. Biochem. Biotechnol., 2012, 166, 1843-1855.

[36] Li, Z.; Sun, M.; Li, Q.; Li, A.; Zhang, C. Profiling of carotenoids in six microalgae (Eustigmatophyceae) and assessment of their $\beta$-carotene productions in bubble column photobioreactor. Biotechnol. Lett., 2012, 34, 2049-2053.

[37] Li, Z.; Ma, X.; Li, A.; Zhang, C. A novel potential source of $\beta$ carotene: Eustigmatos cf. polyphem (Eustigmatophyceae) and pilot $\beta$ carotene production in bubble column and flat panel photobioreactors. Bioresource Technol., 2012, 117, 257-263.

[38] Lin, J-H.; Lee, D-J.; Chang, J-S. Lutein production from biomass: marigold flowers versus microalgae. Bioresource Technol., 2015, 184, 421-428.

[39] Dineshkumar, R.; Dhanarajan, G.; Dash, S.K.; Sen, R. An advanced hybrid medium optimization strategy for the enhanced productivity of lutein in Chlorella minutissima. Algal Res., 2015, 7, 24-32.

[40] Yoshii, Y.; Takaichi, S.; Maoka, T.; Suda, S.; Sekiguchi, H.; Nakayama, T.; Inoue, I. Variation of siphonaxanthin series among the genus Nephroselmis (Prasinophyceae, Chlorophyta), including a novel primary methoxy carotenoid. J. Phycol., 2005, 41, 827-834.

[41] Ernst, H. Recent advances in industrial carotenoid synthesis. Pure Appl. Chem., 2002, 74(8), 1369-1382.

[42] Sajilata, M.G.; Singhal, R.S.; Kamat, M.Y. The carotenoid pigment zeaxanthin-a review. Compr. Rev. Food Sci. Food Saf., 2008, 7, 2949.

[43] Cuaresma, M.; Casal, C.; Forján, E.; Vílchez, C. Productivity and selective accumulation of carotenoids of the novel extremophile microalga Chlamydomonas acidophila grown with different carbon sources in batch systems. J. Ind. Microbiol. Biotechnol., 2011, 38, 167-177.

[44] Schoefs, B. Plant pigments: properties, analysis, degradation. Adv. Food Nutr. Res., 2005, 49, 41-91.

[45] Solymosi, K.; Latruffe, N.; Morant-Manceau, A.; Schoefs, B. In: Colour Additives for Foods and Beverages: Development, Safety and Applications; Scotter, M., Ed. Woodhead Publishing: Amsterdam, 2015, pp. 1-34.

[46] Kang, S.-L.; Ko, H.-C.; Shin, H.-S.; Kim, H.-M.; Hong, Y.-S.; Lee, N.H.; Kim, S. Fucoxanthin exerts different effects on 3T3-L1 cells 
according to differentiation stage and inhibits glucose uptake in mature adipocytes. Biochem. Biophys. Res. Commun., 2011, 409, 769-774.

[47] Gagez A.L; Thiery V.; Pasquet V.; Cadoret J.P.; Picot L. Epoxycarotenoids and cancer (review). Curr. Bioactive Comp., 8(2), 109-141, 2012

[48] Heo, S.-J.; Yoon, W.-S.; Kim, K.-N.; Oh, C.; Choi, Y.-U.; Yoon, K.-T.; Kang, D.-H.; Qian, Z.-J.; Chai, I.-W.; Junk, W.-K. Anti-inflammatory effect of fucoxanthin derivatives isolated from Sargassum siliquastrum in lipopolysaccharide-stimulated RAW 264.7 macrophage. Food Chem. Toxicol. 2012, 50, 3336-3342.

[49] Everts, S. Note-by-note cuisine. Chem. Engin. News, 2012, 90(46), 33.

[50] Scotter, M.J. Colour Additives for Food and Beverages: Development, Safety and Applications, Woodhead Publishing: Amsterdam, 2015.

[51] Moran, N.A.; Jarvik, T. Lateral transfer of genes from fungi underlies carotenoids production in aphids. Science, 2010, 328(5978), 624-627.

[52] Altincinek, B.; Kovacs, J.L.; Gerardo, N.M. Horizontally transferred fungal carotenoid genes in the two-spotted spider mite Tetranychus urticae. Biol. Lett., 2012, 8, 253-257.

[53] Eroglu, A.; Harrison, E.H. Carotenoid metabolism in mammals, including man: formation, occurrence, and function of apocarotenoids. J. Lipid Res., 2013, 54(7), 1719-1730.

[54] Cazzonelli, C.I. Carotenoids in nature: insights from plants and beyond. Funct. Plant Biol., 2011, 38(11), 833-847.

[55] Britton, G. Structure and properties of carotenoids in relation to function. FASEB J., 1995, 9(15), 1551-1558.

[56] Britton, G.; Liaanen-Jensen, S.; Pfander, H. Carotenoids Handbook, Birkhäuser: Basel, 2004.

[57] Mortensen, A. Carotenoids and other pigments as natural colorants. Pure Appl. Chem., 2006, 78, 1477-1491.

[58] Schoefs, B. Chlorophyll and carotenoid analysis in food products. Properties of the pigments and methods of analysis. Trends Food Sci. Technol., 2002, 13, 361-371.

[59] Nakazawa, Y.; Sashima, T.; Hosokawa, M.; Miyashita, K. Comparative evaluation of growth inhibitory effect of stereoisomers of fucoxanthin in human cancer cell lines. J. Funct. Foods, 2009, 1(1), 88-97.

[60] Schoefs, B.; Lemoine, Y.; Bertrand, M. Reversed-phase highperformance liquid chromatography separation of photosynthetic pigments and their precursors. Amer. Biotechnol. Lab, 1996, 14, 1822.

[61] Pfeil, B.; Schoefs, B.; Spetea, C. Function and evolution of channels and transporters in photosynthetic membranes. Cell. Mol. Life Sci., 2014, 71, 979-998.

[62] Miyashita, K.; Nishikawa, S.; Beppu, F.; Tsukui, T.; Abe, M.; Hosokawa, M. The allenic carotenoid fucoxanthin, a novel marine nutraceutical from brown seaweeds. J. Sci. Food Agric., 2011, 91, 1166-1174.

[63] Ruzicka, L. The isoprene rule and the biogenesis of terpenic compounds. Experientia, 1953, 9, 353-367.

[64] Rohmer, M. The discovery of a mevalonate-independent pathway for isoprenoid biosynthesis in bacteria, algae and higher plants. Nat. Prod. Rep., 1999, 16(5), 565-574.

[65] Bertrand, M. Carotenoid biosynthesis in diatoms. Photosynth. Res., 2010, 106(1-2), 89-102.

[66] Domonkos, I.; Kis, M.; Gombos, Z.; Ughy, B. Carotenoids, versatile components of oxygenic photosynthesis. Prog. Lipid Res., 2013, 52, 539-561.

[67] Eisenreich, W.; Scharz, M.; Cartayrade, A.; Arigoni, D.; Zenk, M.H.; Bacher, A. The deoxyxylulose phosphate pathway of terpenoid biosynthesis in plants and microorganisms. Chem. Biol., 1998, 5, 221233.

[68] Lichtenthaler, H.K. The 1-deoxy-D-xylulose-5-phosphate pathway of isoprenoid biosynthesis in plants. Annu. Rev. Plant Physiol. Plant Mol. Biol., 1999, 50, 47-65.

[69] Massé, G.; Belt, S.T.; Rowland, S.J.; Rohmer, M. Isoprenoid biosynthesis in the diatoms Rhizosolenia setigera (Brightwell) and Haslea ostrearia (Simonsen). Proc. Natl. Acad. Sci. USA, 2004, 101, 4413-4418.

[70] Lombard, J.; Moreira, D. Origins and early evolution of the mevalonate pathway of isoprenoid biosynthesis in the three domains of life. Mol. Biol. Evol., 2011, 28, 87-99.

[71] Wilson, R.J.M. Progress with parasite plastids. J. Mol. Biol., 2002, 319, 257-274.

[72] Voynova, N.E.; Rios, S.E.; Miziorko, H.M. Staphylococcus aureus mevalonate kinase: isolation and characterization of an enzyme of the isoprenoid biosynthetic pathway. J. Bacteriol., 2004, 186, 61-67.

[73] Steussy, C.N.; Robison, A.D.; Tetrick, A.M.; Knight, J.T.; Rodwell, V.W.; Stauffacher, C.V.; Sutherlin, A.L. A structural limitation on enzyme activity: the case of HMG-CoA synthase. Biochemistry, 2006, $45,14407-14414$

[74] Bisanz, C.; Botté, C.; Saïdani, N.; Bastien, O.; Cesbron-Delauw, M.-F.; Maréchal, E. In: Plant Cell Compartments - Selected Topics; Schoefs, B., Ed.; Research Signpost: Trivandrum, 2008; pp. 393-423.

[75] Solymosi, K. Plastid structure, diversification and interconversions. I. Algae. Curr. Chem. Biol., 2012, 6(3), 167-186.

[76] Solymosi, K.; Keresztes, Á. Plastid structure, diversification and interconversions. I. Land plants. Curr. Chem. Biol., 2012, 6(3), 187204.

[77] Lange, B.M.; Rujan, T.; Martin, W.; Croteau, R. Isoprenoid biosynthesis: the evolution of two ancient and distinct pathways across genomes. Proc. Natl. Acad. Sci. U.S.A., 2000, 97, 13172-13177.

[78] Cvejic, J.H.; Rohmer, M. CO2 as main carbon source for isoprenoid biosynthesis via the mevalonate-independent methylerythritol 4phosphate route in the marine diatoms Phaeodactylum tricornutum and Nitzschia ovalis. Phytochemistry, 2000, 53(1), 21-28.

[79] Nabeta, K.; Kawae, T.; Kikuchi, T.; Saitoh, T.; Oluyama, H. Biosynthesis of chlorophyll a from ${ }^{13} \mathrm{C}$-labelled mevalonates and glycine in liverwort. Nonequivalent labelling of phytyl side chain. Chem. Commun., 1995, 24, 2529-2530.

[80] Schwender, J.; Seemann, M.; Lichtenthaler, H.K.; Rohmer, M. Biosynthesis of isoprenoids (carotenoids, sterols, prenyl side-chains of chlorophylls and plastoquinone) via a novel pyruvate/glyceraldehyde 3-phosphate non-mevalonate pathway in the green alga Scenedesmus obliquus. Biochem. J., 1996, 316, 73-80.

[81] Disch, A.; Schwender, J.; Müller, C.; Lichtenthaler, H.K.; Röhmer, M. Distribution of the mevalonate and glyceraldehyde phosphate/pyruvate pathways for isoprenoid biosynthesis in unicellular algae and the cyanobacterium Synechocystis PCC 6714. Biochem. J., 1988, 333, 381-388

[82] Maurey, K.; Wolf, F.; Golbeck, J. 3-hydroxy-3-methylglutaryl coenzyme A reductase activity in Ochromonas malhamensis: A system to study the relationship between enzyme activity and rate of steroid biosynthesis. Plant Physiol., 1986, 82(2), 523-527.

[83] Lee, P.C.; Schmidt-Dannert, C. Metabolic engineering towards biotechnological productions of carotenoids in microorganisms. Appl. Microbiol. Biotechnol., 2002, 60, 1-11.

[84] Mojaat, M.; Pruvost, J.; Foucault, A.; Legrand, J. Effect of organic carbon sources and $\mathrm{Fe}^{2+}$ ions on growth and $\beta$-carotene accumulation by Dunaliella salina. Biochem. Eng. J., 2008, 39, 177-184.

[85] Schoefs, B.; Rmiki, N.; Rachidi, J.; Lemoine, Y. Astaxanthin synthesis in Haematococcus pluvialis requires a cytochrome $\mathrm{P} 450$-dependent hydroxylase and an active synthesis of fatty acids. FEBS Lett., 2001, 500, 125-128.

[86] Moulin, P.; Lemoine, Y.; Schoefs, B. In: Handbook of Plant and Crop Stress, 3rd Edt.; Pessarakli, M., Ed.; Taylor and Francis: New York, 2010; pp. 407-433.

[87] Ip, F.P.; Chen, F. Employment of reactive oxygen species to enhance astaxanthin formation in Chlorella zofingiensis in heterotrophic cultures. Process Biochem., 2005, 40, 3491-3496.

[88] Masmoudi, S.; Nguyen-Deroche, N.; Caruso, A.; Ayadi, H.; MorantManceau, A.; Tremblin, G.; Bertrand, M.; Schoefs, B. Metals in diatoms: from heaven to hell - a review. Cryptogamie Algol., 2013, $34,185-225$

[89] Yu, X.; Cui, H.; Cui, Y.; Wang, Y.; Li, X.; Liu, Z.; Qin, S. Gene cloning, sequence analysis, and expression profiles of a novel $\beta$-ring carotenoid hydroxylase gene from the photoheterotrophic green alga Chlorella kessleri. Mol. Biol. Rep., 2014, 41, 7103-7113.

[90] Kirilovsky, D. Dissipating energy by carotenoids. Nat. Chem. Biol., 2015, 11, 242-243.

[91] Bode, S.; Quentmeier, C.C.; Liao, P.N.; Hafi, N.; Barros, T.; Wilk, L.; Bittner, F.; Walla P.J. On the regulation of photosynthesis by excitonic interactions between carotenoids and chlorophylls. Proc. Natl. Acad. Sci. U.S.A., 2009, 106(30), 12311-12316.

[92] Holt, N.E.; Zigmantas, D.; Valkunas, L.; Li, X.-P.; Niyogi, K.K.; Fleming, G.R. Carotenoid cation formation and the regulation of photosynthetic light harvesting. Science, 2005, 307, 433-436.

[93] Ruban, A.V.; Berera, R.; Ilioaia, C.; van Stokkum, I.H.M.; Kennis, J.T.M.; Pascal, A.A.; van Amerongen, H.; Robert, B.; Horton, P.; van Grondelle, R. Identification of a mechanism of photoprotective energy dissipation in higher plants. Nature, 2007, 450, 575-578.

[94] Staleva, H.; Komenda, J.; Shukla, M.; Slouf, V.; Kana, R.; Polivka, T.; Sobotka, R. Mechanism of photoprotection in the cyanobacterial ancestor of plant antenna proteins. Nat. Chem. Biol., 2015, 11, 287292.

[95] Domozych, D.S.; Sørensen, I.; Willats, W.G.T. The distribution of cell wall polymers during antheridium development and spermatogenesis 
in the Charophycean green alga Chara corallina. Ann. Bot., 2009, 104, 1045-1056.

[96] Ferruzzi, M.G.; Failla, M.; Schwartz, S.J. Assessment of degradation and intestinal cell uptake of chlorophyll derivatives from spinach puree using an in vitro digestion and Caco-2 human cell model. $J$. Agric. Food Chem., 2001, 9, 2082-2089.

[97] van Bennekum, A.; Werder, M.; Thuahnai, S.T.; Han, C.-H.; Duong, P.; Williams, D.L.; Wettstein, P.; Schulthess, G.; Phillips, M.C. Class B scavenger receptor-mediated intestinal absorption of dietary $\beta$ carotene and cholesterol. Biochemistry, 2005, 44(11), 4517-4525.

[98] Heo, J.; Kim, S.H.; Lee, P.C. New insight into the cleavage reaction of Nostoc sp. strain PCC 7120 carotenoid cleavage dioxygenase in natural and nonnatural carotenoids. Appl. Environ. Microbiol., 2013, 79(11), 3336-3345.

[99] Ambati, R.R.; Phang, S.-M.; Ravi, S.; Aswathanarayana, R.G. Astaxanthin: sources, extraction, stability, biological activities and its commercial applications - a review. Mar. Drugs, 2014, 12, 128-152.

[100] Stahl, W.; Junghans, A.; de Boer, B.; Driomina, E.S.; Briviba, K.; Sies, H. Carotenoid mixtures protect multilamellar liposomes against oxidative damage: synergistic effects of lycopene and lutein. FEBS Lett., 1998, 427(2), 305-308.

[101] Stahl, W.; Sies, H. Bioactivity and protective effects of natural carotenoids. Biochim. Biophys. Acta, 2005, 1740(2), 101-107.

[102] Steenbock, H. White corn vs. yellow corn and a probable relationship between the fat soluble vitamins and yellow plant pigments. Science, 1919, 50, 352-353.

[103] Lakshman, M.R. Alpha and omega of carotenoid cleavage. J. Nutr., 2010, 134(2), 241S-245S

[104] Faure, H.; Fayol, V.; Galabert, C.; Grolier, P.; Le Moel, G.; Steghens, J.P.; Nabet, F. Les caroténoïdes: 1. Métabolisme et physiologie. Ann. Biol. Clin. 1999, 57, 169-183.

[105] Carrillo-Lopez, A.; Yahia, E.M.; Ramirez-Padilla, G.K. Bioconversion of carotenoids in five fruits and vegetables to vitamin A measured by retinol accumulation in rat livers. Am. J. Agric. Biol. Sci., 2010, 5(2), 215-221.

[106] Zeb, A.; Mehmood, S. Carotenoids contents from various sources and their potential health applications. Pakistan J. Nutr., 2004, 3(3), 199204.

[107] Tanumihardjo, S.A. Factors influencing the conversion of carotenoids to retinol: bioavailability to bioconversion to bioefficacy. Int. J. Vit. Nutr. Res., 2002, 72(1), 40-45.

[108] Nagao, A.; Olson, J.A. Enzymatic formation of 9-cis, 13-cis, and all trans retinals from isomers of $\beta$-carotene. FASEB J., 1994, 8, 968-973.

[109] Heyman, R.A.; Mangelsdorf, D.J.; Dyck, J.A.; Stein, R.B.; Eichele, G.; Evans, R.M.; Thaller, C. 9-cis retinoic acid is a high affinity ligand for the retinoid X receptor. Cell, 1992, 68, 397-406.

[110] Deming, D.M.; Teixeira, S.R.; Erdman, J.W. Jr. All-trans $\beta$-carotene appears to be more bioavailable than 9-cis or 13-cis $\beta$-carotene in gerbils given single oral doses of each isomer J. Nutr., 2002, 132(9), 2700-2708.

[111] National Research Council. Dietary Reference Intakes for Vitamin A, Vitamin K, Arsenic, Boron, Chromium, Copper, Iodine, Iron, Manganese, Molybdenum, Nickel, Silicon, Vanadium, and Zinc; The National Academies Press: Washington, 2001

[112] Borowitzka, M.A. Commercial production of microalgae: ponds, tanks, tubes and fermenters. J. Biotechnol., 1999, 70(1), 313-321.

[113] Spolaore, P.; Joannis-Cassan, C.; Duran, E.; Isambert, A. Commercial applications of microalgae. J. Biosci. Bioeng., 2006, 101(2), 87-96.

[114] Tang, G.; Suter, P.M. Vitamin A, nutrition, and health values of algae: Spirulina, Chlorella, and Dunaliella. J. Pharm. Nutr. Sci., 2011, 1(2), 111-118.

[115] Thinakar V.; von der Weid, D.; Edwin N. "Spirulina, a nutrition booster." 7th World Congress on Clinical Nutrition, New Delhi, India, 1999. (http://www.antennaindia.org/thinakar.html).

[116] Priyadarshani, I.; Rath, B. Commercial and industrial applications of microalgae - A review. J. Algal Biomass Utln., 2012, 3(4), 89-100.

[117] Finkel, T. Oxygen radicals and signaling. Curr. Opin. Cell Biol., 1998, 10(2), 248-253.

[118] Pashkow, F.J.; Watumull, D.G.; Campbell, C.L. Astaxanthin: a novel potential treatment for oxidative stress and inflammation in cardiovascular disease. Am. J. Cardiol., 2008, 101(10), S58-S68.

[119] Nishikawa, T.; Edelstein, D.; Du, X.L.; Yamagishi, S.I.; Matsumura, T.; Kaneda, Y.; Brownlee, M. Normalizing mitochondrial superoxide production blocks three pathways of hyperglycaemic damage. Nature, 2000, 404(6779), 787-790.

[120] Nemoto, S.; Takeda, K.; Yu, Z.X.; Ferrans, V.J.; Finkel, T. Role for mitochondrial oxidants as regulators of cellular metabolism. Mol. Cell. Biol., 2000, 20(19), 7311-7318.
[121] Papas, A.M. Determinants of antioxidant status in humans. Lipids, 1996, 31(1), S77-S82.

[122] Johnson, E.J. The role of carotenoids in human health. Nutr. Clinic. Care, 2002, 5(2), 56-65.

[123] Agarwal, S.; Rao, A.V. Tomato lycopene and its role in human health and chronic diseases. Can. Med. Assoc. J., 2000, 163(6), 739-744.

[124] Elliott, R. Mechanisms of genomic and non-genomic actions of carotenoids. Biochim. Biophys. Acta, 2005, 1740(2), 147-154.

[125] Ngo, D.H.; Wijesekara, I.; Vo, T.S.; Van Ta, Q.; Kim, S.K. Marine food-derived functional ingredients as potential antioxidants in the food industry: an overview. Food Res. Int., 2011, 44(2), 523-529.

[126] Sies, H.; Stahl, W. Vitamins E and C, beta-carotene, and other carotenoids as antioxidants. Am. J. Clin. Nutr., 1995, 62(6), 1315S$1321 \mathrm{~S}$

[127] Murthy, K.C.; Vanitha, A.; Rajesha, J.; Swamy, M.M.; Sowmya, P.R.; Ravishankar, G.A. In vivo antioxidant activity of carotenoids from Dunaliella salina - a green microalga. Life Sci., 2005, 76(12), 13811390.

[128] Levin, G.; Mokady, S. Antioxidant activity of 9-cis compared to alltrans- $\beta$-carotene in vitro. Free Radic. Biol. Med., 1994, 17(1), 77-82.

[129] Li, H.B;, Cheng, K.W.; Wong, C.C.; Fan, K.W.; Chen, F.; Jiang, Y. Evaluation of antioxidant capacity and total phenolic content of different fractions of selected microalgae. Food Chem., 102(3), 771776

[130] Dambeck, M.; Sandmann, G. Antioxidative activities of algal keto carotenoids acting as antioxidative protectants in the chloroplast. Photochem. Photobiol., 2014, 90(4), 814-819.

[131] Paiva, S.A.; Russell, R.M. $\beta$-Carotene and other carotenoids as antioxidants. J. Am. Coll. Nutr., 1999, 18(5), 426-433.

[132] Skibsted, L.H. Carotenoids in antioxidant networks. Colorants or radical scavengers. J. Agric. Food Chem., 2012, 60(10), 2409-2417.

[133] Truscott, T.G. New trends in photobiology: the photophysics and photochemistry of the carotenoids. J. Photochem. Photobiol. B:Biol., 1990, 6(4), 359-371.

[134] Young, A.J.; Lowe, G.M. Antioxidant and prooxidant properties of carotenoids. Arch. Biochem. Biophys., 2001, 385(1), 20-27.

[135] Martin, H.D.; Jäger, C.; Ruck, C.; Schmidt, M.; Walsh, R.; Paust, J. Anti-and prooxidant properties of carotenoids. J. Prakt. Chem., 1999, 341(3), 302-308.

[136] Rodrigues, E.; Mariutti, L.R.; Mercadante, A.Z. Scavenging capacity of marine carotenoids against reactive oxygen and nitrogen species in a membrane-mimicking system. Mar. Drugs, 2012, 10(8), 1784-1798.

[137] Zhang, J.; Sun, Z.; Sun, P.; Chen, T.; Chen, F. Microalgal carotenoids: beneficial effects and potential in human health. Food Funct., 2014, $5(3), 413-425$.

[138] Hussein, G.; Goto, H.; Oda, S.; Sankawa, U.; Matsumoto, K.; Watanabe, H. Antihypertensive potential and mechanism of action of astaxanthin: III. Antioxidant and histopathological effects in spontaneously hypertensive rats. Biol. Pharm. Bull., 2006, 29(4), 684688.

[139] Hussein, G.; Sankawa, U.; Goto, H.; Matsumoto, K.; Watanabe, H. Astaxanthin, a carotenoid with potential in human health and nutrition. J. Nat. Prod., 2006, 69(3), 443-449.

[140] McNulty, H.P.; Byun, J.; Lockwood, S.F.; Jacob, R.F.; Mason, R.P Differential effects of carotenoids on lipid peroxidation due to membrane interactions: X-ray diffraction analysis. Biochim. Biophys. Acta, 2007, 1768(1), 167-174.

[141] Gouveia, L.; Batista, A.P.; Sousa, I.; Raymundo, A.; Bandarra, N.M. In: Food Chemistry Research Developments; Papadopoulos, K.N., Ed.; Nova Science Publishers: New York, 2008; pp. 1-37.

[142] Augusti, P.R.; Quatrin, A.; Somacal, S.; Conterato, G.M.; Sobieski, R.; Ruviaro, A.R.; Emanuelli, T. Astaxanthin prevents changes in the activities of thioredoxin reductase and paraoxonase in hypercholesterolemic rabbits. J. Clin. Biochem. Nutr., 2012, 51(1), 42.

[143] Kamath, B.S.; Srikanta, B.M.; Dharmesh, S.M.; Sarada, R.; Ravishankar, G.A. Ulcer preventive and antioxidative properties of astaxanthin from Haematococcus pluvialis. Eur. J. Pharmacol., 2008, 590(1-3), 387-395.

[144] Nomura, T.; Kikuchi, M.; Kubodera, A.; Kawakami, Y. Proton-donative antioxidant activity of fucoxanthin with 1,1-diphenyl-2-picrylhydrazyl (DPPH). IUBMB Life, 1997, 42(2), 361370.

[145] Sachindra, N.M.; Sato, E.; Maeda, H.; Hosokawa, M.; Niwano, Y.; Kohno, M.; Miyashita, K. Radical scavenging and singlet oxygen quenching activity of marine carotenoid fucoxanthin and its metabolites. J. Agric. Food Chem., 2007, 55(21), 8516-8522.

[146] Peng, J.; Yuan, J.P.; Wu, C.F.; Wang, J.H. Fucoxanthin, a marine carotenoid present in brown seaweeds and diatoms: metabolism and 
bioactivities relevant to human health. Mar. Drugs, 2011, 9(10), 18061828.

[147] Böhm, F.; Edge, R.; Lange, L.; Truscott, T.G. Enhanced protection of human cells against ultraviolet light by antioxidant combinations involving dietary carotenoids. J. Photochem. Photobiol. B: Biol., 1998, 44(3), 211-215.

[148] Palozza, P.; Krinsky, N.I. $\beta$-Carotene and $\alpha$-tocopherol are synergistic antioxidants. Arch. Biochem. Biophys., 1992, 297(1), 184-187.

[149] Libby, P. Inflammatory mechanisms: the molecular basis of inflammation and disease. Nutr. Rev., 65(S3), 2007, S140-S146.

[150] Pan, M.H.; Lai, C.S.; Dushenkov, S.; Ho, C.T. Modulation of inflammatory genes by natural dietary bioactive compounds. J. Agric. Food Chem., 2009, 57(11), 4467-4477.

[151] Soontornchaiboon, W.; Joo, S.S.; Kim, S.M. Anti-inflammatory effects of violaxanthin isolated from microalga Chlorella ellipsoidea in RAW 264.7 macrophages. Biol. Pharm. Bull., 2012, 35(7), 11371144.

[152] Lee, S.J.; Bai, S.K.; Lee, K.S.; Namkoong, S.; Na, H.J.; Ha, K.S.; Han, J.A.; Yim, S.V.; Chang, K.; Kwon, Y.G.; Lee, S.K.; Kim, Y.M. Astaxanthin inhibits nitric oxide production and inflammatory gene

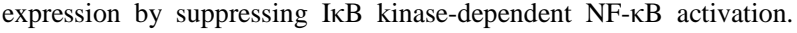
Mol. Cells, 2003, 16(1), 97-105.

[153] Salminen, A.; Lehtonen, M.; Suuronen, T.; Kaarniranta, K.; Huuskonen, J. Terpenoids: natural inhibitors of NF- $\kappa \mathrm{B}$ signaling with anti-inflammatory and anticancer potential. Cell. Mol. Life Sci., 2008, 65(19), 2979-2999.

[154] Yang, D.J.; Lin, J.T.; Chen, Y.C.; Liu, S.C.; Lu, F.J.; Chang, T.J.; Chang, Y.Y. Suppressive effect of carotenoid extract of Dunaliella salina alga on production of LPS-stimulated pro-inflammatory mediators in RAW264.7 cells via NF- $\kappa \mathrm{B}$ and JNK inactivation. $J$. Funct. Foods, 2013, 5(2), 607-615.

[155] Izumi-Nagai, K.; Nagai, N.; Ohgami, K.; Satofuka, S.; Ozawa, Y.; Tsubota, K.; Ishida, S. Macular pigment lutein is antiinflammatory in preventing choroidal neovascularization. Arterioscl. Throm. Vas., 2007, 27(12), 2555-2562.

[156] Jin, X.H.; Ohgami, K.; Shiratori, K.; Suzuki, Y.; Hirano, T.; Koyama, Y.; Ohno, S. Inhibitory effects of lutein on endotoxin-induced uveitis in Lewis rats. Investig. Ophthalmol. Visual Sci., 2006, 47(6), 25622568.

[157] Bai, S.K.; Lee, S.J.; Na, H.J.; Ha, K.S.; Han, J.A.; Lee, H.; Kim, Y.M. $\beta$-carotene inhibits inflammatory gene expression in lipopolysaccharide-stimulated macrophages by suppressing redoxbased NF- $\kappa$ B activation. Exp. Mol. Med., 2005, 37(4), 323-334.

[158] Kim, K.N.; Heo, S.J.; Yoon, W.J.; Kang, S.M.; Ahn, G.; Yi, T.H.; Jeon, Y.J. Fucoxanthin inhibits the inflammatory response by suppressing the activation of NF- $\kappa \mathrm{B}$ and MAPKs in lipopolysaccharide-induced RAW 264.7 macrophages. Eur. J. Pharmacol., 2010, 649(1), 369-375.

[159] Konishi, I.; Hosokawa, M.; Sashima, T.; Maoka, T.; Miyashita, K. Suppressive effects of alloxanthin and diatoxanthin from Halocynthia roretzi on LPS-induced expression of pro-inflammatory genes in RAW264.7 cells. J. Oleo Sci., 2008, 57(3), 181-189.

[160] Heo, S.J.; Ko, S.C.; Kang, S.M.; Kang, H.S.; Kim, J.P.; Kim, S.H.; Jeon, Y.J. Cytoprotective effect of fucoxanthin isolated from brown algae Sargassum siliquastrum against $\mathrm{H}_{2} \mathrm{O}_{2}$-induced cell damage. Eur. Food Res. Technol., 2008, 228(1), 145-151.

[161] Heo, S.J.; Yoon, W.J.; Kim, K.N.; Ahn, G.N.; Kang, S.M.; Kang, D.H.; Jeon, Y.J. Evaluation of anti-inflammatory effect of fucoxanthin isolated from brown algae in lipopolysaccharide-stimulated RAW 264.7 macrophages. Food Chem. Toxicol., 2010, 48(8), 2045-2051.

[162] Choi, S.K.; Park, Y.S.; Choi, D.K.; Chang, H.I. Effects of astaxanthin on the production of NO and the expression of COX-2 and iNOS in LPS-stimulated BV2 microglial cells. J. Microbiol. Biotechnol., 2008, 18(12), 1990-1996.

[163] Sakai, S.; Sugawara, T.; Matsubara, K.; Hirata, T. Inhibitory effect of carotenoids on the degranulation of mast cells via suppression of antigen-induced aggregation of high affinity $\operatorname{IgE}$ receptors. J. Biol. Chem., 2009, 284(41), 28172-28179.

[164] Sakai, S.; Sugawara, T.; Hirata, T. Inhibitory effect of dietary carotenoids on dinitrofluorobenzene-induced contact hypersensitivity in mice. Biosci. Biotechnol. Biochem., 2011, 75(5), 1013-1015.

[165] González, S.; Astner, S.; An, W.; Goukassian, D.; Pathak, M.A. Dietary lutein/zeaxanthin decreases ultraviolet B-induced epidermal hyperproliferation and acute inflammation in hairless mice. J. Invest. Dermatol., 2003, 121(2), 399-405.

[166] Riccioni, G.; Bucciarelli, T.; D’Orazio, N.; Palumbo, N.; Di Ilio, E.; Corradi, F.; Bazzano, L.A. Plasma antioxidants and asymptomatic carotid atherosclerotic disease. Ann. Nutr. Metab., 2008, 53(2), 86-90.
[167] Gammone, M.A.; Riccioni, G.; D'Orazio, N. Carotenoids: potential allies of cardiovascular health? Food Nutr. Res., 2015, 59, 26762.

[168] de Jesus Raposo, M.F.; de Morais, A.M.M.B. Microalgae for the prevention of cardiovascular disease and stroke. Life Sci., 2015, 125, 32-41.

[169] Iwamoto, T.; Hosoda, K.; Hirano, R.; Kurata, H.; Matsumoto, A.; Miki, W.; Kondo, K. Inhibition of low-density lipoprotein oxidation by astaxanthin. J. Atheroscler. Thromb., 2000, 7(4), 216-222.

[170] Murillo, E. Hypercholesterolemic effect of canthaxanthin and astaxanthin in rats. Arch. Latinoamer. Nutr., 1992, 42(4), 409-413.

[171] Augusti, P.R.; Conterato, G.M.; Somacal, S.; Sobieski, R.; Quatrin, A.; Maurer, L.; Rocha, M.P.; Denardin, I.T.; Emanuelli, T. Astaxanthin reduces oxidative stress, but not aortic damage in atherosclerotic rabbits. J. Cardiovasc. Pharmacol. Ther., 2009, 14(4), 314-322.

[172] Yoshida, H.; Yanai, H.; Ito, K.; Tomono, Y.; Koikeda, T.; Tsukahara, H.; Tada, N. Administration of natural astaxanthin increases serum HDL-cholesterol and adiponectin in subjects with mild hyperlipidemia. Atherosclerosis, 2010, 209(2), 520-523.

[173] Jialal, I.; Norkus, E.P.; Cristol, L.; Grundy, S.M. $\beta$-Carotene inhibits the oxidative modification of low-density lipoprotein. Biochim. Biophys. Acta, 1991, 1086(1), 134-138.

[174] Shaish, A.; Harari, A.; Hananshvili, L.; Cohen, H.; Bitzur, R.; Luvish, T.; Ulman, E.; Golan, M.; Ben-Amotz, A.; Gavish, D.; Rotstein, Z.; Harats, D. 9-cis $\beta$-carotene-rich powder of the alga Dunaliella bardawil increases plasma HDL-cholesterol in fibrate-treated patients. Atherosclerosis, 2006, 189(1), 215-221.

[175] Harari, A.; Harats, D.; Marko, D.; Cohen, H.; Barshack, I.; Kamari, Y.; Shaish, A. A 9-cis $\beta$-carotene-enriched diet inhibits atherogenesis and fatty liver formation in LDL receptor knockout mice. J. Nutr., 2008, 138(10), 1923-1930.

[176] El-Baky, A.; El Baz F.K.; El-Baroty, G.S. Production of carotenoids from marine microalgae and its evaluation as safe food colorant and lowering cholesterol agents. Am.-Euras. J. Agric. Environ. Sci., 2007, 2, 792-800.

[177] Chidambara-Murthy, K.N.; Vanitha, A.; Rajesha, J.; MahadevaSwamy, M.; Sowmya, P.R.; Ravishankar, G.A. In vivo antioxidant activity of carotenoids from Dunaliella salina - a green microalga. Life Sci., 2005, 76, 1381-1390.

[178] Nakaya, N.; Homma, Y.; Goto, Y. Cholesterol lowering effect of Spirulina. Nutr. Rep. Int., 1988, 37, 1329-1337.

[179] Ramamoorthy, A.; Premakumari, S. Effect of supplementation of Spirulina on hypercholesterolemic patients. J. Food Sci. Technol., 1996, 33(2), 124-128.

[180] Fong, B.; Cheung, M.; Lee, M. Effect of dietary Spirulina on plasma cholesterol and triglyceride levels in mice. 4th Asia-Pacific Conference on Algal Biotechnology, 2000, p. 150.

[181] Fuhrman, B.; Elis, A.; Aviram, M. Hypocholesterolemic effect of lycopene and $\beta$-carotene is related to suppression of cholesterol synthesis and augmentation of LDL receptor activity in macrophages. Biochem. Biophys. Res. Commun., 1997, 233(3), 658-662.

[182] Holvoet, P.; Collen, D. Oxidized lipoproteins in atherosclerosis and thrombosis. FASEB J., 1994, 8(15), 1279-1284.

[183] Frei, B. Cardiovascular disease and nutrient antioxidants: Role of low-density lipoprotein oxidation. Crit. Rev. Food Sci. Nutr., 1995, 35(1-2), 83-98.

[184] Kaliora, A.C.; Dedoussis, G.V.Z.; Schmidt, H. Dietary antioxidants in preventing atherogenesis. Atherosclerosis, 2006, 187(1), 1-17.

[185] Abidov, M.; Ramazanov, Z.; Seifulla, R.; Grachev, S. The effects of Xanthigen $^{\mathrm{TM}}$ in the weight management of obese premenopausal women with non-alcoholic fatty liver disease and normal liver fat. Diabetes Obes. Metab., 2010, 12(1), 72-81.

[186] D’Orazio, N.; Gammone, M.A.; Gemello, E.; De Girolamo, M.; Cusenza, S.; Riccioni, G. Marine bioactives: Pharmacological properties and potential applications against inflammatory diseases. Mar. Drugs, 2012, 10(4), 812-833.

[187] D’Orazio, N.; Gemello, E.; Gammone, M.A.; de Girolamo, M.; Ficoneri, C.; Riccioni, G. Fucoxanthin: A treasure from the sea. Mar. Drugs, 2012, 10(3), 604-616.

[188] Gammone, M.A.; Gemello, E.; Riccioni, G.; D'Orazio, N. Marine bioactives and potential application in sports. Mar. Drugs, 2014, 12(5), 2357-2382.

[189] Arnal, E.; Miranda, M.; Barcia, J.; Bosch-Morell, F.; Romero, F.J. Lutein and docosahexaenoic acid prevent cortex lipid peroxidation in streptozotocin-induced diabetic rat cerebral cortex. Neuroscience, 2010, 166(1), 271-278.

[190] Kim, J.E.; Leite, J.O.; Smyth, J.A.; Clark, R.M.; Fernandez, M.L. A lutein-enriched diet prevents cholesterol accumulation and decreases 
oxidized LDL and inflammatory cytokines in the aorta of guinea pigs. J. Nutr., 2011, 141(8), 1458-1463.

[191] Kritchevsky, S.B.; Bush, A.J.; Pahor, M.; Gross, M.D. Serum carotenoids and markers of inflammation in nonsmokers. Amer. J. Epidemiol., 2000, 152(11), 1065-1071.

[192] Aizawa, T.; Wei, H.; Miano, J.M.; Abe, J.I.; Berk, B.C.; Yan, C. Role of phosphodiesterase 3 in NO/cGMP-mediated antiinflammatory effects in vascular smooth muscle cells. Circ. Res., 2003, 93(5), 406413.

[193] Monroy-Ruiz, J.; Sevilla, M.Á.; Carrón, R.; Montero, M.J. Astaxanthin-enriched-diet reduces blood pressure and improves cardiovascular parameters in spontaneously hypertensive rats. Pharmacol. Res., 2011, 63(1), 44-50.

[194] Preuss, H.G.; Echard, B.; Yamashita, E.; Perricone, N.V. High dose astaxanthin lowers blood pressure and increases insulin sensitivity in rats: are these effects interdependent? Int. J. Med. Sci., 2011, 8(2), 126-138.

[195] Hussein, G.; Nakamura, M.; Zhao, Q.; Iguchi, T.; Goto, H.; Sankawa, U.; Watanabe, H. Antihypertensive and neuroprotective effects of astaxanthin in experimental animals. Biol. Pharmaceut. Bull., 2005, $28(1), 47-52$.

[196] Sasaki, Y.; Kobara, N.; Higashino, S.; Giddings, J.C.; Yamamoto, J. Astaxanthin inhibits thrombosis in cerebral vessels of stroke-prone spontaneously hypertensive rats. Nutr. Res., 2011, 31(10), 784-789.

[197] Hu, M.Y.; Li, Y.L.; Jiang, C.H.; Liu, Z.Q.; Qu, S.L.; Huang, Y.M. Comparison of lycopene and fluvastatin effects on atherosclerosis induced by a high-fat diet in rabbits. Nutrition, 2008, 24(10), 10301038.

[198] Martin, K.R.; Wu, D.; Meydani, M. The effect of carotenoids on the expression of cell surface adhesion molecules and binding of monocytes to human aortic endothelial cells. Atherosclerosis, 2000, $150(2), 265-274$

[199] Hozawa, A.; Jacobs Jr, D.R.; Steffes, M.W.; Gross, M.D.; Steffen, L.M.; Lee, D.H. Circulating carotenoid concentrations and incident hypertension: the Coronary Artery Risk Development in Young Adults (CARDIA) study. J. Hypertension, 2009, 27(2), 237.

[200] Cai, X.; Li, X.; Li, L.; Huang, X.Z.; Liu, Y.S.; Chen, L.; Zhang, M. Adiponectin reduces carotid atherosclerotic plaque formation in ApoE/-mice: Roles of oxidative and nitrosative stress and inducible nitric oxide synthase. Mol. Med. Rep., 2015, 11(3), 1715-1721.

[201] Kim, O.Y.; Koh, S.J.; Jang, Y.; Chae, J.S.; Kim, J.Y.; Kim, H.J.; Lee, J.H. Plasma adiponectin is related to other cardiovascular risk factors in nondiabetic Korean men with CAD, independent of adiposity and cigarette smoking: cross-sectional analysis. Clin. Chim. Acta, 2006, 370(1), 63-71.

[202] Li, W.; Hellsten, A.; Jacobsson, L.S.; Blomqvist, H.M.; Olsson, A.G.; Yuan, X.M. Alpha-tocopherol and astaxanthin decrease macrophage infiltration, apoptosis and vulnerability in atheroma of hyperlipidaemic rabbits. J. Mol. Cell. Cardiol., 2004, 37(5), 969-978.

[203] Uchiyama, A.; Okada, Y. Clinical efficacy of astaxanthin-containing Haematococcus pluvialis extract for the volunteers at risk of metabolic syndrome. J. Clin. Biochem. Nutr., 2008, 43, 38-43.

[204] Kishimoto, Y.; Tani, M.; Uto-Kondo, H.; Iizuka, M.; Saita, E.; Sone, H.; Kondo, K. Astaxanthin suppresses scavenger receptor expression and matrix metalloproteinase activity in macrophages. Eur. J. Nutr., 2010, 49(2), 119-126.

[205] Klipstein-Grobusch, K.; Launer, L.; Geleijnse, J.M.; Boeing, H.; Hofman, A.; Witteman, J.C.M. Serum carotenoids and atherosclerosis: the Rotterdam study. Atherosclerosis, 2000, 148(1), 49-56.

[206] Riccioni, G.; D'Orazio, N.; Palumbo, N.; Bucciarelli, V.; di Ilio, E.; Bazzano, L.A.; Bucciarelli, T. Relationship between plasma antioxidant concentrations and carotid intima-media thickness: the Asymptomatic Carotid Atherosclerotic Disease In Manfredonia Study. Eur. J. Cardiovasc. Prev. Rehab., 2009, 16(3), 351-357.

[207] Vílchez, C.; Forján, E.; Cuaresma, M.; Bédmar, F.; Garbayo, I.; Vega, J.M. Marine carotenoids: biological functions and commercial applications. Mar. Drugs, 2011, 9(3), 319-333.

[208] Pool-Zobel, B.L.; Bub, A.; Müller, H.; Wollowski, I.; Rechkemmer, G. Consumption of vegetables reduces genetic damage in humans: first results of a human intervention trial with carotenoid-rich foods. Carcinogenesis, 1997, 18(9), 1847-1850.

[209] Agarwal, S.; Rao, A.V. Tomato lycopene and low density lipoprotein oxidation: a human dietary intervention study. Lipids, 1998, 33(10), 981-984.

[210] Rao, A.V.; Agarwal, S. Effect of diet and smoking on serum lycopene and lipid peroxidation. Nutr. Res., 1998, 18(4), 713-721.

[211] Rissanen, T.; Voutilainen, S.; Nyyssönen, K.; Salonen, R.; Salonen, J.T. Low plasma lycopene concentration is associated with increased intima-media thickness of the carotid artery wall. Arterioscl. Throm. Vas., 2000, 20(12), 2677-2681.

[212] Dwyer, J.H.; Navab, M.; Dwyer, K.M.; Hassan, K.; Sun, P.; Shircore, A.; Fogelman, A.M. Oxygenated carotenoid lutein and progression of early atherosclerosis: the Los Angeles Atherosclerosis study. Circulation, 2001, 103(24), 2922-2927.

[213] Dwyer, J.H.; Paul-Labrador, M.J.; Fan, J.; Shircore, A.M.; Merz, C.N.B.; Dwyer, K.M. Progression of carotid intima-media thickness and plasma antioxidants: the Los Angeles Atherosclerosis Study. Arterioscl. Throm. Vas., 2004, 24(2), 313-319.

[214] Rissanen, T.; Voutilainen, S.; Nyyssönen, K.; Salonen, J.T. Lycopene, atherosclerosis, and coronary heart disease. Exp. Biol. Med., 2002 227(10), 900-907.

[215] Ascherio, A.; Rimm, E.B.; Hernán, M.A.; Giovannucci, E.; Kawachi, I.; Stampfer, M.J.; Willett, W.C. Relation of consumption of vitamin $\mathrm{E}$, vitamin $\mathrm{C}$, and carotenoids to risk for stroke among men in the United States. Ann. Intern. Med., 1999, 130(12), 963-970.

[216] Ikeda, K.; Kitamura, A.; Machida, H.; Watanabe, M.; Negishi, H.; Hiraoka, J.; Nakano, T. Effect of Undaria pinnatifida (Wakame) on the development of cerebrovascular diseases in stroke-prone spontaneously hypertensive rats. Clin. Exp. Pharmacol. Physiol., 2003, 30(1-2), 44-48.

[217] Handelman, G.J.; Packer, L.; Cross, C.E. Destruction of tocopherols, carotenoids, and retinol in human plasma by cigarette smoke. Am. $J$. Clin. Nutr., 1996, 63(4), 559-565.

[218] Street, D.A.; Comstock, G.W.; Salkeld, R.M.; Schüep, W.; Klag, M.J. Serum antioxidants and myocardial infarction. Are low levels of carotenoids and alpha-tocopherol risk factors for myocardial infarction? Circulation, 1994, 90(3), 1154-1161.

[219] Kohlmeier, L.; Kark, J.D.; Gomez-Gracia, E.; Martin, B.C.; Steck, S.E.; Kardinaal, A.F.; Kok, F.J. Lycopene and myocardial infarction risk in the EURAMIC study. Am. J. Epidemiol., 1997, 146(8), 618626.

[220] Koh, W.P.; Yuan, J.M.; Wang, R.; Lee, Y.P.; Lee, B.L.; Yu, M.C.; Ong, C.N. Plasma carotenoids and risk of acute myocardial infarction in the Singapore Chinese Health Study. Nutr. Metab. Cardiovasc. Dis., 2011, 21(9), 685-690.

[221] Kristenson, M.; Ziedén, B.; Kucinskienë, Z.; Elinder, L.S.; Bergdahl, B.; Elwing, B.; Abaravicius, A.; Razinkovienë, L.; Calkauskas, H.; Olsson, A.G. Antioxidant state and mortality from coronary heart disease in Lithuanian and Swedish men: concomitant cross sectional study of men aged 50. Br. Med. J., 1997, 314(7081), 629-633.

[222] Osganian, S.K.; Stampfer, M.J.; Rimm, E.; Spiegelman, D.; Manson, J.E.; Willett, W.C. Dietary carotenoids and risk of coronary artery disease in women. Am. J. Clin. Nutr., 2003, 77(6), 1390-1399.

[223] Sesso, H.D.; Liu, S.; Gaziano, J.M.; Buring, J.E. Dietary lycopene, tomato-based food products and cardiovascular disease in women. $J$. Nutr., 2003, 133(7), 2336-2341.

[224] Sesso, H.D.; Buring, J.E.; Norkus, E.P.; Gaziano, J.M. Plasma lycopene, other carotenoids, and retinol and the risk of cardiovascular disease in men. Am. J. Clin. Nutr., 2005, 81(5), 990-997.

[225] Voutilainen, S.; Nurmi, T.; Mursu, J.; Rissanen, T.H. Carotenoids and cardiovascular health. Am. J. Clin. Nutr., 2006, 83(6), 1265-1271.

[226] Ito, Y.; Kurata, M.; Suzuki, K.; Hamajima, N.; Hishida, H.; Aoki, K. Cardiovascular disease mortality and serum carotenoid levels: a Japanese population-based follow-up study. J. Epidemiol., 2006, 16(4), 154-160.

[227] Lidebjer, C.; Leanderson, P.; Ernerudh, J.; Jonasson, L. Low plasma levels of oxygenated carotenoids in patients with coronary artery disease. Nutr. Metab. Cardiovasc. Dis., 2007, 17(6), 448-456.

[228] Riccioni, G.; D’Orazio, N.; Franceschelli, S.; Speranza, L. Marine carotenoids and cardiovascular risk markers. Mar. Drugs, 2011, 9(7), 1166-1175.

[229] Nakao, R.; Nelson, O.L.; Park, J.S.; Mathison, B.D.; Thompson, P.A.; Chew, B.P. Effect of astaxanthin supplementation on inflammation and cardiac function in $\mathrm{BALB} / \mathrm{c}$ mice. Anticancer Res., 2010, 30(7), 2721-2725.

[230] Kritchevsky, S.B. $\beta$-carotene, carotenoids and the prevention of coronary heart disease. J. Nutr., 1999, 129(1), 5-8.

[231] Ford, E.S.; Giles, W.H. Serum vitamins, carotenoids, and angina pectoris: findings from the National Health and Nutrition Examination Survey III. Ann. Epidemiol., 2000, 10(2), 106-116.

[232] Christensen, W.G.; Gaziano, J.M.; Hennekens, C.H. Design of Physicians' Health Study II-a randomized trial of beta-carotene, vitamins $\mathrm{E}$ and $\mathrm{C}$, and multivitamins, in prevention of cancer, cardiovascular disease, and eye disease, and review of results of completed trials. Ann. Epidemiol., 2000, 10(2), 125-134. 
[233] Zinov'eva, V.N.; Spasov, A.A. Mechanisms of the anticancer effects of plant polyphenols. II. Suppression of tumor growth. BiochemistryMoscow, 2011, 5(3), 231-240.

[234] Hosokawa, M.; Wanezaki, S.; Miyauchi, K.; Kurihara, H.; Kohno, H.; Kawabata, J.; Odashima, S.; Takahashi, K. Apoptosis-inducing effect of fucoxanthin on human leukemia cell line HL-60. Food Sci. Technol. Res., 1999, 5(3), 243-246.

[235] Hosokawa, M.; Kudo, M.; Maeda, H.; Kohno, H.; Tanaka, T.; Miyashita, K. Fucoxanthin induces apoptosis and enhances the antiproliferative effect of the PPAR $\gamma$ ligand, troglitazone, on colon cancer cells. Biochim. Biophys. Acta, 2004, 1675(1), 113-119.

[236] Kotake-Nara, E.; Terasaki, M.; Nagao, A. Characterization of apoptosis induced by fucoxanthin in human promyelocytic leukemia cells. Biosci. Biotechnol. Biochem., 2005, 69(1), 224-227.

[237] Kotake-Nara, E.; Asai, A.; Nagao, A. Neoxanthin and fucoxanthin induce apoptosis in PC-3 human prostate cancer cells. Cancer Lett., 2005, $220(1), 75-84$.

[238] Das, S.K.; Hashimoto, T.; Shimizu, K.; Yoshida, T.; Sakai, T.; Sowa, Y.; Komoto, A.; Kanazawa, K. Fucoxanthin induces cell cycle arrest at G0/G1 phase in human colon carcinoma cells through up-regulation of p21WAF1/Cip1. Biochim. Biophys. Acta, 2005, 1726(3), 328-335.

[239] Das, S.K.; Hashimoto, T.; Kanazawa, K. Growth inhibition of human hepatic carcinoma HepG2 cells by fucoxanthin is associated with down-regulation of cyclin D. Biochim. Biophys. Acta, 2008, 1780(4), 743-749.

[240] Moreau, D.; Tomasoni, C.; Jacquot, C.; Kaas, R.; Le Guedes, R.; Cadoret, J.P.; Muller-Feuga, A.; Kontiza, I.; Vagias, C.; Roussis, V.; Roussakis, C. Cultivated microalgae and the carotenoid fucoxanthin from Odontella aurita as potent anti-proliferative agents in bronchopulmonary and epithelial cell lines. Environ. Toxicol. Pharmacol., 2006, 22(1), 97-103.

[241] Cui, Y.; Lu, Z.; Bai, L.; Shi, Z.; Zhao, W.E.; Zhao, B. $\beta$-carotene induces apoptosis and up-regulates peroxisome proliferator-activated receptor $\gamma$ expression and reactive oxygen species production in MCF7 cancer cells. Eur. J. Cancer, 2007, 43(17), 2590-2601.

[242] Bertram, J.S. Carotenoids and gene regulation. Nutr. Rev., 1999, 57(6), 182-191.

[243] Guerin, M.; Huntley, M.E.; Olaizola, M. Haematococcus astaxanthin: applications for human health and nutrition. Trends Biotechnol., 2003, 21(5), 210-216.

[244] Bertram, J.S.; Bortkiewicz, H. Dietary carotenoids inhibit neoplastic transformation and modulate gene expression in mouse and human cells. Am. J. Clin. Nutr., 1995, 62(6), 1327S-1336S.

[245] Stahl, W.; Nicolai, S.; Briviba, K.; Hanusch, M.; Broszeit, G.; Peters, M.; Sies, H. Biological activities of natural and synthetic carotenoids: induction of gap junctional communication and singlet oxygen quenching. Carcinogenesis, 1997, 18(1), 89-92.

[246] Daubrawa, F.; Sies, H.; Stahl, W. Astaxanthin diminishes gap junctional intercellular communication in primary human fibroblasts. J. Nutr., 2005, 135(11), 2507-2511.

[247] Hix, L.M.; Lockwood, S.F.; Bertram, J.S. Upregulation of connexin 43 protein expression and increased gap junctional communication by water soluble disodium disuccinate astaxanthin derivatives. Cancer Lett., 2004, 211(1), 25-37.

[248] Jyonouchi, H.; Sun, S.; Iijima, K.; Gross, M.D. Antitumor activity of astaxanthin and its mode of action. Nutr. Cancer, 2000, 36(1), 59-65.

[249] Okuzumi, J.; Nishino, H.; Murakoshi, M.; Iwashima, A.; Tanaka, Y.; Yamane, T.; Takahashi, T. Inhibitory effects of fucoxanthin, a natural carotenoid, on $\mathrm{N}$-myc expression and cell cycle progression in human malignant tumor cells. Cancer Lett., 1990, 55(1), 75-81.

[250] Cerveny, C.G.; Chew, B.P.; Park, J.S.; Wong, T.S. Dietary lutein inhibits tumor growth and normalizes lymphocyte subsets in tumorbearing mice. FASEB J., 1999, 13(4), A210.

[251] Chew, B.P.; Brown, C.M.; Park, J.S.; Mixter, P.F. Dietary lutein inhibits mouse mammary tumor growth by regulating angiogenesis and apoptosis. Anticancer Res., 2003, 23(4), 3333-3339.

[252] Sumantran, V.N.; Zhang, R.; Lee, D.S.; Wicha, M.S. Differential regulation of apoptosis in normal versus transformed mammary epithelium by lutein and retinoic acid. Cancer Epidem. Biomar., 2000, 9(3), 257-263.

[253] Chew, B.P.; Park, J.S. Carotenoid action on the immune response. $J$. Nutr., 2004, 134(1), 257S-261S.

[254] Chew, B.P.; Park, J.S.; Wong, M.W.; Wong, T.S. A comparison of the anticancer activities of dietary $\beta$-carotene, canthaxanthin and astaxanthin in mice in vivo. Anticancer Res., 1999, 19(3A), 18491853

[255] Gyémánt, N.; Tanaka, M.; Molnár, P.; Deli, J.; Mándoky, L.; Molnár, J. Reversal of multidrug resistance of cancer cells in vitro: modification of drug resistance by selected carotenoids. Anticancer Res., 2006, 26(1A), 367-374.

[256] Pasquet, V.; Morisset, P.; Lhammouine, S.; Chepied, A.; Aumailley, L.; Berard, J.B.; Picot, L. Antiproliferative activity of violaxanthin isolated from bioguided fractionation of Dunaliella tertiolecta extracts. Mar. Drugs, 2011, 9(5), 819-831.

[257] Hashimoto, T.; Ozaki, Y.; Taminato, M.; Das, S.K.; Mizuno, M Yoshimura, K.; Kanazawa, K. The distribution and accumulation of fucoxanthin and its metabolites after oral administration in mice. $B r . J$. Nutr., 2009, 102(02), 242-248.

[258] Rwigemera, A.; Mamelona, J.; Martin, L.J. Comparative effects between fucoxanthinol and its precursor fucoxanthin on viability and apoptosis of breast cancer cell lines MCF-7 and MDA-MB-231. Anticancer Res., 2015, 35(1), 207-219.

[259] Jewell, C.; O'Brien, N.M. Effect of dietary supplementation with carotenoids on xenobiotic metabolizing enzymes in the liver, lung, kidney and small intestine of the rat. Br. J. Nutr., 1999, 81(3), 235242.

[260] Tanumihardjo, S.A.; Yang, Z. In: Encyclopedia of Human Nutrition. 2nd ed.; Caballero, B.; Allen, L.; Prentice, A., Eds.; Elsevier Ltd: Oxford, 2005, pp. 339-345.

[261] Baudelet, P.H.; Gagez, A.L.; Bérard, J.B.; Juin, C.; Bridiau, N.; Kaas, R.; Picot, L. Antiproliferative activity of Cyanophora paradoxa pigments in melanoma, breast and lung cancer cells. Mar. Drugs, 2013, 11(11), 4390-4406.

[262] Liu, Y.Z.; Yang, C.M.; Chen, J.Y.; Liao, J.W.; Hu, M.L. $\alpha$-carotene inhibits metastasis in Lewis lung carcinoma in vitro, and suppresses lung metastasis and tumor growth in combination with taxol in tumor xenografted C57BL/6 mice. J. Nutr. Biochem., 2015, 26(6), 607-615.

[263] Murakoshi, M.; Nishino, H.; Satomi, Y.; Takayasu, J.; Hasegawa, T.; Tokuda, H.; Iwasaki, R. Potent preventive action of $\alpha$-carotene against carcinogenesis: spontaneous liver carcinogenesis and promoting stage of lung and skin carcinogenesis in mice are suppressed more effectively by $\alpha$-carotene than by $\beta$-carotene. Cancer Res., 1992, 52(23), 6583-6587.

[264] Bertram, J.S. Induction of connexin 43 by carotenoids: functional consequences. Arch. Biochem. Biophys., 2004, 430(1), 120-126.

[265] Bertram, J.S.; Vine, A.L. Cancer prevention by retinoids and carotenoids: independent action on a common target. Biochim. Biophys. Acta, 2005, 1740(2), 170-178.

[266] Mayne, S.T.; Handelman, G.J.; Beecher, G. $\beta$-carotene and lung cancer promotion in heavy smokers - a plausible relationship? J. Natl. Cancer Inst., 1996, 88(21), 1513-1515.

[267] Senesse, P.; Touvier, M.; Kesse, E.; Faivre, J.; Boutron-Ruault, M.C Tobacco use and associations of $\beta$-carotene and vitamin intakes with colorectal adenoma risk. J. Nutr., 2005, 135(10), 2468-2472.

[268] Kim, K.N.; Heo, S.J.; Kang, S.M.; Ahn, G.; Jeon, Y.J. Fucoxanthin induces apoptosis in human leukemia HL-60 cells through a ROSmediated Bcl-xL pathway. Toxicol. In Vitro, 2010, 24(6), 1648-1654.

[269] Konishi, I.; Hosokawa, M.; Sashima, T.; Kobayashi, H.; Miyashita, K. Halocynthiaxanthin and fucoxanthinol isolated from Halocynthia roretzi induce apoptosis in human leukemia, breast and colon cancer cells. Comp. Biochem. Physiol. Part C: Toxicol. Pharmacol., 2006 142(1), 53-59.

[270] Sugawara, T.; Baskaran, V.; Tsuzuki, W.; Nagao, A. Brown algae fucoxanthin is hydrolyzed to fucoxanthinol during absorption by Caco-2 human intestinal cells and mice. J. Nutr., 2002, 132(5), 946951.

[271] Ishikawa, C.; Tafuku, S.; Kadekaru, T.; Sawada, S.; Tomita, M.; Okudaira, T.; Mori, N. Antiadult T-cell leukemia effects of brown algae fucoxanthin and its deacetylated product, fucoxanthinol. Int. J. Cancer, 2008, 123(11), 2702-2712.

[272] Ganesan, P.; Noda, K.; Manabe, Y.; Ohkubo, T.; Tanaka, Y.; Maoka, T.; Hirata, T. Siphonaxanthin, a marine carotenoid from green algae, effectively induces apoptosis in human leukemia (HL-60) cells. Biochim. Biophys. Acta, 2011, 1810(5), 497-503.

[273] Yamamoto, K.; Ishikawa, C.; Katano, H.; Yasumoto, T.; Mori, N. Fucoxanthin and its deacetylated product, fucoxanthinol, induce apoptosis of primary effusion lymphomas. Cancer Lett., 2011, 300(2), 225-234.

[274] Tanaka, T.; Morishita, Y.; Suzui, M.; Kojima, T.; Okumura, A.; Mori, H. Chemoprevention of mouse urinary bladder carcinogenesis by the naturally occurring carotenoid astaxanthin. Carcinogenesis, 1994, 15(1), 15-19.

[275] Anderson, M. Method of inhibiting 5-a reductase with astaxanthin to prevent and treat benign prostate hyperplasia $(\mathrm{BPH})$ and prostate cancer in human males. U.S. patent 6,277,417, August 21, 2001 
[276] Asai, A.; Sugawara, T.; Ono, H.; Nagao, A. Biotransformation of fucoxanthinol into amarouciaxanthin A in mice and HepG2 cells: formation and cytotoxicity of fucoxanthin metabolites. Drug Metab. Dispos., 2004, 32(2), 205-211.

[277] Rafi, M.M.; Kanakasabai, S.; Gokarn, S.V.; Krueger, E.G.; Bright, J.J. Dietary lutein modulates growth and survival genes in prostate cancer cells. J. Med. Food, 2015, 18(2), 173-181.

[278] Kotake-Nara, E.; Kushiro, M.; Zhang, H.; Sugawara, T.; Miyashita, K.; Nagao, A. Carotenoids affect proliferation of human prostate cancer cells. J. Nutr., 2001, 131(12), 3303-3306.

[279] Zhang, Z.; Zhang, P.; Hamada, M.; Takahashi, S.; Xing, G.; Liu, J.; Sugiura, N. Potential chemoprevention effect of dietary fucoxanthin on urinary bladder cancer EJ-1 cell line. Oncol. Rep., 2008, 20(5), 1099-1103.

[280] Yoshiko, S.; Hoyoku, N. Fucoxanthin, a natural carotenoid, induces G1 arrest and GADD45 gene expression in human cancer cells. In Vivo, 2007, 21(2), 305-309.

[281] Satomi, Y.; Nishino, H. Implication of mitogen-activated protein kinase in the induction of G1 cell cycle arrest and gadd45 expression by the carotenoid fucoxanthin in human cancer cells. Biochim. Biophys. Acta, 2009, 1790(4), 260-266.

[282] Graydon, R.; Gilchrist, S.E.; Young, I.S.; Obermüller-Jevic, U.; Hasselwander, O.; Woodside, J.V. Effect of lycopene supplementation on insulin-like growth factor-1 and insulin-like growth factor binding protein-3: a double-blind, placebo-controlled trial. Eur. J. Clin. Nutr., 2007, 61(10), 1196-1200.

[283] Schwarz, S.; Obermüller-Jevic, U.C.; Hellmis, E.; Koch, W.; Jacobi, G.; Biesalski, H.K. Lycopene inhibits disease progression in patients with benign prostate hyperplasia. J. Nutr., 2008, 138(1), 49-53.

[284] Giovannucci, E.; Ascherio, A.; Rimm, E.B.; Stampfer, M.J.; Colditz, G.A.; Willett, W.C. Intake of carotenoids and retinol in relation to risk of prostate cancer. J. Natl. Cancer Inst., 1995, 87(23), 1767-1776.

[285] Wang, Y.; Cui, R.; Xiao, Y.; Fang, J.; Xu, Q. Effect of carotene and lycopene on the risk of prostate cancer: a systematic review and doseresponse meta-analysis of observational studies. PLOS ONE, 2015, 10(9), e0137427.

[286] Enger, S.M.; Longnecker, M.P.; Chen, M.J.; Harper, J.M.; Lee, E.R.; Frankl, H.D.; Haile, R.W. Dietary intake of specific carotenoids and vitamins $\mathrm{A}, \mathrm{C}$, and $\mathrm{E}$, and prevalence of colorectal adenomas. Cancer Epidemiol. Biomarkers Prev., 1996, 5(3), 147-153.

[287] Mori, H.; Tanaka, T.; Sugie, S.; Yoshimi, N.; Kawamori, T.; Hirose, Y.; Ohnishi, M. Chemoprevention by naturally occurring and synthetic agents in oral, liver, and large bowel carcinogenesis. J. Cell Biochem. Suppl., 1997, 27, 35-41.

[288] Tanaka, T.; Kawamori, T.; Ohnishi, M.; Makita, H.; Mori, H.; Satoh, K.; Hara, A. Suppression of azoxymethane-induced rat colon carcinogenesis by dietary administration of naturally occurring xanthophylls astaxanthin and canthaxanthin during the postinitiation phase. Carcinogenesis, 1995, 16(12), 2957-2963.

[289] Palozza, P.; Torelli, C.; Boninsegna, A.; Simone, R.; Catalano, A.; Mele, M.C.; Picci, N. Growth-inhibitory effects of the astaxanthin-rich alga Haematococcus pluvialis in human colon cancer cells. Cancer Lett., 2009, 283(1), 108-117.

[290] Cha, K.H.; Koo, S.Y.; Lee, D.U. Antiproliferative effects of carotenoids extracted from Chlorella ellipsoidea and Chlorella vulgaris on human colon cancer cells. J. Agric. Food Chem., 2008, 56(22), 10521-10526.

[291] Kawee-Ai, A.; Kim, S.M. Application of microalgal fucoxanthin for the reduction of colon cancer risk: inhibitory activity of fucoxanthin against beta-glucuronidase and DLD-1 cancer cells. Nat. Prod. Сотmun., 2014, 9(7), 921-924.

[292] Kim, J.M.; Araki, S.; Kim, D.J.; Park, C.B.; Takasuka, N.; BabaToriyama, H.; Ota, T.; Nir, Z.; Khachik, F.; Shimidzu, N.; Tanaka, Y.; Osawa, T.; Uraji, T.; Murakoshi, M.; Nishino, H.; Tsuda, H. Chemopreventive effects of carotenoids and curcumins on mouse colon carcinogenesis after 1,2-dimethylhydrazine initiation. Carcinogenesis, 1998, 19(1), 81-85.

[293] Narisawa, T.; Fukaura, Y.; Hasebe, M.; Ito, M.; Aizawa, R.; Murakoshi, M.; Uemura, S.; Khachik, F.; Nishino, H. Inhibitory effects of natural carotenoids, $\alpha$-carotene, $\beta$-carotene, lycopene and lutein, on colonic aberrant crypt foci formation in rats. Cancer Lett., 1996, 107(1), 137-142.

[294] Khare, S.; Chaudhary, K.; Bissonnette, M.; Carroll, R. Aberrant crypt foci in colon cancer epidemiology. Meth. Mol. Biol., 2009, 472, 373386.

[295] Erhardt, J.G.; Meisner, C.; Bode, J.C.; Bode, C. Lycopene, $\beta$-carotene, and colorectal adenomas. Am. J. Clin. Nutr., 2003, 78(6), 1219-1224.
[296] Huang, R.F.; Wei, Y.J.; Inbaraj, B.S.; Chen, B.H. Inhibition of colon cancer cell growth by nanoemulsion carrying gold nanoparticles and lycopene. Int. J. Nanomed., 2015, 10, 2823-2846.

[297] San Millán, C.; Soldevilla, B.; Martín, P.; Gil-Calderón, B.; Compte, M.; Pérez-Sacristán, B.; Donoso, E.; Peña, C.; Romero, J.; GranadoLorencio, F.; Bonilla, F.; Domínguez, G. $\beta$-cryptoxanthin synergistically enhances the antitumoral activity of oxaliplatin through $\triangle$ NP73 negative regulation in colon cancer. Clin. Cancer Res., 2015, 21(19), 4398-4409.

[298] Ugocsai, K.; Varga, A.; Molnár, P.; Antus, S.; Molnár, J. Effects of selected flavonoids and carotenoids on drug accumulation and apoptosis induction in multidrug-resistant colon cancer cells expressing MDR1/LRP. In Vivo, 2005, 19(2), 433-438.

[299] Gradelet, S.; Le Bon, A.M.; Bergès, R.; Suschetet, M.; Astorg, P. Dietary carotenoids inhibit aflatoxin B1-induced liver preneoplastic foci and DNA damage in the rat: role of the modulation of aflatoxin B1 metabolism. Carcinogenesis, 1998, 19(3), 403-411.

[300] Astorg, P.; Gradelet, S.; Bergès, R.; Suschetet, M. Dietary lycopene decreases the initiation of liver preneoplastic foci by diethylnitrosamine in the rat. Nutr. Cancer, 1997, 29(1), 60-68.

[301] Yang, C.M.; Huang, S.M.; Liu, C.L.; Hu M.L. Apo-8'-1ycopenal induces expression of HO-1 and NQO-1 via the ERK/p38-Nrf2-ARE pathway in human HepG2 cells. J. Agric. Food Chem., 2012, 60(6), 1576-1585.

[302] Song, X.; Wang, M.; Zhang, L.; Zhang, J.; Wang, X.; Liu, W.; Gu, X.; Lv, C. Changes in cell ultrastructure and inhibition of JAK1/STAT3 signaling pathway in CBRH-7919 cells with astaxanthin. Toxicol. Mech. Methods, 2012, 22(9), 679-686.

[303] Liu, C.L.; Huang, Y.S.; Hosokawa, M.; Miyashita, K.; Hu, M.L. Inhibition of proliferation of a hepatoma cell line by fucoxanthin in relation to cell cycle arrest and enhanced gap junctional intercellular communication. Chem. Biol. Interact., 2009a, 182(2-3), 165-172.

[304] Liu, C.L.; Lim, Y.P.; Hu, M.L. Fucoxanthin enhances cisplatininduced cytotoxicity via NFKB-mediated pathway and downregulates DNA repair gene expression in human hepatoma HepG2 cells. Mar. Drugs, 2013, 11(1), 50-66.

[305] Lee, B.J.; Park, J.-J.; Jung, S.J.; Hong, S.G.; Joo, M.K.; Kim, J.H.; Yeon, J.E.; Kim, J.S.; Chun, H.J.; Lee, H.S.; Byun, K.S.; Lee, S.W.; Bak, Y.-T. Anticancer effects of astaxanthin in stomach cancer cell lines. Gastroenterology, 2009, 136(5), A-319.

[306] Yu, R.X.; Hu, X.M.; Xu, S.Q.; Jiang, Z.J.; Yang, W. Effects of fucoxanthin on proliferation and apoptosis in human gastric adenocarcinoma MGC-803 cells via JAK/STAT signal pathway. Eur. J. Pharmacol., 2011, 657(1-3), 10-19.

[307] Park, Y.; Choi, J.; Lim, J.W.; Kim, H. $\beta$-carotene-induced apoptosis is mediated with loss of $\mathrm{Ku}$ proteins in gastric cancer AGS cells. Genes Nutr., 2015, 10(4), 467.

[308] Kim, M.J.; Kim, H. Anticancer effect of lycopene in gastric carcinogenesis. J. Cancer Prev., 2015, 20(2), 92-96.

[309] Liu, B.H.; Lee, Y.K. Effect of total secondary carotenoids extracts from Chlorococcum sp. on Helicobacter pylori-infected BALB/c mice. Int. Immunopharmacol., 2003, 3(7), 979-986.

[310] Amaro, H.M.; Barros, R.; Guedes, A.C.; Sousa-Pinto, I.; Malcata, F.X. Microalgal compounds modulate carcinogenesis in the gastrointestinal tract. Trends Biotechnol., 2013, 31(2), 92-98.

[311] Bennedsen, M.; Wang, X.; Willén, R.; Wadström, T.; Andersen, L.P. Treatment of $H$. pylori infected mice with antioxidant astaxanthin reduces gastric inflammation, bacterial load and modulates cytokine release by splenocytes. Immunol. Lett., 2000, 70(3), 185-189.

[312] Garewal, H.S.; Schantz, S. Emerging role of $\beta$-carotene and antioxidant nutrients in prevention of oral cancer. Arch. Otolaryngol. Head. Neck. Surg., 1995, 121(2), 141-144.

[313] Garewal, H. Antioxidants in oral cancer prevention. Am. J. Clin. Nutr., 1995, 62(6 Suppl), 1410S-1416S.

[314] Nagao, T.; Warnakulasuriya, S.; Nakamura, T.; Kato, S.; Yamamoto, K.; Fukano, H.; Suzuki, K.; Shimozato, K.; Hashimoto, S. Treatment of oral leukoplakia with a low-dose of beta-carotene and vitamin C supplements: a randomized controlled trial. Int. J. Cancer, 2015, 136(7), 1708-1717.

[315] Kurihara, H.; Koda, H.; Asami, S.; Kiso, Y.; Tanaka, T. Contribution of the antioxidative property of astaxanthin to its protective effect on the promotion of cancer metastasis in mice treated with restraint stress. Life Sci., 2002, 70(21), 2509-2520.

[316] Kozuki, Y.; Miura, Y.; Yagasaki, K. Inhibitory effects of carotenoids on the invasion of rat ascites hepatoma cells in culture. Cancer Lett., 2000, 151(1), 111-115.

[317] Tripathi, D.N.; Jena, G.B. Astaxanthin intervention ameliorates cyclophosphamide-induced oxidative stress, DNA damage and early 
hepatocarcinogenesis in rat: role of Nrf2, p53, p38 and phase-II enzymes. Mutat. Res., 2010, 696(1), 69-80.

[318] Kang, J.O.; Kim, S.J.; Kim, H. Effect of astaxanthin on the hepatotoxicity, lipid peroxidation and antioxidative enzymes in the liver of $\mathrm{CCl}_{4}$-treated rats. Methods Find. Exp. Clin. Pharmacol., 2001, 23(2), 79-84.

[319] Ohno, T.; Shimizu, M.; Shirakami, Y.; Miyazaki, T.; Ideta, T.; Kochi, T.; Kubota, M.; Sakai, H.; Tanaka, T.; Moriwaki, H. Preventive effects of astaxanthin on diethylnitrosamine-induced liver tumorigenesis in C57/BL/KsJ-db/db obese mice. Hepatol. Res., 2016, 46(3), E201E209.

[320] Prabhu, P.N.; Ashokkumar, P.; Sudhandiran, G. Antioxidative and antiproliferative effects of astaxanthin during the initiation stages of 1,2-dimethyl hydrazine-induced experimental colon carcinogenesis. Fundam. Clin. Pharm., 2009, 23(2), 225-234.

[321] Vine, A.L.; Bertram, J.S. Upregulation of connexin 43 by retinoids but not by non-provitamin A carotenoids requires RARs. Nutr. Cancer, 2005, 52(1), 105-113.

[322] Krishnaraj, R.N.; Kumari, S.S.; Mukhopadhyay, S.S. Antagonistic molecular interactions of photosynthetic pigments with molecular disease targets: a new approach to treat AD and ALS. J. Recept. Signal Transduct., 2016, 36(1), 67-71.

[323] Prema, A.; Janakiraman, U.; Manivasagam, T.; Arokiasamy, J.T. Neuroprotective effect of lycopene against MPTP induced experimental Parkinson's disease in mice. Neurosci. Lett., 2015, 599, $12-19$.

[324] Ikeda, Y.; Tsuji, S.; Satoh, A.; Ishikura, M.; Shirasawa, T.; Shimizu, T. Protective effects of astaxanthin on 6-hydroxydopamine-induced apoptosis in human neuroblastoma SH-SY5Y cells. J. Neurochem., 2008, 107(6), 1730-1740.

[325] Shen, H.; Kuo, C.C.; Chou, J.; Delvolve, A.; Jackson, S.N.; Post, J.; Harvey, B.K. Astaxanthin reduces ischemic brain injury in adult rats. FASEB J., 2009, 23(6), 1958-1968.

[326] Dufossé, L.; Galaup, P.; Yaron, A.; Arad, S.M.; Blanc, P.; Murthy, K.N.C.; Ravishankar, G.A. Microorganisms and microalgae as sources of pigments for food use: a scientific oddity or an industrial reality? Trends Food Sci. Technol., 2005, 16(9), 389-406.

[327] Kidd, P. Astaxanthin, cell membrane nutrient with diverse clinical benefits and anti-aging potential. Altern. Med. Rev., 2011, 16(4), 355364.

[328] Liu, X.; Shibata, T.; Hisaka, S.; Osawa, T. Astaxanthin inhibits reactive oxygen species-mediated cellular toxicity in dopaminergic SH-SY5Y cells via mitochondria-targeted protective mechanism. Brain Res., 2009, 1254, 18-27.

[329] Choi, A.M.; Alam, J. Heme oxygenase-1: function, regulation, and implication of a novel stress-inducible protein in oxidant-induced lung injury. Am. J. Respir. Cell Mol. Biol., 1996, 15(1), 9-19.

[330] Lee, D.H.; Lee, Y.J.; Kwon, K.H. Neuroprotective effects of astaxanthin in oxygen-glucose deprivation in SH-SY5Y cells and global cerebral ischemia in rat. J. Clin. Biochem. Nutr., 2010, 47(2), 121-129.

[331] Wang, H.Q.; Sun, X.B.; Xu, Y.X.; Zhao, H.; Zhu, Q.Y.; Zhu, C.Q. Astaxanthin upregulates heme oxygenase-1 expression through ERK1/2 pathway and its protective effect against beta-amyloidinduced cytotoxicity in SH-SY5Y cells. Brain Res., 2010, 1360, 159167

[332] Chang, C.H.; Chen, C.Y.; Chiou, J.Y.; Peng, R.Y.; Peng, C.H. Astaxanthin secured apoptotic death of PC12 cells induced by $\beta$ amyloid peptide 25-35: Its molecular action targets. J. Med. Food, 2010, 13(3), 548-556

[333] Ye, Q.; Huang, B.; Zhang, X.; Zhu, Y.; Chen, X. Astaxanthin protects against $\mathrm{MPP}^{+}$-induced oxidative stress in $\mathrm{PC} 12$ cells via the $\mathrm{HO}$ 1/NOX2 axis. BMC Neurosci., 2012, 13(1), 156.

[334] Chan, K.C.; Mong, M.C.; Yin, M.C. Antioxidative and anti-inflammatory neuroprotective effects of astaxanthin and canthaxanthin in nerve growth factor differentiated PC12 cells. $J$. Food Sci., 2009, 74(7), H225-H231.

[335] Wen, X.; Huang, A.; Hu, J.; Zhong, Z.; Liu, Y.; Li, Z.; Liu, Z. Neuroprotective effect of astaxanthin against glutamate-induced cytotoxicity in HT22 cells: Involvement of the Akt/GSK-3 $\beta$ pathway. Neuroscience, 2015, 303, 558-568.

[336] Kim, J.H.; Choi, W.; Lee, J.H.; Jeon, S.J.; Choi, Y.H.; Kim, B.W.; Nam, S.W. Astaxanthin inhibits $\mathrm{H}_{2} \mathrm{O}_{2}$-mediated apoptotic cell death in mouse neural progenitor cells via modulation of P38 and MEK signaling pathways. J. Microbiol. Biotechnol., 2009a, 19(11), 13551363.

[337] Lu, Y.P.; Liu, S.Y.; Sun, H.; Wu, X.M.; Li, J.J.; Zhu, L. Neuroprotective effect of astaxanthin on $\mathrm{H}_{2} \mathrm{O}_{2}$-induced neurotoxicity in vitro and on focal cerebral ischemia in vivo. Brain Res., 2010, 1360, 40-48.

[338] Lin, T.Y.; Lu, C.W.; Wang, S.J. Astaxanthin inhibits glutamate release in rat cerebral cortex nerve terminals via suppression of voltage-dependent $\mathrm{Ca}^{2+}$ entry and mitogen-activated protein kinase signaling pathway. J. Agric. Food Chem., 2010, 58(14), 8271-8278.

[339] Kim, J.H.; Nam, S.W.; Kim, B.W.; Kim, W.J.; Choi, Y.H. Astaxanthin improves the proliferative capacity as well as the osteogenic and adipogenic differentiation potential in neural stem cells. Food Chem. Toxicol., 2010, 48(6), 1741-1745.

[340] Bai, W.; Wang, X.; Wang, Z.; Wang, H.; Chen, J. The effect of astaxanthin (AST) on neurotrophin-3 (NT-3) expression in rats after compressive spinal cord injury (SCI). Afr. J. Pharm. Pharmacol., 2012, 6(34), 2559-2564.

[341] Abadie-Guedes, R.; Santos, S.D.; Cahú, T.B.; Guedes, R.C.; De Souza Bezerra, R. Dose-dependent effects of astaxanthin on cortical spreading depression in chronically ethanol-treated adult rats. Alcohol. Clin. Exp. Res., 2008, 32(8), 1417-1421.

[342] Abadie-Guedes, R.; Guedes, R.C.; Bezerra, R.S. The impairing effect of acute ethanol on spreading depression is antagonized by astaxanthin in rats of 2 young-adult ages. Alcohol. Clin. Exp. Res., 2012, 36(9), $1563-1567$.

[343] Nakashima, Y.; Ohsawa, I.; Konishi, F.; Hasegawa, T.; Kumamoto, S.; Suzuki, Y.; Ohta, S. Preventive effects of Chlorella on cognitive decline in age-dependent dementia model mice. Neurosci. Lett., 2009, 464(3), 193-198.

[344] Min, J.Y.; Min, K.B. Serum lycopene, lutein and zeaxanthin, and the risk of Alzheimer's disease mortality in older adults. Dement. Geriatr. Cogn. Disord., 2014, 37, 246-256.

[345] Takeda, A.; Nyssen, O.P.; Syed, A.; Jansen, E.; Bueno-de-Mesquita, B.; Gallo, V. Vitamin A and carotenoids and the risk of Parkinson's disease: a systematic review and meta-analysis. Neuroepidemiology, 2014, 42(1), 25-38.

[346] Paolisso, G.; Giugliano, D. Oxidative stress and insulin action: is there a relationship? Diabetologia, 1996, 39(3), 357-363.

[347] Tyssandier, V.; Reboul, E.; Dumas, J.F.; Bouteloup-Demange, C.; Armand, M.; Marcand, J.; Borel, P. Processing of vegetable-borne carotenoids in the human stomach and duodenum. Am. J. Physiol. Gastroint. Liver Physiol., 2003, 284(6), G913-G923.

[348] Ma, Q.Y.; Fang, M.; Zheng, J.H.; Ren, D.F.; Lu, J. Optimised extraction of $\beta$-carotene from Spirulina platensis and hypoglycaemic effect in streptozotocin-induced diabetic mice. J. Sci. Food Agric., 2016, 96(5), 1783-1789.

[349] Harari, A.; Harats, D.; Marko, D.; Cohen, H.; Barshack, I.; Gonen, A.; Shaish, A. Supplementation with 9-cis- $\beta$-carotene-rich alga Dunaliella improves hyperglycemia and adipose tissue inflammation in diabetic mice. J. Appl. Phycol., 2013, 25(2), 687-693.

[350] Maeda, H.; Hosokawa, M.; Sashima, T.; Murakami-Funayama, K.; Miyashita, K. Anti-obesity and anti-diabetic effects of fucoxanthin on diet-induced obesity conditions in a murine model. Mol. Med. Rep., 2009, 2(6), 897-902

[351] Maeda, H. Nutraceutical effects of fucoxanthin for obesity and diabetes therapy: a review. J. Oleo Sci., 2015, 64(2), 125-132.

[352] Uchiyama, K.; Naito, Y.; Hasegawa, G.; Nakamura, N.; Takahashi, J.; Yoshikawa, T. Astaxanthin protects $\beta$-cells against glucose toxicity in diabetic db/db mice. Redox Rep., 2002, 7(5), 290-293.

[353] Otton, R.; Marin, D.P.; Bolin, A.P.; dos Santos, R.D.C.M.; Polotow, T.G.; Sampaio, S.C.; de Barros, M.P. Astaxanthin ameliorates the redox imbalance in lymphocytes of experimental diabetic rats. Chem. Biol. Interact., 2010, 186(3), 306-315.

[354] Hussein, G.; Nakagawa, T.; Goto, H.; Shimada, Y.; Matsumoto, K.; Sankawa, U.; Watanabe, H. Astaxanthin ameliorates features of metabolic syndrome in SHR/NDmcr-cp. Life Sci., 2007, 80(6), 522529.

[355] Bhuvaneswari, S.; Arunkumar, E.; Viswanathan, P.; Anuradha, C.V. Astaxanthin restricts weight gain, promotes insulin sensitivity and curtails fatty liver disease in mice fed a obesity-promoting diet. Process Biochem., 2010, 45(8), 1406-1414.

[356] Bhuvaneswari, S.; Anuradha, C.V. Astaxanthin prevents loss of insulin signaling and improves glucose metabolism in liver of insulin resistant mice. Can. J. Physiol. Pharmacol., 2012, 90(11), 1544-1552.

[357] Jono, T.; Miyazaki, A.; Nagai, R.; Sawamura, T.; Kitamura, T.; Horiuchi, S. Lectin-like oxidized low density lipoprotein receptor-1 (LOX-1) serves as an endothelial receptor for advanced glycation end products (AGE). FEBS Lett., 2002, 511(1), 170-174.

[358] Forbes, J.M.; Yee, L.T.L.; Thallas, V.; Lassila, M.; Candido, R.; Jandeleit-Dahm, K.A.; Allen, T.J. Advanced glycation end product 
interventions reduce diabetes-accelerated atherosclerosis. Diabetes, 2004, 53(7), 1813-1823.

[359] Ahmed, N. Advanced glycation endproducts - role in pathology of diabetic complications. Diabetes Res. Clin. Pr., 2005, 67(1), 3-21.

[360] Stitt, A.W.; McGoldrick, C.; Rice-McCaldin, A.; McCance, D.R.; Glenn, J.V.; Hsu, D.K.; Gardiner, T.A. Impaired retinal angiogenesis in diabetes: role of advanced glycation end products and Galectin-3. Diabetes, 2005, 54(3), 785-794.

[361] Yamamoto, N.; Ozaki, N.; Murakami, K. Trypan-blue-and endoillumination-assisted phacoemulsification in eyes with vitreous hemorrhage during combined cataract and vitreous surgery. Ophthalmologica, 2005, 219(6), 338-344.

[362] Reddy, V.P.; Beyaz, A. Inhibitors of the Maillard reaction and AGE breakers as therapeutics for multiple diseases. Drug Discov. Today, 2006, 11(13), 646-654.

[363] Kawanishi, K.; Ueda, H.; Moriyasu, M. Aldose reductase inhibitors from the nature. Curr. Med. Chem., 2003, 10(15), 1353-1374.

[364] Manzanaro, S.; Salvá, J.; de la Fuente, J.Á. Phenolic marine natural products as aldose reductase inhibitors. J. Nat. Prod., 2006, 69(10), 1485-1487.

[365] Sun, Z.; Peng, X.; Liu, J.; Fan, K.W.; Wang, M.; Chen, F. Inhibitory effects of microalgal extracts on the formation of advanced glycation endproducts (AGEs). Food Chem., 2010, 120(1), 261-267.

[366] Sun, Z.; Liu, J.; Zeng, X.; Huangfu, J.; Jiang, Y.; Wang, M.; Chen, F. Protective actions of microalgae against endogenous and exogenous advanced glycation endproducts (AGEs) in human retinal pigment epithelial cells. Food Function, 2011, 2(5), 251-258.

[367] Ulmann, L.; Blanckaert, V.; Mimouni, V.; Andersson, M.X.; Schoefs, B.; Chénais B. Plastid-derived fatty acids and lipids and their implication in health and disease. Mini-Rev. Med. Chem. submitted to this Special Issue.

[368] Kowluru, R.A.; Menon, B.; Gierhart, D.L. Beneficial effect of zeaxanthin on retinal metabolic abnormalities in diabetic rats. Investig. Ophthalmol. Visual Sci., 2008, 49(4), 1645-1651.

[369] Naito, Y.; Uchiyama, K.; Aoi, W.; Hasegawa, G.; Nakamura, N.; Yoshida, N.; Yoshikawa, T. Prevention of diabetic nephropathy by treatment with astaxanthin in diabetic db/db mice. Biofactors, 2004, 20(1), 49-59.

[370] Manabe, E.; Handa, O.; Naito, Y.; Mizushima, K.; Akagiri, S.; Adachi, S.; Yoshikawa, T. Astaxanthin protects mesangial cells from hyperglycemia-induced oxidative signaling. J. Cell. Biochem., 2008, 103(6), 1925-1937.

[371] Marin, D.P.; Bolin, A.P.; Macedo, R.D.C.S.; Sampaio, S.C.; Otton, R. ROS production in neutrophils from alloxan-induced diabetic rats treated in vivo with astaxanthin. Int. Immunopharmacol., 2011, 11(1), 103-109.

[372] Kim, Y.J.; Kim, Y.A.; Yokozawa, T. Protection against oxidative stress, inflammation, and apoptosis of high-glucose-exposed proximal tubular epithelial cells by astaxanthin. J. Agric. Food Chem., 2009, 57(19), 8793-8797.

[373] Chan, K.C.; Pen, P.J.; Yin, M.C. Anticoagulatory and antiinflammatory effects of astaxanthin in diabetic rats. J. Food Sci., 2012, 77(2), H76-H80.

[374] Maeda, K.; Cao, H.; Kono, K.; Gorgun, C.Z.; Furuhashi, M.; Uysal, K.T.; Hotamisligil, G.S. Adipocyte/macrophage fatty acid binding proteins control integrated metabolic responses in obesity and diabetes. Cell Metab., 2005, 1(2), 107-119.

[375] Maeda, H.; Hosokawa, M.; Sashima, T.; Miyashita, K. Dietary combination of fucoxanthin and fish oil attenuates the weight gain of white adipose tissue and decreases blood glucose in obese/diabetic KK-A' mice. J. Agric. Food Chem., 2007, 55, 7701-7706.

[376] Lee, J.; Li, Y.; Li, C.; Li, D. Natural products and body weight control. North Am. J. Med. Sci., 2011, 3(1), 13-19.

[377] Ikeuchi, M.; Koyama, T.; Takahashi, J.; Yazawa, K. Effects of astaxanthin in obese mice fed a high-fat diet. Biosci. Biotechnol. Biochem., 2007, 71(4), 893-899.

[378] Ikeuchi, M.; Koyama, T.; Takahashi, J.; Yazawa, K. Effects of astaxanthin supplementation on exercise-induced fatigue in mice. Biol. Pharmaceut. Bull., 2006, 29(10), 2106-2110.

[379] Arunkumar, E.; Bhuvaneswari, S.; Anuradha, C.V. An intervention study in obese mice with astaxanthin, a marine carotenoid - effects on insulin signaling and pro-inflammatory cytokines. Food Function, 2012, 3(2), 120-126.

[380] Gammone, M.A.; D’Orazio, N.; Anti-obesity activity of the marine carotenoid fucoxanthin. Mar. Drugs, 2015, 13, 2196-2214.

[381] Maeda, H.; Hosokawa, M.; Sashima, T.; Funayama, K.; Miyashita, K. Fucoxanthin from edible seaweed, Undaria pinnatifida, shows antiobesity effect through UCP1 expression in white adipose tissues. Biochem. Biophys. Res. Commun., 2005, 332, 392-397.

[382] Maeda, H.; Hosokawa, M.; Sashima, T.; Funayama, K.; Miyashita, K. Effect of medium-chain triacylglycerols on anti-obesity effect of fucoxanthin. J. Oleo Sci., 2007, 56(12), 615-621.

[383] Krinsky, N.I.; Landrum, J.T.; Bone, R.A. Biologic mechanisms of the protective role of lutein and zeaxanthin in the eye. Annu. Rev. Nutr. 2003, 23(1), 171-201.

[384] Jacques P.F. The potential preventive effects of vitamins for cataract and age-related macular degeneration. Int. J. Vitamin Nutr. Res., 1999, 69(3), 198-205.

[385] Lyle, B.J.; Mares-Perlman, J.A.; Klein, B.E.; Klein, R.; Palta, M.; Bowen, P.E.; Greger, J.L. Serum carotenoids and tocopherols and incidence of age-related nuclear cataract. Am. J. Clin. Nutr., 1999 69(2), 272-277.

[386] Seddon, J.M.; Ajani, U.A.; Sperduto, R.D.; Hiller, R.; Blair, N.; Burton, T.C.; Willett, W. Dietary carotenoids, vitamins A, C, and E, and advanced age-related macular degeneration. JAMA, 1994, 272(18), 1413-1420.

[387] Karppi, J.; Laukkanen, J.A.; Kurl, S. Plasma lutein and zeaxanthin and the risk of age-related nuclear cataract among the elderly Finnish population. Br. J. Nutr., 2012, 108(1), 148-154.

[388] Junghans, A.; Sies, H.; Stahl, W. Macular pigments lutein and zeaxanthin as blue light filters studied in liposomes. Arch. Biochem. Biophys., 2001, 391(2), 160-164.

[389] Zhao, L.; Sweet, B.V. Lutein and zeaxanthin for macular degeneration. Am. J. Health Syst. Pharm., 2008, 65(13), 1232-1238.

[390] Bone, R.A.; Landrum, J.T.; Mayne, S.T.; Gomez, C.M.; Tibor, S.E.; Twaroska, E.E. Macular pigment in donor eyes with and without AMD: a case-control study. Invest. Ophthalmol. Visual Sci., 2001, 42(1), 235-240.

[391] Richer, S.; Stiles, W.; Statkute, L.; Pulido, J.; Frankowski, J.; Rudy, D.; Nyland, J. Double-masked, placebo-controlled, randomized trial of lutein and antioxidant supplementation in the intervention of atrophic age-related macular degeneration: the Veterans LAST study (Lutein Antioxidant Supplementation Trial). Optometry, 2004, 75(4), 216-229.

[392] O'Connor, I.; O'Brien, N. Modulation of UVA light-induced oxidative stress by $\beta$-carotene, lutein and astaxanthin in cultured fibroblasts. $J$. Dermat. Sci., 1998, 16(3), 226-230.

[393] Tso, M.O.M.; Lam, T.T. Method of retarding and ameliorating central nervous system and eye damage. U.S. Patent 5,527,533, June 18, 1996.

[394] Sawaki, K.; Yoshigi, H.; Aoki, K.; Koikawa, N.; Azumane, A.; Kaneko, K.; Yamaguchi, M. Sports performance benefits from taking natural astaxanthin characterized by visual activity and muscle fatigue improvements in humans. J. Clin. Ther. Med., 2002, 18(9), 73-88.

[395] Nagaki, Y.; Mihara, M.; Tsukahara, H.; Ono, S. The supplementation effect of astaxanthin on accommodation and asthenopia. J. Clin. Ther. Med., 2006, 22(1), 41-54.

[396] Izumi-Nagai, K.; Nagai, N.; Ohgami, K.; Satofuka, S.; Ozawa, Y.; Tsubota, K.; Ishida, S. Inhibition of choroidal neovascularization with an anti-inflammatory carotenoid astaxanthin. Investig. Ophthalmol. Visual Sci., 2008, 49(4), 1679-1685

[397] Ohgami, K.; Shiratori, K.; Kotake, S.; Nishida, T.; Mizuki, N.; Yazawa, K.; Ohno, S. Effects of astaxanthin on lipopolysaccharideinduced inflammation in vitro and in vivo. Invest. Ophthalmol. Visual Sci., 2003, 44(6), 2694-2701.

[398] Suzuki, Y.; Ohgami, K.; Shiratori, K.; Jin, X.H.; Ilieva, I.; Koyama, Y.; Ohno, S. Suppressive effects of astaxanthin against rat endotoxininduced uveitis by inhibiting the $\mathrm{NF}-\kappa \mathrm{B}$ signaling pathway. Exp. Eye Res., 2006, 82(2), 275-281.

[399] Shiratori, K.; Ohgami, K.; Ilieva, I.; Jin, X.H.; Koyama, Y.; Miyashita, K.; Ohno, S. Effects of fucoxanthin on lipopolysaccharideinduced inflammation in vitro and in vivo. Exp. Eye Res., 2005, 81(4), $422-428$

[400] Cort, A.; Ozturk, N.; Akpinar, D.; Unal, M.; Yucel, G.; Ciftcioglu, A.; Aslan, M. Suppressive effect of astaxanthin on retinal injury induced by elevated intraocular pressure. Regul. Toxicol. Pharmacol., 2010, 58(1), 121-130.

[401] Tsai, C.F.; Lu, F.J.; Hsu, Y.W. Protective effects of Dunaliella salina - a carotenoids-rich alga - against ultraviolet B-induced corneal oxidative damage in mice. Mol. Vis., 2012, 18, 1540-1547.

[402] Lyons, N.M.; O'Brien, N.M. Modulatory effects of an algal extract containing astaxanthin on UVA-irradiated cells in culture. $J$. Dermatol. Sci., 2002, 30(1), 73-84.

[403] Camera, E.; Mastrofrancesco, A.; Fabbri, C.; Daubrawa, F.; Picardo, M.; Sies, H.; Stahl, W. Astaxanthin, canthaxanthin and $\beta$-carotene differently affect UVA-induced oxidative damage and expression of 
oxidative stress-responsive enzymes. Exp. Dermatol., 2009, 18(3), 222-231.

[404] Suganuma, K.; Nakajima, H.; Ohtsuki, M.; Imokawa, G. Astaxanthin attenuates the UVA-induced up-regulation of matrixmetalloproteinase-1 and skin fibroblast elastase in human dermal fibroblasts. J. Dermatol. Sci., 2010, 58(2), 136-142.

[405] Stahl, W.; Heinrich, U.; Jungmann, H.; Sies, H.; Tronnier, H. Carotenoids and carotenoids plus vitamin E protect against ultraviolet light-induced erythema in humans. Am. J. Clin. Nutr., 2000, 71(3), 795-798.

[406] Stahl, W.; Heinrich, U.; Wiseman, S.; Eichler, O.; Sies, H.; Tronnier, H. Dietary tomato paste protects against ultraviolet light-induced erythema in humans. J. Nutr., 2001, 131(5), 1449-1451.

[407] Sourkes, T.L. The discovery and early history of carotene. Bull. Hist. Chem., 2009, 34(1), 32-38.

[408] Inhoffen, H.H.; Pommer, H.; Bohlmann, F.; Synthesen in der Carotinoid-reihe, XIV. Aufbau des $\beta$-Carotins. Liebigs Ann. Chem., 1950, 569, 237-246.

[409] Inhoffen, H.H.; Pommer, H., Westphal, F. Synthesen in der Carotinoid-reihe, XVI. Eine weitere Synthese des $\beta$-Carotins. Liebigs Ann. Chem., 1950, 570, 69-72.

[410] Code of Federal Regulations, 2011. 21 CFR Part 70: Color additives; Part 71: Color additive petitions; Part 73: Color additives exempt from certification; Part 74: Color additives subject to certification; Part 80: Color additive certification; Part 81: General specifications and general restrictions for provisional color additives; Part 82: Certified provisionally listed colors and specifications. U.S. Food and Drug Administration, Washington, DC. http://www.fda.gov/ForIndustry/ColorAdditives/default.htm (accessed 25.04.14).

[411] Wrolstad, R.E.; Culver, C.A. Alternatives to those artificial FD\&C food colorants. Annu. Rev. Food Sci. Technol., 2012, 3, 59-77.

[412] Mercadante, A.Z.; Rodriguez-Amaya, D.B. Effects of ripening, cultivar differences, and processing on the carotenoid composition of mango. J. Agric. Food Chem., 1998, 46, 128-130.

[413] Coultate, T.P. Food: The Chemistry of its Components, 3rd ed.; Royal Society of Chemistry: Cambridge, 1996.

[414] Alija, A.J.; Bresgen, N.; Sommerburg, O.; Siems, W.; Eckl, P.M. Cytotoxic and genotoxic effects of $\beta$-carotene breakdown products on primary rat hepatocytes. Carcinogenesis, 2004, 25(5), 827-831.

[415] Khoo, H.-E.; Prasad, K.N.; Kong, K.-W.; Jiang, Y.; Ismail, A. Carotenoids and their isomers: color pigments in fruits and vegetables. Molecules, 2011, 16, 1710-1738.

[416] Report of the Joint FAO/WHO Expert Committee on Food Additives. Evaluation of Certain Food Additives and Contaminants; 57th. WHO, Geneva, Switzerland, pp. 909, 2002.

[417] Ben-Amotz, A. In: Enigmatic Microorganisms and Life in Extreme Environments; Seckbach, J., Ed.; Springer: Dordrecht, 1999; pp. 401410.

[418] Cooper, R.D.G.; Davis, J.B.; Leftwick, A.P.; Price, C.; Weedon, B. Carotenoids and related compounds. XXXII. Synthesis of astaxanthin, hoenicoxanthin, hydroxyechinenone, and the corresponding diosphenols. J. Chem. Soc. Perkin Trans. 1975, 1(21), 2195-2204.

[419] Yuan, J.P.; Peng, J.; Yin, K.; Wang, J.H. Potential health-promoting effects of astaxanthin: a high-value carotenoid mostly from microalgae. Mol. Nutr. Food Res., 2011, 55, 150-165.

[420] van Wijk, A.A.C.; Spaans, A.; Uzunbajakava, N., Otto, C.; de Groot, H.J.M.; Lugtenburg, J.; Buda, F. Spectroscopy and quantum chemical modeling reveal a predominant contribution of excitonic interactions to the bathochromic shift in $\alpha$-crustacyanin, the blue carotenoprotein in the carapace of the lobster Homarus gammarus. J. Am. Chem. Soc., 2005, 127(5), 1438-1445.

[421] Lorenz, R.T.; Cysewski, G.R. Commercial potential for Haematococcus microalgae as a natural source of astaxanthin. Trends Biotechnol., 2000, 18, 160-167.
[422] Lubbe, A.; Verpoorte, R. Cultivation of medicinal and aromatic plants for specialty industrial materials. Ind. Crop. Prod., 2011, 34, 785-801.

[423] Lemoine, Y.; Rmiki, N.-E.; Créach, A.; Rachidi, J.; Schoefs, B. In: Plant Cell Compartments - Selected Topics; Schoefs, B., Ed.; Research Signpost: Trivandrum, 2008; pp. 251-284.

[424] Frey, D.A.; Kataisto, E.W.; Ekmanis, J.L.; O’Malley, S.; Lockwood, S.F. The efficient synthesis of disodium dissucinate astaxanthin (Cardax). Org. Process Res. Dev., 2004, 8, 796-801.

[425] Cardounel, A.J.; Dumitrescu, C.; Zweier, J.L.; Lockwood, S.F. Direct superoxide anion scavenging by a sodium disuccinate astaxanthin derivative: relative efficacy of individual stereoisomers versus the statistical mixture of stereoisomers by electron paramagnetic resonance imaging. Biochem. Biophys. Res. Commun., 2003, 307(3), 706-712.

[426] Zsila, F.; Simonyi, M.; Lockwood, S.F. Interaction of the disodium disuccinate derivative of meso-astaxanthin with human serum albumin: from chiral complexation to self-assembly. Bioorg. Med. Chem. Lett., 2003, 13, 1093-1100.

[427] Gross, G.J.; Lockwood, S.F. Acute and chronic administration of disodium disuccinate astaxanthin $\left(\mathrm{Cardax}^{\mathrm{TM}}\right)$ produces marked cardioprotection in dog hearts. Mol. Cell. Biochem., 2005, 272, 221227.

[428] Kim, S.H.; Kim, J.H.; Lee, B.Y.; Lee, P.C. The astaxanthin dideoxyglucoside biosynthesis pathway in Sphingomonas sp. PB304. Appl. Microbiol. Biotechnol., 2014, 98, 9983-10003

[429] Asker, D.; Amano, S.I.; Morita, K.; Tamura, K.; Sakud, S.; Kikuchi, N.; Furihata, K.; Matsufuji, H.; Beppu, T.; Ueda, K. Astaxanthin dirhamnoside, a new astaxanthin produced by a radiotolerant bacterium, Sphingomonas astaxanthinifaciens. J. Antibiot., 2009, 62(7), 397-399.

[430] Metting, F.B. Biodiversity and application of microalgae. J. Ind. Microbiol., 1996, 17, 477-489.

[431] Ramesha, B.T.; Gertsch, J.; Ravikanth, G.; Priti, V.; Ganeshaiah, K.N.; Shaanker, R.U. Biodiversity and chemodiversity: Future perspectives in bioprospecting. Curr. Drug Targets, 2011, 12, 15151530.

[432] Deli, J.; Gonda, S.; Nagy, L.Z.; Szabó, I.; Gulyás-Fekete, G.; Agocs, A.; Marton, K.; Vasas, G. Carotenoid composition of three bloomforming alga species. Food Res. Int., 2014, 65, 215-223.

[433] Nishino, H.; Murokoshi, M.; Tokuda, H.; Satomi, Y. Cancer prevention by carotenoids. Arch. Biochem. Biophys., 2009, 482, 163 168.

[434] Chang, J.J.; Thia, C.; Lin, H.Y.; Liu, H.L.; Ho, F.J.; Wu, J.T.; Shih, M.C.; Li, W.H.; Li, W.H.; Huang, C.C. Integrating an algal $\beta$-carotene hydroxylase gene into a designed carotenoid-biosynthesis pathway increases carotenoid production in yeast. Bioresource Technol., 2015 184, 2-8.

[435] Scaife, M.A.; Burja, A.M.; Wright, P.C. Characterization of cyanobacterial $\beta$-carotene ketolase and hydroxylase genes in Escherichia coli, and their application for astaxanthin biosynthesis. Biotechnol. Bioeng., 2009, 103(5), 944-955.

[436] Niu, J.-F.; Wang, G.-C.; Lin, X.; Zhou, B.-C. Large-scale recovery of C-phycocyanin from Spirulina platensis using expanded bed adsorption chromatography. J. Chromatogr. B., 2007, 850(1-2), 267276.

[437] Mysliwa-Kurdziel, B., Solymosi, K. Phycobilins and phycobiliproteins used in food industry and medicine. Mini-Rev. Med. Chem. submitted to this Special Issue.

[438] Solymosi, K., Mysliwa-Kurdziel, B. Chlorophylls and their derivatives used in food industry and medicine. Mini-Rev. Med. Chem. submitted to this Special Issue. 